UNIVERSIDADE DE SÃO PAULO

FACULDADE DE ECONOMIA, ADMINISTRAÇÃO E CONTABILIDADE DEPARTAMENTO DE ADMINISTRAÇÃO PROGRAMA DE PÓS-GRADUAÇÃO EM ADMINISTRAÇÃO

UMA CONTRIBUIÇÃO PARA A ELABORAÇÃO DE MAPAS ESTRATÉGICOS: UM ESTUDO DA APLICAÇÃo DO MÉTODO DE ANÁLISE E ESTRUTURAÇÃO DE MODELOS (AEM)

Daniel Estima de Carvalho

Orientador: Prof. Dr. James Terence Coulter Wright

SÃO PAULO 
Profa. Dra. Suely Vilela

Reitora da Universidade de São Paulo

Prof. Dr. Carlos Roberto Azzoni

Diretora da Faculdade de Economia, Administração e Contabilidade

Prof. Dr. Isak Kruglianskas

Chefe do Departamento de Administração

Prof. Dr. Lindolfo Galvão de Albuquerque

Coordenador do Programa de Pós-Graduação em Administração 


\section{UMA CONTRIBUIÇÃO PARA A ELABORAÇÃO DE MAPAS ESTRATÉGICOS: UM ESTUDO DA APLICABILIDADE DO MÉTODO DE ANÁLISE E ESTRUTURAÇÃO DE MODELOS (AEM)}

Dissertação apresentada ao Departamento de Administração da Faculdade de Economia, Administração e Contabilidade da Universidade de São Paulo como um dos requisitos para a obtenção do título de Mestre em Administração.

Orientador: Prof. Dr. James Terence Coulter Wright 


\section{FICHA CATALOGRÁFICA}

Elaborada pela Seção de Processamento Técnico do SBD/FEA/USP

\section{Carvalho, Daniel Estima de}

Uma contribuição para a elaboração de mapas estratégicos: um estudo da aplicação do método de análise e estruturação de modelos (AEM) / Daniel Estima de Carvalho. -- São Paulo, 2009.

$138 \mathrm{p}$.

Dissertação (Mestrado) - Universidade de São Paulo, 2009.

Bibliografia.

1. Estratégia organizacional 2. Tomada de decisão em grupo 3. Trabalho em grupo 4. Experimentos científicos I. Universidade de São Paulo. Faculdade de Economia, Administração e Contabilidade II. Título.

$$
\text { CDD }-658.401
$$


A todos que torceram para que eu chegasse aqui. 


\section{Agradecimentos}

Ao meu orientador professor James Wright, por sua paciência, ensinamentos, incentivo e, especialmente, pelo acompanhamento de toda uma jornada. Registro aqui minha admiração por sua habilidade na arte de ser um Professor. Não tenho palavras para agradecer-lhe toda a confiança que me é dada.

Aos professores Hamilton Corrêa e Heitor Pereira pelas valorosas contribuições na banca de qualificação.

Ao apoio do Programa de Estudos do Futuro (PROFUTURO) e do MBA Executivo Internacional e de todos os amigos que lá trabalham, em especial dos Professores Washington Mathias e Renata Spers, pelas discussões e incentivos em todo o meu mestrado, e de Cristiane Oliveira, Ivana Franco, Priscila Mills, por toda a ajuda.

Aos Professores da FEA/USP, em especial aqueles cujas aulas tive a oportunidade, o prazer e o privilégio de participar: Ana Ikeda, Daniel Moreira (in memoriam), Eduardo Vasconcellos, Martinho Almeida e Silvio A. Santos.

A toda a equipe da Secretaria do Programa de Pós-Graduação do Departamento de Administração, da Secretaria de Pós-graduação da FEA e da Biblioteca/FEA, pelo suporte e presteza.

Aos professores e coordenadores dos cursos, que gentilmente abriram espaços em suas programações e permitiram que a pesquisa fosse aplicada. $\mathrm{E}$ aos alunos que a responderam.

Aos amigos professores, pelo companheirismo e trocas de experiências ao longo do curso: Afonso Lima, Ailton Jussani, Antonia Souza, Carlos Honorato, Hamilton Cippolla, Leandro Fraga, Leandro Morilhas, Silvio Bertoncello, Wilson Weber e Wilian Feitosa.

À especial ajuda dos amigos Flavio Hourneaux Junior e João Azevedo Abreu pelo apoio e incentivo antes, com o projeto de pesquisa, e durante o mestrado.

A toda força e motivação vinda da família e dos amigos, agradeço em especial, a Rubens C. Santos, Marli, Ismael e Veronica, aos meus irmãos Daiane e Felipe e aos meus pais, Apolonio e Vandi, pelo carinho, exemplo, dedicação e por me fazerem acreditar.

A minha esposa Carolina, pelo amor e apoio incondicional nas fases mais críticas da pesquisa, em pleno início de nosso casamento e principalmente por entender que minhas conquistas, na verdade, são nossas.

A todos minha eterna gratidão. 


\section{RESUMO}

A complexidade do ambiente competitivo obriga as organizações empregar métodos cada vez mais sofisticados para trabalhar com sua estratégia corporativa. Uma das ferramentas discutidas academicamente e no meio corporativo, relacionada a gerir a estratégia empresarial, é o Balanced Scorecard, que possui, entre seus componentes, o Mapa Estratégico. Este estudo aborda a aplicação do método de Análise e Estruturação de Modelos (AEM), metodologia que lida essencialmente com temas complexos, na construção de Mapas Estratégicos. Os objetivos desta pesquisa consistem em entender se o resultado da aplicação da AEM contribui para a construção de Mapas Estratégicos, se este método colabora para uma maior participação das pessoas e se aprimora o processo de construção de um Mapa Estratégico. Foi realizada uma pesquisa experimental com uma amostra por conveniência de 110 alunos de pós-graduação de escolas de São Paulo, que participaram de um exercício de construção de Mapa Estratégico baseado em um caso real de uma empresa de gerenciamento de projetos de engenharia. Os grupos experimentais adotaram a AEM para construir seus mapas, enquanto que os grupos de controle construíram seus mapas no papel. Analisando os mapas construídos pelos grupos, como resultado apurou-se que o uso da AEM propiciou uma explicitação maior e mais abrangente das relações de causa e efeito existentes entre os diferentes objetivos estratégicos da empresa estudada. Já em termos das opiniões registradas nos questionários, a comparação entre os dois grupos trouxe apontamentos que evidenciam um processo mais estruturado, com a participação de cada integrante do grupo melhor distribuída, na construção dos mapas estratégicos dos grupos experimentais. Por outro lado, o grupo de controle foi mais enfático em destacar a aprendizagem de seus integrantes em relação à estratégia contida no caso e à concordância com o resultado do exercício, após construir seus mapas estratégicos no papel, apesar de o grupo experimental mostrar opiniões positivas sobre estes elementos também. Esta diferença de opiniões a favor do grupo de controle pode ter sido causada pelas melhorias que o software da metodologia AEM deveria passar na opinião dos respondentes, que, ainda assim, em sua totalidade, avaliaram positivamente o uso da ferramenta no exercício, como apoio à construção de Mapas Estratégicos. Por estes resultados, entende-se que existem evidências que apontam valer a pena utilizar a AEM nesta função, especialmente se seu software for aprimorado, tornando-se assim uma opção interessante para o apoio ao gerenciamento de estratégias empresariais por meio da construção de Mapas Estratégicos. 


\begin{abstract}
The complexity of the competitive environment requires organizations to adopt increasingly sophisticated methods to work with their competitive strategy. Among the tools discussed in both the academic world and the corporate milieu, is the Balanced Scorecard, which in turn has the Strategy Map among its components. This study approaches the application of the method of Interpretive Structural Modeling Structuring (ISM), a methodology essentially devoted to complex subjects, to the construction of Strategy Maps. This research aims at the following points: whether the employment of ISM could contribute to the construction of Strategy Maps; whether this method plays a role in making more people to participate; and whether it improves the process of construction of a Strategy Map. An experimental research has been conducted, with a convenience sample of 110 graduate students from business schools in the city of São Paulo who took part in an exercise of Strategy Map construction based on a real case of an engineering project management enterprise. The experimental groups employed the ISM to construct their maps, whereas the control group constructed their maps on paper. The ensuing comparison of the maps thus produced would show that applying the ISM allows for a greater and more comprehensive explanation of the causeeffect relations existing among the different strategy objectives of the company under study. As for the opinions recorded in the questionnaires, the comparison has provided evidence of a more structured process, with a better distributed individual participation within each group in the construction of strategy maps by the experimental groups. On the other hand, the control group has shown a deeper learning by its members in relation to both the strategy contained in the case and the agreement regarding the results of the exercise after constructing its strategy maps on paper, even though the experimental group has shown positive opinions regarding these elements as well. This difference in favor of the control group may have been caused by the improvements the ISM methodology software should have undergone, in the opinion of the respondents, all of whom, however, positively evaluated the tool in support to the construction of Strategy Maps during the exercise. Such results provide evidence that it is worthwhile to use the ISM in that function, especially if the software is improved, thus offering an interesting alternative for the support to the management of business strategies by means of the construction of Strategy Maps.
\end{abstract}




\section{SUMÁRIO}

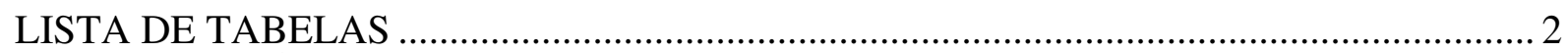

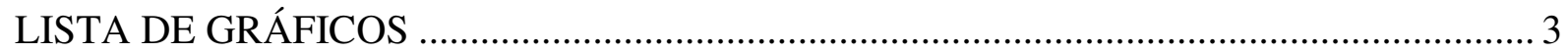

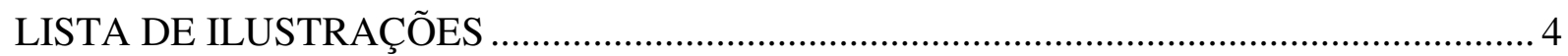

1 INTRODUÇÃO: O PROBLEMA DE PESQUISA …................................................. 5

1.1 O desafio da elaboração de Mapas Estratégicos................................................... 5

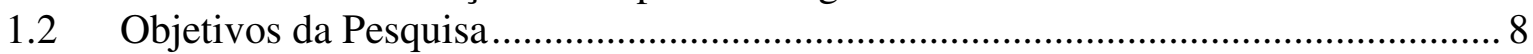

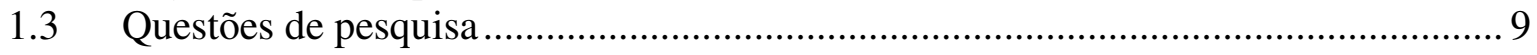

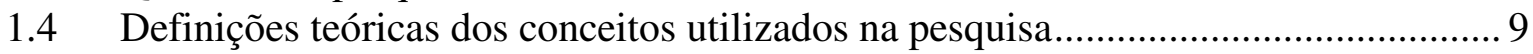

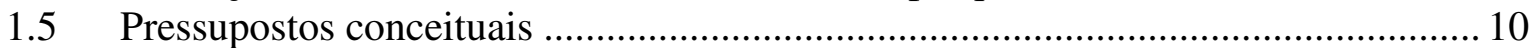

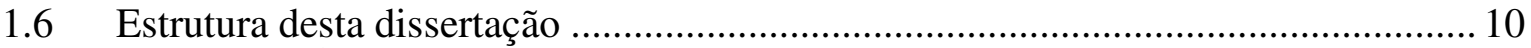

2 MAPAS ESTRATÉGICOS E AEM: FERRAMENTAS PARA O APOIO DA ESTRATÉGIA, DA COMPLEXIDADE E DO TRABALHO EM GRUPO ........................... 13

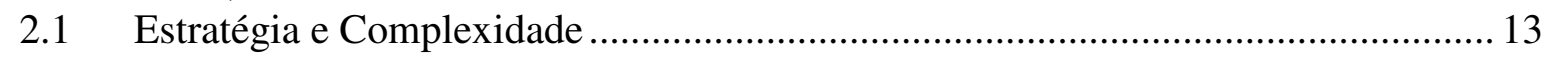

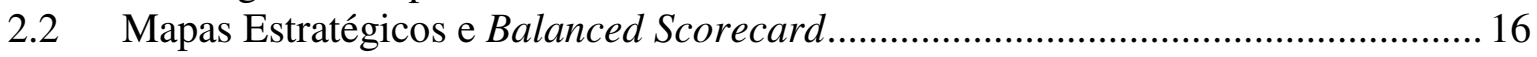

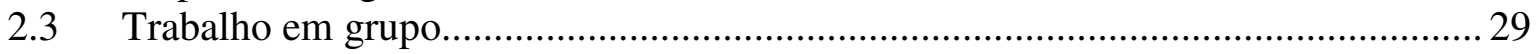

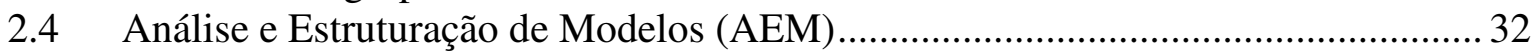

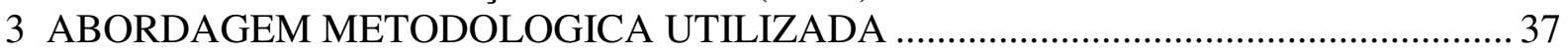

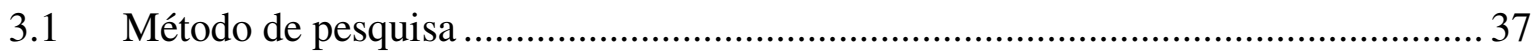

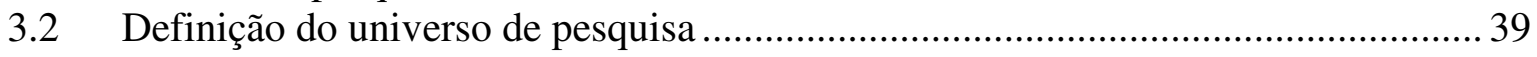

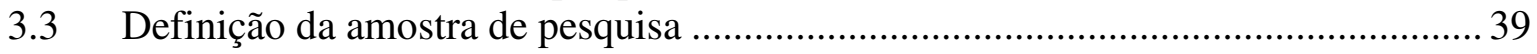

3.4 Estratégia de coleta dos dados: descrição do experimento...................................... 40

3.5 Técnicas de tratamento estatístico dos dados ............................................................ 42

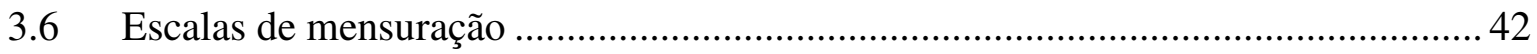

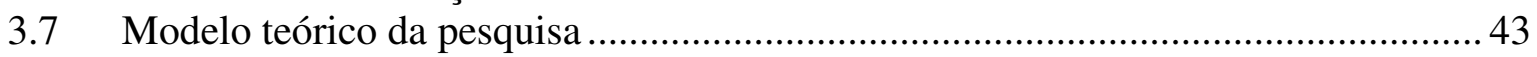

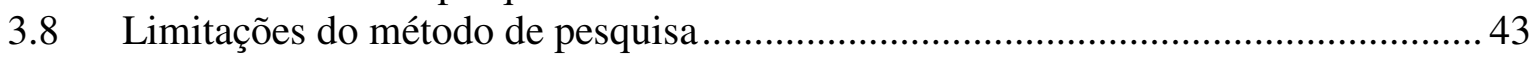

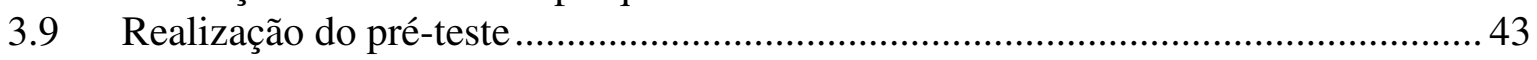

3.10 Ajustes a partir dos resultados do pré-teste ....................................................... 44

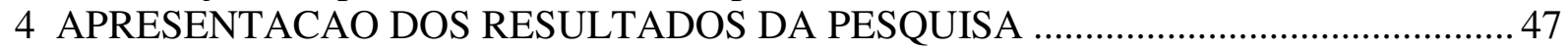

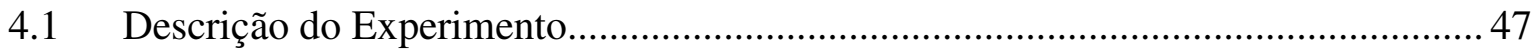

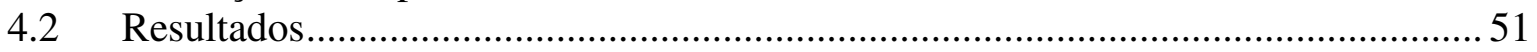

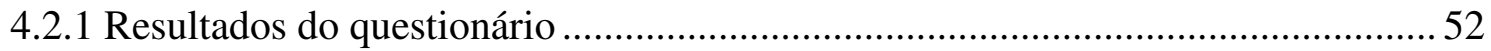

4.2.2 Análise dos Mapas Estratégicos elaborados .......................................................... 78

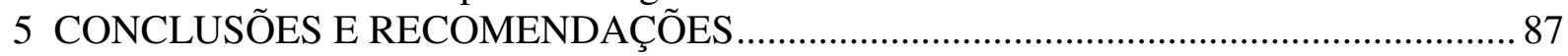

5.1 Diferenças entre os Mapas Estratégicos construídos pelos dois grupos....................87

5.2 Conclusões sobre o processo de construção de Mapas Estratégicos ........................ 90

5.3 Opinião dos participantes sobre a aplicação da AEM ............................................ 92

5.4 Percepção da aprendizagem dos participantes..................................................... 92

5.5 Considerações sobre a aplicabilidade da AEM .................................................. 93

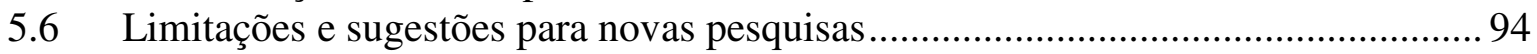

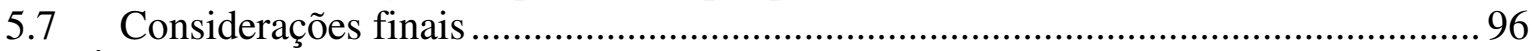

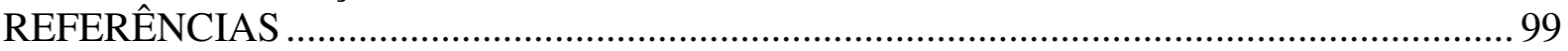

APÊNDICE I - EXERCÍCIO DE APLICAÇÃO DO EXPERIMENTO ............................. 105

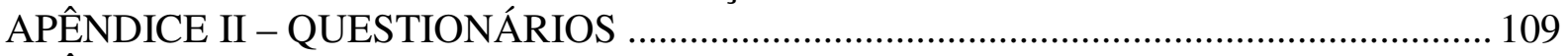

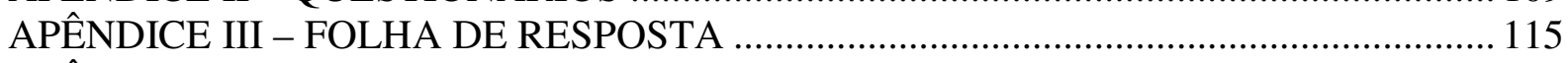

APÊNDICE IV - MAPAS PRODUZIDOS PELOS GRUPOS ......................................... 117 


\section{LISTA DE TABELAS}

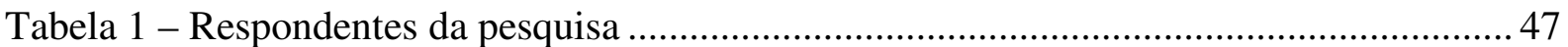

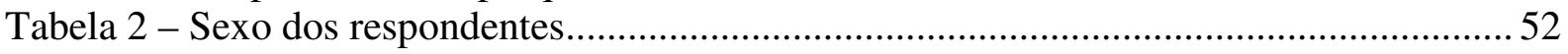

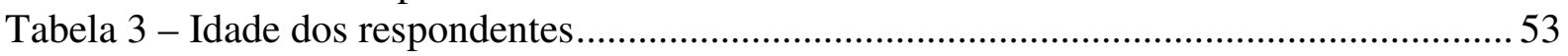

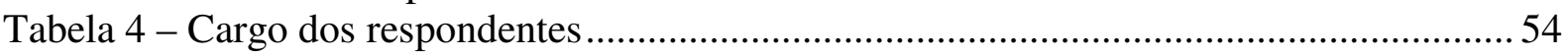

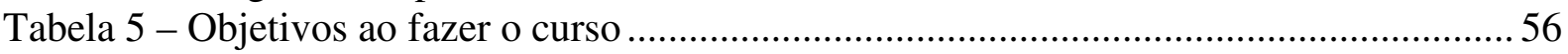

Tabela 6 - Nível de interesse na disciplina de estratégia ...................................................5 57

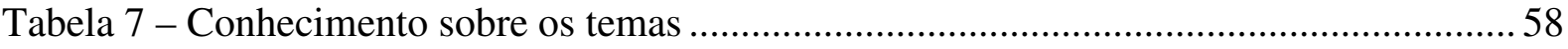

Tabela 8 - Adoção das ferramentas pela empresa na qual cada respondente trabalha ............60

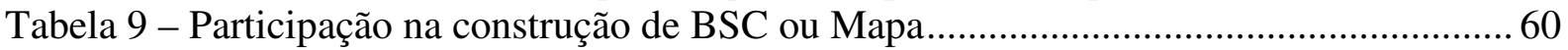

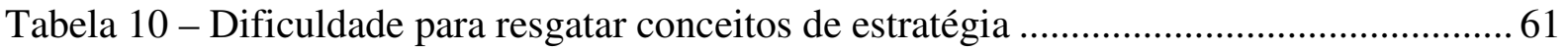

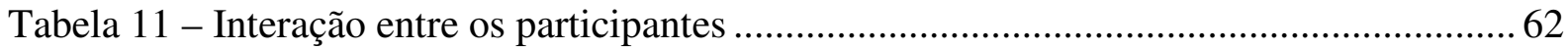

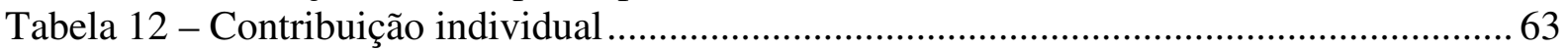

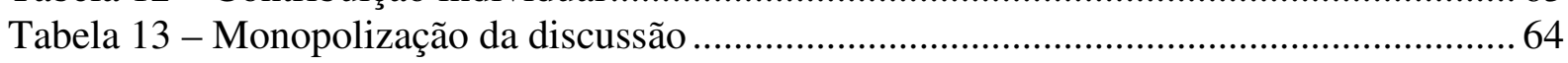

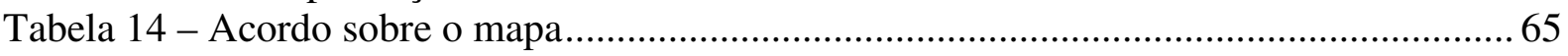

Tabela 15 - Distribuição dos objetivos entre as dimensões do mapa ......................................66

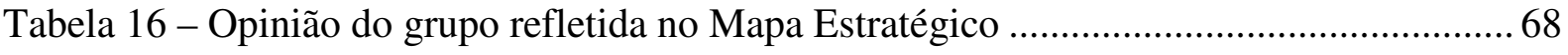

Tabela 17 - Aumento da percepção sobre a estratégia descrita no caso ..................................69

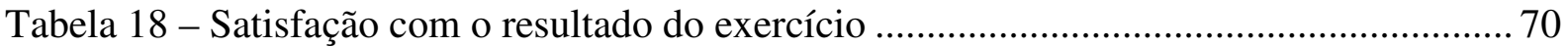

Tabela 19 - Utilização da AEM na compreensão da estratégia do caso ................................... 71

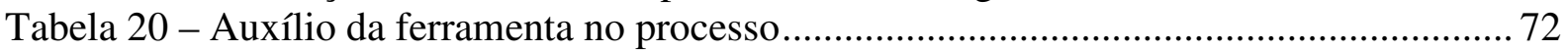

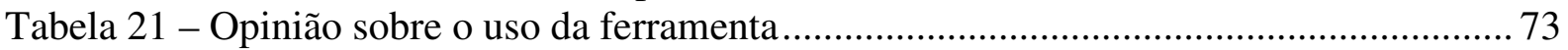

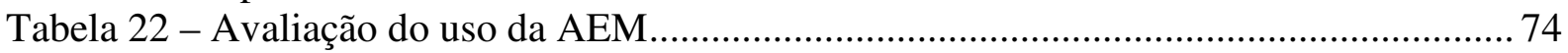

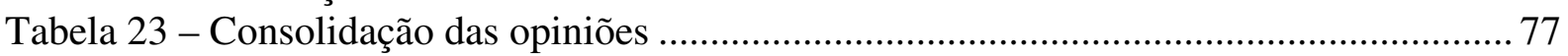




\section{LISTA DE GRÁFICOS}

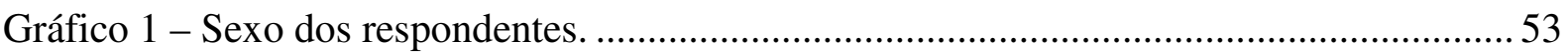

Gráfico 2 - Média e mediana da idade dos respondentes da pesquisa.....................................5 54

Gráfico 3 - Cargos dos respondentes do grupo de controle.................................................... 55

Gráfico 4 - Cargos dos respondentes do grupo experimental...............................................55

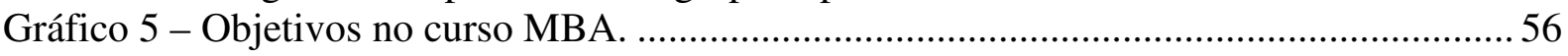

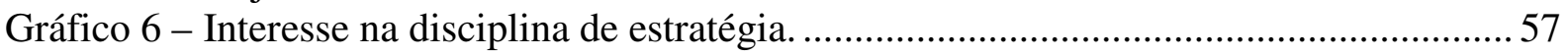

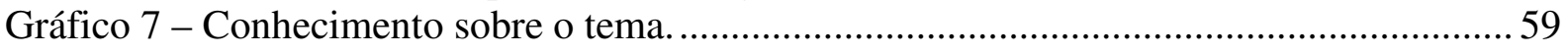

Gráfico 8 - Adoção do BSC ou Mapa pela empresa onde o respondente trabalha.................. 60

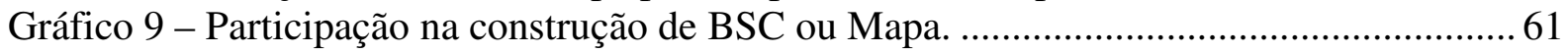

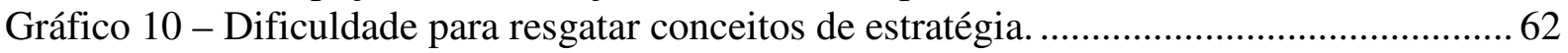

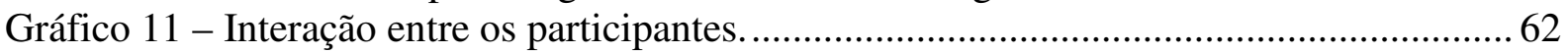

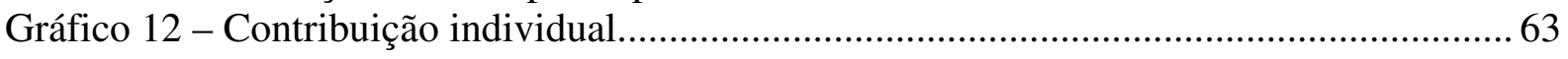

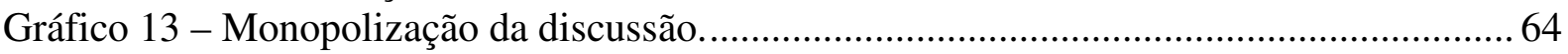

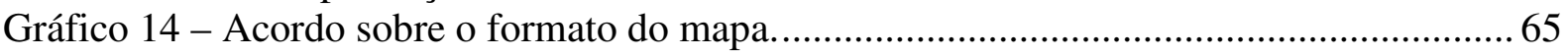

Gráfico 15 - Distribuição dos objetivos entre as dimensões. ................................................ 67

Gráfico 16 - Opinião do grupo refletida no Mapa Estratégico. ............................................... 68

Gráfico 17 - Aumento da percepção sobre a estratégia descrita no caso. ................................6 69

Gráfico 18 - Satisfação com o resultado do exercício. ............................................................ 70

Gráfico 19 - Utilização da AEM na compreensão da estratégia do caso. ................................ 71

Gráfico 20 - Auxílio da ferramenta no processo. ................................................................... 72

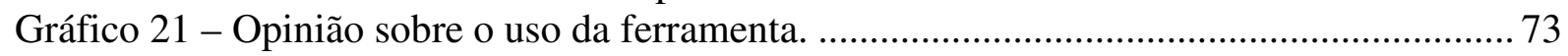

Gráfico 22 - Avaliação do uso da AEM. ............................................................................... 74 


\section{LISTA DE ILUSTRAÇÕES}

Ilustração 1 - Relação entre Estratégia, BSC e Mapas Estratégicos........................................ 17

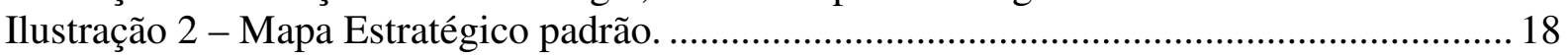

Ilustração 3 - Ciclo de Execução da Estratégia. ................................................................... 19

Ilustração 4 - A evolução do Balanced Scorecard. .............................................................. 23

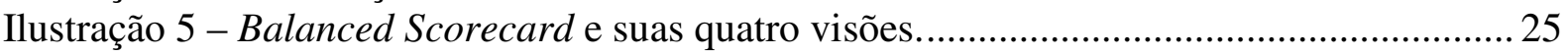

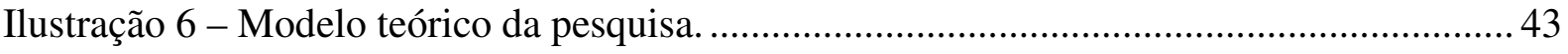

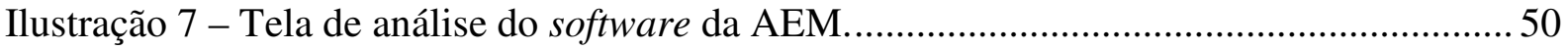

Ilustração 8 - Tela de respostas do software da AEM..............................................................51

Ilustração 9 - Mapa Estratégico do grupo 3 da turma de Especialização em Gestão

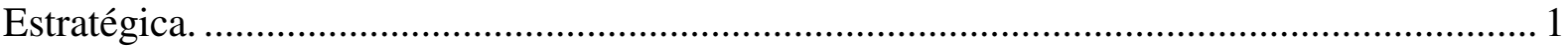

Ilustração 10 - Mapa Estratégico do grupo 1 da Turma 36 do MBA Executivo Internacional. 1

Ilustração 11 - Mapa Estratégico resumo dos grupos de controle........................................... 82

Ilustração 12 - Mapa Estratégico do grupo 5 da Turma 36 do MBA Executivo Internacional. 1

Ilustração 13 - Mapa Estratégico do grupo 2 da turma de Especialização em Gestão

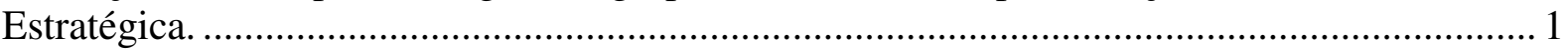

Ilustração 14 - Mapa Estratégico resumo dos grupos experimentais. ……............................. 86

Ilustração 15 - Mapa Estratégico tabulado dos dois grupos. .................................................. 89 


\section{INTRODUÇÃO: O PROBLEMA DE PESQUISA}

\subsection{O desafio da elaboração de Mapas Estratégicos}

A abertura das economias e as facilidades de comunicação, dentre outros aspectos, acirraram a competição entre empresas por mercados lucrativos e por retornos acima da média. Os mercados crescentemente desafiadores, o aumento da concorrência e o maior grau de exigência dos clientes e dos governos caracterizam um ambiente cada vez mais complexo que obriga as companhias a estabelecer planos e métodos melhor delineados, que, por sua vez, levam à concepção e implementação de estratégias corporativas sofisticadas.

A estratégia, conceito vindo da área militar, possibilita que as empresas reflitam sobre diversos aspectos e variáveis que influenciam seu dia-a-dia e que necessitam ser contemplados para que a empresa planeje seu futuro e consiga usar seus recursos da melhor forma possível. Desta maneira, espera-se que a empresa vislumbre e aproveite oportunidades em seu ambiente, obtendo melhores resultados do que seus concorrentes e garantindo sua competitividade.

Pode-se conceituar estratégia como "um conjunto integrado e coordenado de compromissos e ações, definido para explorar competências essenciais e obter vantagens competitivas" (HITT et al, 2008). Ao definirem uma estratégia, as empresas escolhem alternativas para competir, indicando o que pretendem e o que não pretendem fazer. Segundo os autores, a competitividade estratégica é obtida quando uma empresa consegue formular e implantar com sucesso uma estratégia de criação de valor, enquanto que a vantagem competitiva é alcançada quando se implementa uma estratégia que os concorrentes não conseguem copiar.

Após a formulação de uma estratégia, a empresa deve usar ferramentas que acompanhem seu desenvolvimento e sua implementação por meio da verificação de seu desempenho. Em outras palavras, faz-se necessário o uso de instrumentos de gestão estratégica. Tais ferramentas asseguram acompanhar se a estratégia está sendo realizada de fato como foi concebida/planejada e se seus objetivos estratégicos estão sendo alcançados. Dentre as opções de ferramenta de gestão estratégica, tem-se o Balanced Scorecard (BSC) como um dos métodos discutidos tanto na academia como no meio empresarial, através de artigos, cursos, livros e seminários disponíveis tanto no Brasil quanto no exterior. Em âmbito nacional, o 
interesse pelo tema foi evidenciado por Oliveira (2008), que analisou 243 dissertações e teses realizadas no Brasil entre 1999 e 2007. Internacionalmente, o BSC foi aclamado pela Harvard Business Review como uma das 75 idéias mais influentes do século XX (NIVEN, 2005).

O BSC é uma ferramenta de implementação e gestão da estratégia corporativa que, a partir da definição e acompanhamento de objetivos e metas estratégicas, torna a estratégia empresarial concebida passível de ser gerenciada e alcançada. De acordo com Kaplan e Norton (2004), a ligação entre a estratégia corporativa definida e o BSC, que fará seu acompanhamento, ocorre por meio de um Mapa Estratégico. O Mapa Estratégico organiza, em relações de causa e efeito, segundo as visões do BSC, os objetivos estratégicos de forma hierarquizada, deixando, de forma visualmente clara em um mapa, quais objetivos precisam ser alcançados em primeiro lugar e quais contribuirão para atingir os outros objetivos que estão hierarquicamente acima dele.

Esta forma de organização trazida pelo conceito de Mapa Estratégico caracteriza-se pelo propósito de comunicar em uma única página a estratégia definida pela alta direção da organização para qualquer colaborador da empresa. Assim, o Mapa Estratégico constitui um componente importante para o sucesso do funcionamento BSC e da estratégia empresarial Beber et al (2006) destacam que relações de causa e efeito mal estabelecidas, presentes em um Mapa Estratégico, são um dos motivos de fracasso em implementações de BSC. Uma relação adequada de causa e efeito entre os objetivos estratégicos contribui para o entendimento da estratégia empresarial e para o estabelecimento de metas e indicadores adequados. Os autores destacam que muitas dessas relações são dinâmicas e complexas, o que dificulta sua correta identificação. Por sua vez, Martins e Marquitti (2006) analisam caso problemático de implementação de um BSC em que o Mapa Estratégico foi concebido por apenas uma pessoa. Este fato contribui para o baixo entendimento do conteúdo do mapa e da falta de uniformidade e concordância quanto às relações entre objetivos apresentados, já que cada executivo da empresa estudada colocava a sua interpretação pessoal, em vez de uma visão compartilhada do entendimento do Mapa Estratégico. Outras falhas de concepção e implementação, como, por exemplo, um fraco treinamento, uma equipe de implementação pouco preparada, problemas com os indicadores e escopo mal definido, contribuíram para um entendimento desigual da estratégia da empresa por parte dos diversos níveis organizacionais, impossibilitando que o BSC e o Mapa Estratégico fossem usados corretamente. A estratégia ao alcance da compreensão de todos na organização contribui para que se tenha uma equipe 
coesa, que caminhe na mesma direção para alcançar os objetivos corporativos traçados pelo planejamento da empresa.

No entanto, a construção dos Mapas Estratégicos não é descrita de forma detalhada por seus autores. Apesar de Kaplan e Norton (2004) destacarem que os objetivos estratégicos devem ser vistos não de forma independente, mas como uma série de relações de causa e efeito, não enfatizam como construir tal mapa de relações. As formas de hierarquização dos objetivos estratégicos não possuem o realce necessário no modelo de Kaplan e Norton (2004) para que se consiga construir o Mapa Estratégico por meio de um método linear a partir do momento em que os objetivos já estão definidos e agrupados pelas dimensões do Balanced Scorecard.

De acordo com Wright (1991), o crescente grau de complexidade nas organizações permite o uso de ferramentas que, se adequadas, podem aprimorar os processos estruturação e modelagem de problemas fundamentais à condução das empresas. Uma técnica de apoio ao trabalho em grupo, comumente empregada para a análise de problemas complexos, poderia ser usada como uma forma de organizar e buscar o entendimento sobre as relações de causa e efeito entre os múltiplos objetivos estratégicos de um Mapa Estratégico.

O uso de tal ferramenta poderia apoiar o estabelecimento de relações entre os objetivos estratégicos, funcionando de forma a facilitar e fortalecer o processo de construção de Mapas Estratégicos e reforçar seu papel de comunicador da estratégia corporativa. Segundo Papalexandris et al (2005), podem ocorrer controvérsias em razão da subjetividade no estabelecimento de correlações entre os objetivos estratégicos na construção do Mapa Estratégico. A visão deste autor concorda condiz com a necessidade de um apoio maior para uma estruturação da relação interna entre os objetivos estratégicos de um mapa. Acreditamos que a aplicação desta ferramenta poderia tanto facilitar o processo de interação entre o grupo de elaboradores do mapa quanto promover a aprendizagem da estratégia corporativa, dirimindo dúvidas quanto ao conteúdo e confiabilidade do mapa. Estes pontos ajudariam a construir um Mapa Estratégico mais completo e facilitaria a compreensão do mesmo por aqueles que o estão construindo, reforçando, desta forma, um dos objetivos expostos por Kaplan e Norton, que é o de facilitar a comunicação da estratégia para todos.

A Análise e Estruturação de Modelos (AEM), adaptação em português do termo ISM Interpretive Structural Modeling, é uma ferramenta de apoio para trabalho em grupo, que 
funciona a partir de um software. Tal ferramenta capta elementos de um problema, com o auxílio de um facilitador, e organiza esses itens em um modelo estrutural hierarquizado de acordo com a opinião do grupo. Segundo Wright (1995), o sistema não analisa e provê uma resposta automática do computador. Para este autor, o objetivo da AEM é de aprimorar a comunicação e a visão de conjunto sobre um problema, por meio da estruturação dos elementos que compõe tal problema, para que este seja discutido e resolvido pelo grupo. Desta forma, a estruturação do problema é feita a partir das respostas do grupo a indagações propostas pelo computador que organiza os elementos do problema em uma estruturação lógica resultante. Quando a estruturação termina, esta é apresentada ao grupo, que reconhece sua opinião representada de forma gráfica e organizada pelo sistema.

Dadas estas características do método AEM para organização de questões complexas objetiva-se estudar nesta pesquisa a aplicabilidade deste conceito como forma de auxiliar o processo de construção de Mapas Estratégicos. O método AEM contribuiria para organizar a entrada de objetivos estratégicos, interagindo com o grupo que está concebendo a estratégia e auxiliando a hierarquizar os objetivos de acordo com o plano deste grupo. Desta forma, a questão que norteará esta pesquisa é: quais contribuições o método AEM traz ao processo de elaboração de Mapas Estratégicos?

A melhor compreensão sobre uma metodologia que possa apoiar o aprimoramento da concepção e estruturação de Mapas Estratégicos pode trazer uma contribuição para a construção de ferramenta que forneça importante apoio à estratégia das organizações. A possibilidade de unir estes temas tão distintos, mas complementares, somado ao desafio de investigar as possibilidades e utilidades da sua aplicação, foram os motivadores desta pesquisa, que trabalha a partir de pesquisas anteriormente realizadas sobre o método AEM.

\subsection{Objetivos da Pesquisa}

O objetivo principal desta pesquisa é caracterizar o resultado da aplicação do método AEM no auxílio à elaboração de Mapas Estratégicos.

Como objetivo secundário, buscar-se-á compreender se a aplicação da AEM contribui para uma maior participação das pessoas e um melhor processo de construção de um Mapa Estratégico, contribuindo para reforçar seu entendimento. 
Espera-se, ainda contribuir para o desenvolvimento dos conceitos estudados nesta pesquisa, em especial aqueles que dizem respeito às metodologias tanto da elaboração de Mapas Estratégicos quanto do uso da AEM

\subsection{Questões de pesquisa}

Algumas questões, derivadas da questão central de pesquisa e dos objetivos, são pertinentes como forma a apoiar o estudo:

1. Quais as diferenças entre a estrutura dos Mapas Estratégicos construídos com ou sem aplicação da AEM?

2. A aplicação da ferramenta AEM resulta em alterações no processo de construção de Mapas Estratégicos?

3. Qual a opinião dos envolvidos a respeito da aplicação da AEM na construção de Mapas Estratégicos?

4. A percepção da aprendizagem da estratégia corporativa é mais evidente nos grupos que utilizaram ou não a AEM para construir Mapas Estratégicos?

\subsection{Definições teóricas dos conceitos utilizados na pesquisa}

Para o entendimento desta pesquisa, é necessário o alinhamento de alguns conceitos que a permeiam e que serão detalhados no Capítulo II.

- Objetivos estratégicos: elaborados a partir da definiçãa da estratégia empresarial, compõem uma declaração expressa do que a organização pretende alcançar e realizar com sua estratégia (KAPLAN E NORTON, 2004).

- Mapas Estratégicos: diagrama que descreve a estratégia mediante a identificação de relações de causa e efeito explícitas entre os objetivos nas quatro perspectivas do BSC (KAPLAN e NORTON, 2004).

- BSC: Sistema de gestão estratégica que, dentre outras funções, implementa e obtém retorno da estratégia organizacional. A partir de sua utilização, assegura o alinhamento e o foco na implementação da estratégia organizacional de longo prazo (KAPLAN E NORTON, 1997). 


\subsection{Pressupostos conceituais}

Serão consideradas aqui as estratégias deliberadas que são formuladas a partir da visão e missão da empresa formulada por sua alta direção.

Estratégias emergentes, que surgem naturalmente à revelia de um processo formal e estruturado de planejamento, não serão objeto da análise efetuada neste estudo.

Uma estratégia pode ser interpretada por meio das relações de causa e efeito entre os objetivos estratégicos estabelecidos. Esta relação é ilustrada por meio de um Mapa Estratégico que evidencia estes relacionamentos de forma linear. Anselmo, no entanto, (2005) sintetiza a visão de vários autores mostrando que a realidade das empresas pode ser mais complexa e dinâmica, como mostram a teoria do caos e complexidade, aspectos que não serão abordados em profundidade nesta pesquisa.

\subsection{Estrutura desta dissertação}

Esta dissertação se divide por cinco capítulos: este Capítulo 1 apresentou uma introdução do tema de pesquisa, seus objetivos e questões de pesquisa que nortearão os capítulos seguintes.

O Capítulo 2 reúne a fundamentação teórica necessária para a condução da pesquisa e para a análise dos resultados da pesquisa de campo. São ressaltados os principais conceitos e comentários relacionados aos Mapas Estratégicos, ao Balanced Scorecard e a Análise e Estruturação de Modelos.

O Capítulo 3 apresenta a metodologia empregada na pesquisa, com a definição do método de pesquisa, o delineamento do experimento, a amostra utilizada, os instrumentos para coleta de dados, bem como as limitações do método de pesquisa. Neste capítulo é comentado o resultado da aplicação do pré-teste da pesquisa.

O Capítulo 4 expõe os resultados da pesquisa aplicada, por meio de tabelas e gráficos que detalham as respostas recebidas em cada questão. Além de efetuar análises e comparações entre os grupos estudados. 
O Capítulo 5 apresenta as conclusões, recomendações e sugestões para novos estudos.

Ao final encontram-se as referências bibliográficas utilizadas neste estudo e os apêndices com os documentos complementares à pesquisa. 


\section{MAPAS ESTRATÉGICOS E AEM: FERRAMENTAS PARA O APOIO DA ESTRATÉGIA, DA COMPLEXIDADE E DO TRABALHO EM GRUPO}

O objetivo deste item é apresentar a discussão dos conceitos que embasaram esta pesquisa e que foram citados nos itens anteriores desta dissertação.

\subsection{Estratégia e Complexidade}

A disponibilidade de informação e as oportunidades de aquisição de conhecimento ocasionadas pelas facilidades de comunicação aumentam os desafios de um mundo cada vez mais acessível e globalizado. De acordo com Sato et al (2005), com a queda das barreiras causadas pelos meios de comunicação, o mundo torna-se cada vez mais complexo, gerando, como consequiência, um aumento do número de atores que podem interagir no ambiente da empresa, exigindo uma crescente evolução das corporações para lidar com novas ameaças e oportunidades de negócios.

As realidades industriais mais simples e os modelos de produção em massa do passado são inadequadas para a realidade atual mais dinâmica e complexa (Sato et al 2005). Com este mundo cada vez mais complexo, que resulta também em problemas maiores e mais elaborados, torna-se relevante examinar de forma abrangente todos seus elementos. Segundo Torrês (2005), examinar isoladamente um componente de um problema ou questão não faz sentido; devem ser examinadas também as relações deste componente com os demais e a visão global constituída por todos eles juntos. Ou seja, na visão deste autor, é necessário que a organização desenvolva uma visão sistêmica para examinar o problema e seus relacionamentos.

A maior complexidade nas questões globais ocasiona também o aumento da incerteza. Wright (1991) afirma que existem menos certezas no campo das ciências humanas e que, desta forma, elementos qualitativos tornam-se importantes para explicar um evento ou absorvê-lo. Neste sentindo, o autor enfatiza que a estrutura e as relações entre fatos, eventos e pessoas parecem ter mais significado do que um conjunto de equações consegue traduzir. É mostrado por Wright (1991) que havia a necessidade de novas metodologias para lidar com uma categoria de problemas de alta complexidade que se apresentam, necessitando de novas abordagens que 
explorassem a riqueza potencial do trabalho em grupo e o entendimento entre especialistas de diversas áreas distintas e grupos afetados para viabilizar o encaminhamento de uma questão complexa, como é, por exemplo, a estratégia de uma empresa.

Segundo Zacarelli (2003), a difusão deste assunto, até então conhecido como planejamento estratégico, começou mais intensamente na década de 70. De acordo com o autor, recentemente passou-se a uma nova fase, na qual o termo "estratégia" foi amadurecendo e ganhando destaque, em detrimento do termo "planejamento estratégico".

Hitt et al (2008) definem estratégia como um conjunto integrado e coordenado de compromissos e ações definido para explorar competências essenciais e obter vantagens competitivas. Na visão deste autor, uma empresa possui vantagem competitiva quando implementa uma estratégia que os concorrentes não conseguem copiar. Por sua vez, Porter (1996) enfatiza que o sucesso da estratégia depende de conseguir integrar e executar muito bem tais ações. Estes autores destacam a importância de combinar e integrar a execução de uma série de atividades para o sucesso da estratégia de uma empresa. Tôrres (2005) enfatiza que a estratégia deve ser vista como um todo complexo. E tal complexidade de uma estratégia é analisada por Porter (1996), que discute como atingir a eficiência operacional de um conjunto de atividades em vez de apenas uma atividade - o que, na visão do autor, não seria estratégia, pois não haveria sustentabilidade da vantagem competitiva, já que os concorrentes poderiam copiar uma atividade isolada fácil e rapidamente. Anselmo (2005) destaca estudos que evidenciam a nova dinâmica de negócios tem tornado impossível às empresas alcançar vantagens competitivas sustentáveis a longo prazo, alterando o paradigma tradicional de competição. Tal complexidade do ambiente competitivo, que exige uma estratégia cada vez melhor delineada e cuja elaboração e implementação são complexas, requer o uso maior de técnicas e ferramentas que auxiliassem a lidar com o desafio da complexidade da construção de uma estratégia corporativa.

A estratégia deve ajudar a empresa a preparar-se para o futuro, a pensar como a organização continuará gerando valor a seus stakeholders e como continuará enfrentando seus concorrentes através de análises do monitoramento dos ambientes competitivos externos e internos. A estratégia deve ser integradora, buscando contemplar todas as competências da empresa e unir todas as suas unidades e áreas em busca de um distinto caminho para o futuro. Quinn (2001) afirma que uma estratégia bem formulada ajuda a ordenar e alocar os recursos 
de uma organização, com base em suas competências e deficiências internas, e auxilia a lidar com mudanças e antecipações, providenciando ações contingenciais em relação a atos de um oponente inteligente. Quando definem uma estratégia, as empresas escolhem alternativas para competir e alcançar um futuro planejado. Nesse sentido, a estratégia escolhida indica o que a empresa pretende e o que não pretende fazer. A competitividade estratégica é obtida quando uma empresa consegue formular, implantar com sucesso e sustentar uma estratégia de criação de valor.

De acordo com o que Hitt et al (2008) recomendam, baseado em diversos autores clássicos da estratégia, a empresa deve avaliar tanto seu ambiente interno quanto o externo, nos quais está envolvida, e planejar suas próximas ações de forma coordenada e organizada, para que atinja os objetivos para os quais se propôs, atendendo a sua missão e visão e, desta forma, alcance melhores resultados em termos das expectativas de clientes, mercados, finanças, acionistas, sociedade e outras partes interessadas em geral. A quantidade de stakeholders a serem atendidos mostra a necessidade de a estratégia trabalhar como uma disciplina integradora tanto externa como internamente, já que para atingir seus resultados e objetivos a empresa deve buscar integrar todas suas áreas (inclusive de apoio) para alcançar e realizar a estratégia planejada.

Após a concepção da estratégia, a empresa deve assegurar que sua implementação tenha sido realizada tal qual planejada. Segundo Wright (2001), o que gera valor para a empresa é a implantação de um bom plano estratégico. Para Fischmann (1987), quando a estratégia é apropriada e a implementação excelente, o sucesso é esperado. Lupoli Junior (2006), citando Tachizawa e Rezende (2000), mostra que um dos grandes problemas da implementação é o fato de a visão dos gestores ser segmentada e setorizada. É recomendável, de acordo com os autores, que se desenvolva uma visão sistêmica das organizações que permita observar as relações de causa e efeito entre os recursos captados e os resultados alcançados. Nessa mesma linha de raciocínio, para Kronmeyer Filho et al (2004), a concepção e implantação da estratégia é um processo transdisciplinar, e sua complexidade necessita de outros elementos, como liderança e comunicação, além de um suporte tecnológico, para ser realizada com sucesso. Para Wright (1991), a crescente complexidade leva à utilização de novas ferramentas para explorar também aspectos qualitativos de um problema, não ficando restrito apenas a ferramentas quantitativas. 
Para a implementação e para o acompanhamento da estratégia podem ser usadas ferramentas de gestão estratégica, como, por exemplo, o Balanced Scorecard (BSC). O BSC surge com uma metodologia que auxilia os gestores a avaliar se a estratégia está atingindo, de fato, seus objetivos e caminhando na direção que foi planejada pela organização. Enquanto o BSC acompanha a estratégia, através da gestão dos objetivos, metas e indicadores, o Mapa Estratégico registra em uma única página a estratégia da corporação, apresentando os objetivos estratégicos em um diagrama com relações de causa e efeito, sob um formato gráfico e compacto, possibilitando levar a estratégia ao alcance de todos na organização. Estes conceitos serão detalhados no item a seguir.

\subsection{Mapas Estratégicos e Balanced Scorecard}

Um Mapa Estratégico é definido por Kaplan e Norton (2004) como a representação visual de causa e efeito entre os componentes da estratégia de uma organização auxiliando assim a construção do BSC. A ilustração 1, a seguir, mostra as relações entre a estratégia, o BSC e o Mapa Estratégico. De acordo com Martins e Marquitti (2006), a construção do Mapa Estratégico é a base para tornar as estratégias da empresa mais explícitas. Assim como o conceito de BSC prega que tal ferramenta deve funcionar como ligação da Estratégia com os indicadores e a parte operacional da empresa, o Mapa Estratégico também cumpre esse papel, auxiliando o BSC a mostrar a relação de objetivos e estratégia de forma gráfica. 


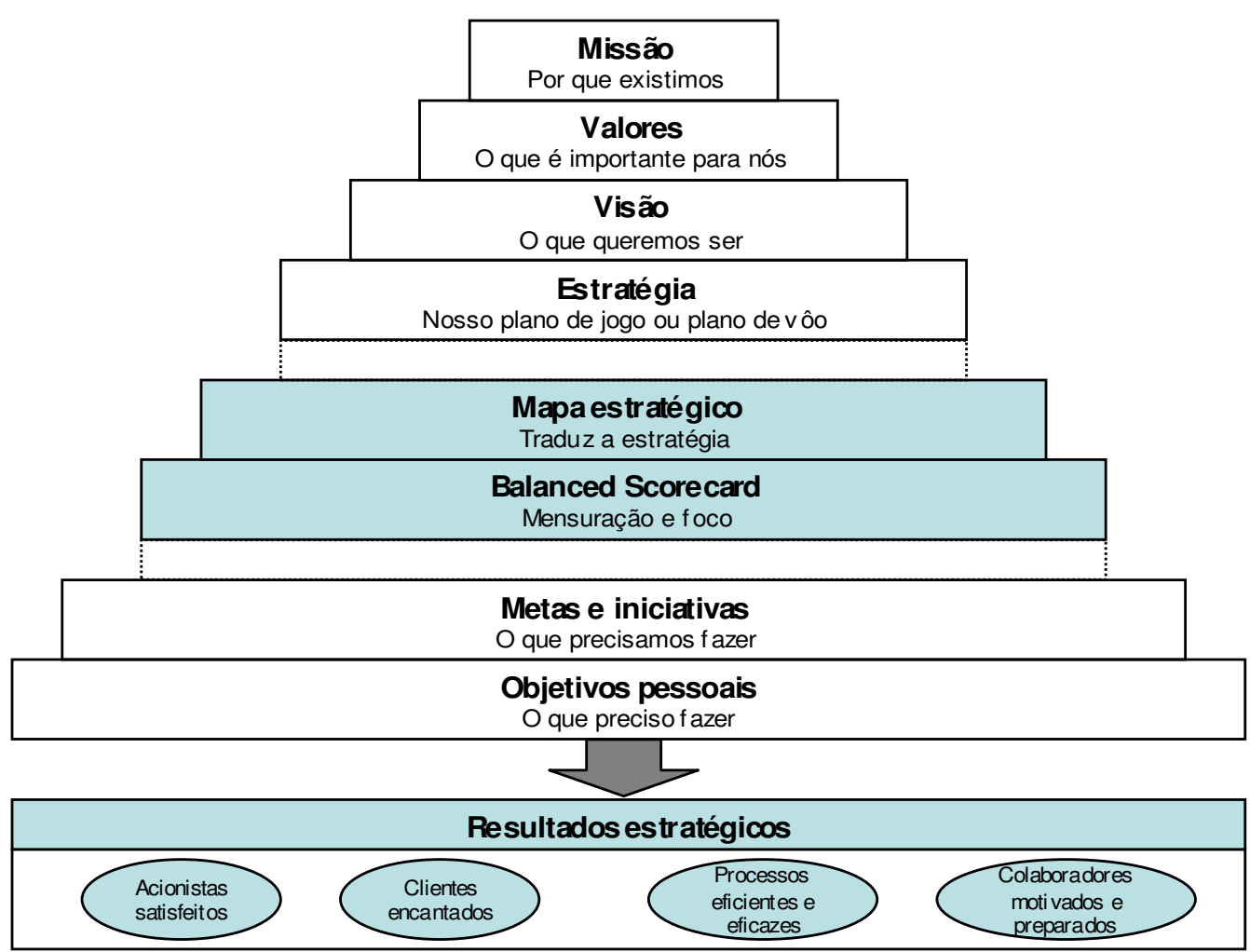

Ilustração 1 - Relação entre Estratégia, BSC e Mapas Estratégicos. FONTE: Kaplan e Norton (2004).

O Mapa Estratégico, segundo Kaplan e Norton (2004), mostra, em uma única página, como os objetivos estratégicos divididos nas quatro perspectivas do BSC se integram e combinam para descrever a estratégia. Esta relação pode ser vista com mais clareza na ilustração 2, a seguir. Para Papalexandris et al. (2005), o Mapa Estratégico acrescenta uma camada de detalhes que ilustra a dinâmica da estratégia, melhorando a clareza e o foco. Kaplan e Norton (2004), por sua vez, asseguram que o Mapa Estratégico revelou-se uma inovação tão importante quanto o próprio BSC, precursor deste conceito. 


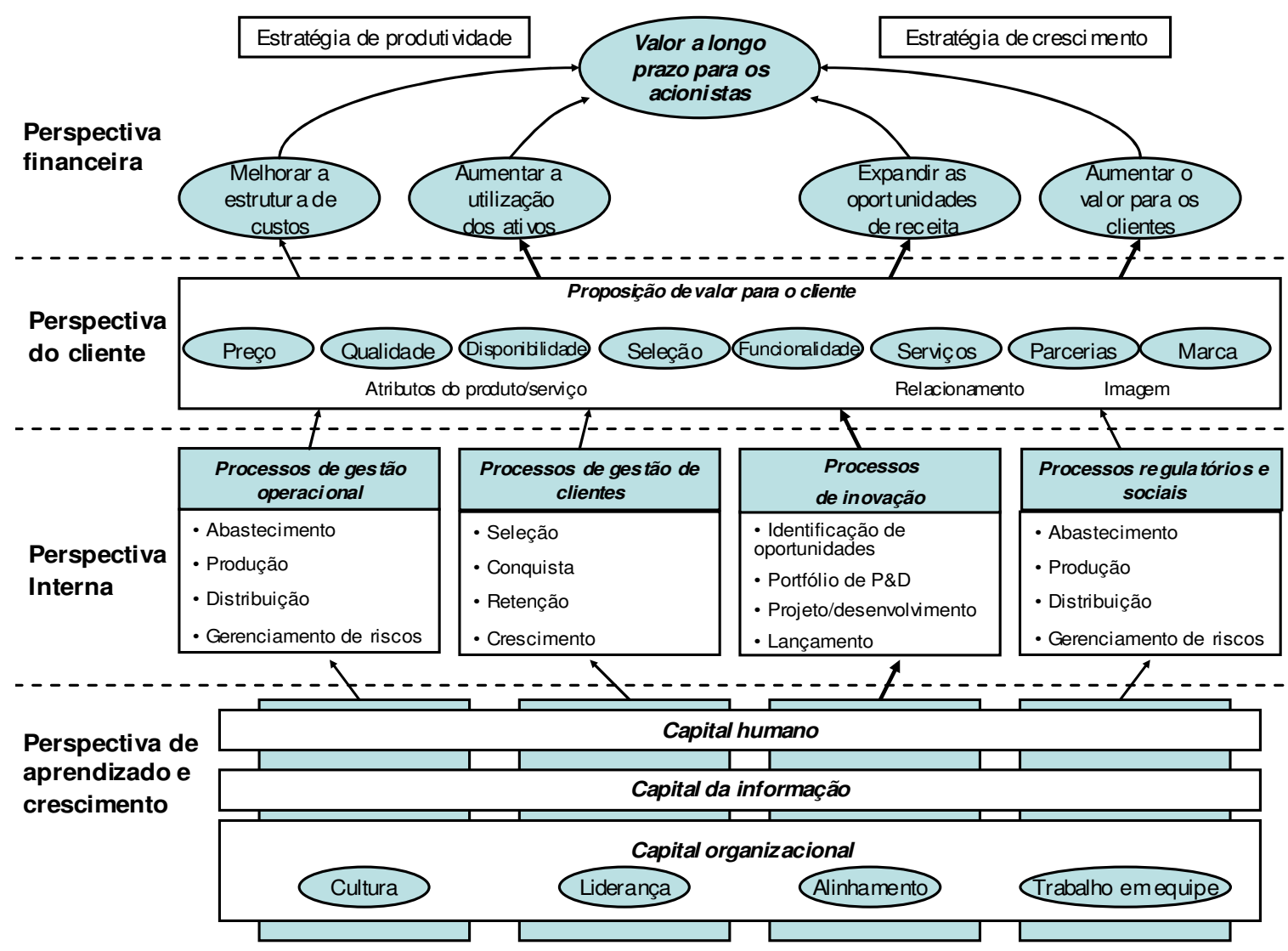

Ilustração 2 - Mapa Estratégico padrão.

FONTE: Kaplan e Norton (2004).

Scholey (2005) propõe a construção de Mapas Estratégicos sem as relações de causa e efeito para obter um efeito mais simétrico e um melhor apelo visual do desenho do mapa. Para este autor, as relações de causa e efeito ocasionam apenas desordem no visual do mapa, opinião que não é compartilhada por outros pesquisadores do tema. O desenvolvimento do Mapa Estratégico é feito justamente para buscar o entendimento da relação de causa e efeito entre os objetivos estratégicos. Kaplan e Norton (2004) contam que, nos primeiros workshops de Mapas Estratégicos com executivos, os objetivos estratégicos eram unidos instintivamente por setas na medida em que eram distribuídos entre as quatro perspectivas. Para Niven (2005), por sua vez, as vinculações de causa e efeito definem a trilha específica que a organização percorrerá para conquistar sua estratégia. Ou seja, conforme a ilustração 2 apresenta, para se atingir "valor em longo prazo para os acionistas" deve-se passar pelo cumprimento de objetivos financeiros, que, por sua vez, estão relacionados ao alcance da proposição de valor ao cliente. Este item é apoiado pelo alcance de metas da perspectiva interna que só é atingida se os indicadores da perspectiva de aprendizado e crescimento (que envolve as pessoas) obtiverem um bom desempenho. Dessa forma, segundo Hikage et al (2006), os profissionais de todas as áreas da organização passam a ter uma visão geral da estratégia, compreendendo 
como os papéis se encaixam e como a sua área contribui com outras, chegando assim a compreensão da estratégia da empresa inteira.

Kaplan e Norton (2004) observam que, na prática, adotam-se numerosas abordagens para formular estratégias. E dessas abordagens resultam-se estratégias diferentes, pelas quais as empresas buscam diferenciar-se de seus concorrentes. Segundo os autores, a essência da estratégia está nas atividades: executar certas atividades de maneira diferente ou executar atividades diferentes das dos concorrentes. É mais difícil para um concorrente copiar várias atividades entrelaçadas do que apenas uma atividade isolada que gere diferenciação. Desta forma o autor afirma que o encaixe estratégico entre muitas atividades é fundamental para gerar e sustentar a vantagem competitiva.

A respeito da execução da estratégia, a ilustração 3 a seguir ilustra a relação entre os objetivos e os indicadores. Para se alcançarem estes objetivos estratégicos, são executadas iniciativas estratégicas que, por sua vez, são avaliadas e acompanhadas. Desta forma, o conjunto de objetivos possui seu conjunto de indicadores de desempenho e metas, que buscam alcançar um bom desempenho para contribuir para atingir o objetivo.

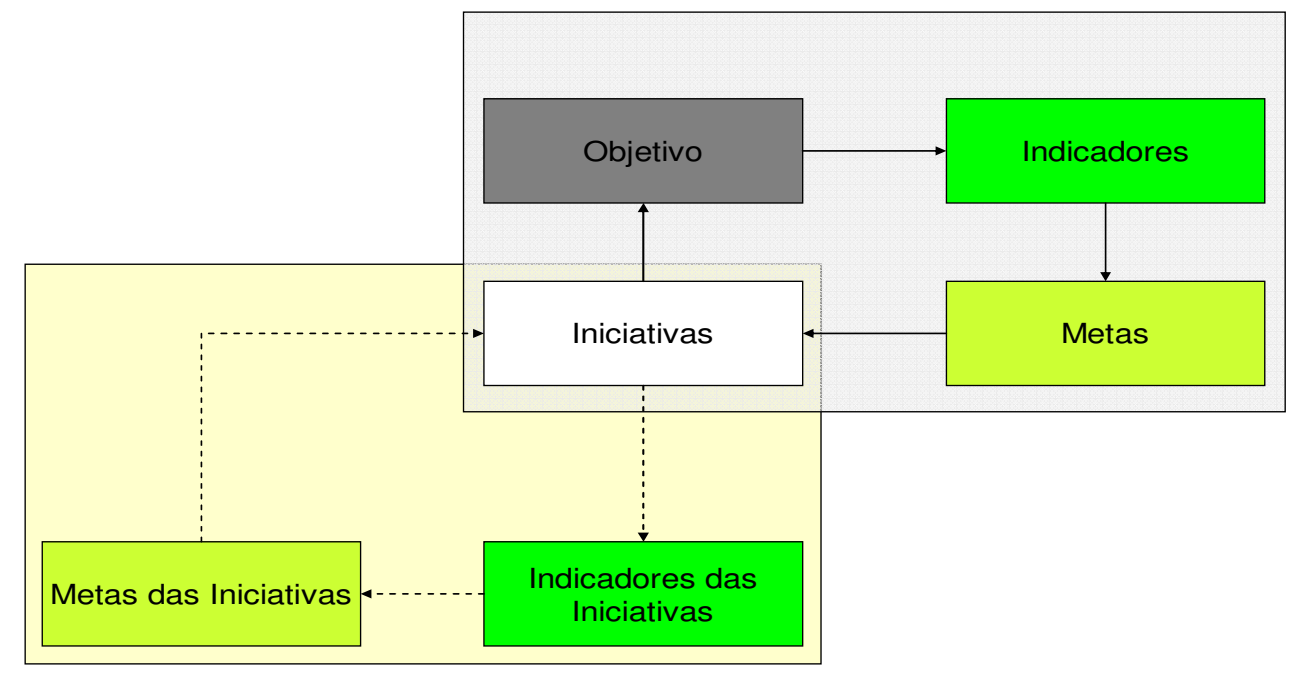

Ilustração 3 - Ciclo de Execução da Estratégia. FONTE: RADUCZINER (2006b).

O Mapa Estratégico fornece uma maneira uniforme e consistente de descrever a estratégia e, assim visa a ação. Segundo Kaplan e Norton (2004), o Mapa Estratégico representa o "elo 
perdido" entre a formulação e a execução da estratégia. Desta forma, é preciso que o Mapa Estratégico esteja alinhado com os propósitos da organização, para surtir o efeito desejado e ser usado da forma correta.

Com as definições de Mapa Estratégico apresentadas, é importante agora discutir os conceitos de Balanced Scorecard, que é a ferramenta central da obra de Kaplan e Norton e que deu origem aos conceitos dos mapas. O Balanced Scorecard (BSC) surge como alternativa para monitoramento de indicadores de todos os aspectos da empresa (e não somente os financeiros), auxiliando dessa forma a gestão estratégica da empresa. Uma das contribuições deste conceito está na ligação dos indicadores com objetivos estratégicos que, se alcançados, levam a empresa a um patamar previsto por sua estratégia. A pesquisa de Castro et al (2009), com 95 empresas, constata que o tempo de uso do BSC está positivamente associado à uma melhor margem de contribuição. Nesta mesma pesquisa não foi encontrado pelos autores esta mesma associação com o faturamento da empresa. Ou seja, de acordo com esta pesquisa, após um ano de implementação do BSC constatou-se que a empresa trabalha seus recursos de forma mais eficiente, o que leva a aumentar sua margem de contribuição.

Conforme descrito por Kaplan e Norton (1997), assim como não é possível pilotar um avião com apenas o mostrador de combustível e pressão de óleo, sem saber, por exemplo, sobre altitude, velocidade e outras informações importantes, na empresa também são necessárias medidas que, mostradas em um quadro conjunto, apresentem uma visão geral do desempenho da empresa nos seus aspectos mais críticos.

Madiolo et al (2003) afirmam que, com o aumento da complexidade do ambiente no qual as organizações estão inseridas, fica claro que o enfoque financeiro, que ajuda a gerenciar orçamentos e relatórios de resultados, não é suficiente para acompanhar as atividades de negócio que são produtoras de resultados. Nos dias de hoje, usar certos indicadores nãofinanceiros ajuda a monitorar as atividades que geram os melhores resultados financeiros. Surge daí a necessidade de monitorar também as operações da empresa. Neste contexto, Raducziner (2006b) destaca a necessidade de se possuir um modelo de medição de desempenho que esteja alinhado às estratégias da companhia e que alcance adequadamente os diversos níveis desta organização. Neste contexto, surge o BSC para suprir essa necessidade de monitorar a empresa como um todo e não apenas os seus aspectos financeiros - que são 
importantes, devem ser acompanhados, mas, conforme dito pelos autores acima, não podem ser utilizados como critério único de gestão de uma empresa.

Segundo Kaplan e Norton (1997), o BSC é uma ferramenta que traduz a missão e a estratégia da organização em um conjunto compreensível de medidas de desempenho, propiciando a formação de uma estrutura de mensuração estratégica e de um sistema de gestão eficiente. Com a utilização do BSC, pode-se esclarecer e traduzir melhor a visão e a estratégia da empresa, destacando-se também a forte ligação entre os indicadores e a estratégia, permitindo que o gestor possa visualizar o comportamento das atividades consideradas fundamentais para o negócio.

O BSC caracteriza-se como uma ferramenta que orienta o usuário desde a visão até a ação, quando a estratégia planejada é colocada em prática. Apesar da ênfase nos indicadores, devese dizer que o BSC oferece uma visão sobre o futuro e um caminho para chegar até ele. Os indicadores, na verdade, devem ser frutos dessa visão estratégica desdobrada em objetivos a serem alcançados pelo bom desempenho dos indicadores.

A partir de uma visão integrada e balanceada da empresa, Kaplan e Norton (2004) afirmam que o BSC permite descrever a estratégia de forma clara, por meio de objetivos estratégicos em quatro perspectivas (financeira, clientes, processos internos e aprendizado \& crescimento), sendo todos eles relacionados entre si em uma cadeia de relações de causa e efeito. Uma empresa que implementa o BSC sabe que é necessário ter bom desempenho em várias áreas, não somente no aspecto financeiro, para conseguir êxito em longo prazo. Além disso, o BSC promove o alinhamento dos objetivos estratégicos com indicadores de desempenho, metas e planos de ação. Desta maneira, é possível gerenciar a estratégia de forma integrada e garantir que os esforços da organização estejam direcionados para a estratégia.

Para Kaplan e Norton (1997, 2004), os objetivos do BSC são esclarecer e traduzir a visão e a estratégia de longo prazo, comunicar e associar objetivos e medidas estratégicas, planejar, estabelecer metas e alinhar iniciativas estratégicas e melhorar o feedback e o aprendizado estratégico.

Analisando o histórico da ferramenta e suas evoluções, o BSC foi criado por Kaplan e Norton no início da década de 90 a partir da observação de várias empresas, nas quais se nota que os 
altos executivos não adotam apenas um conjunto de medidas independentes. É percebido que isoladamente, nenhuma medida proporciona uma avaliação de desempenho ou um enfoque claro das áreas críticas da empresa. Dessa forma, os autores chegam a uma apresentação equilibrada de avaliação de desempenho com medidas financeiras e operacionais, dando origem ao BSC. Martins e Marquitti (2006) mostram que esta ferramenta passou por vários aprimoramentos em seu conceito e resumem a evolução do BSC em três gerações, passando de um sistema de medição de desempenho, em seu início, a um sistema de gestão de desempenho, até chegar a sua definição atual de sistema de gestão estratégica.

A primeira geração do BSC se caracteriza como um sistema de medição de desempenho no qual os indicadores de desempenho financeiros e não-financeiros são agrupados em quatro perspectivas (financeira, cliente, interna dos negócios, e inovação \& aprendizagem) de forma a prover uma visão abrangente do desempenho aos gestores.

Posteriormente, segundo Martins e Marquitti (2006), Kaplan e Norton notam que o desenvolvimento do BSC requer um esclarecimento e compartilhamento da visão e estratégia da organização. Desta forma, o BSC passa a ser desenvolvido a partir desses requisitos e se torna um sistema de gestão do desempenho. As perspectivas mudam para: financeira, cliente, processos internos, e aprendizagem \& crescimento. Além disto, ganham ênfase as relações de causa e efeito entre as perspectivas e as respectivas medidas de desempenho, representadas em um Mapa Estratégico - uma síntese em forma gráfica dos objetivos que constituem a estratégia.

$\mathrm{Na}$ seqüência, na terceira geração, é observado que algumas empresas conseguem, com o BSC, concentrar o trabalho de grande parte dos funcionários no desdobramento e implementação da estratégia. Essas organizações usam o BSC para orientar o processo de implementação da estratégia por meio da aplicação de princípios como: a tradução da estratégia em termos operacionais, a comunicação e integração desta estratégia aos funcionários, o alinhamento da organização à estratégia e, a mobilização da liderança para fazer da estratégia um processo contínuo (PAPALEXANDRIS et al, 2005).

Raducziner (2006b) vai além da evolução em três gerações, mostrando uma quarta geração, conforme a ilustração 4 (a seguir), na qual apresenta o BSC como um modelo de Gestão Estratégica Integrada levando a estratégia até a operação, aumentando o foco das reuniões 
estratégicas e garantindo a velocidade e precisão na comunicação e tomada de decisão estratégica. De acordo com Papalexandris et al (2005), as empresas entenderam que o BSC evoluiu de uma ferramenta de mensuração e acompanhamento de indicadores para um modelo de gestão e comunicação da estratégica.

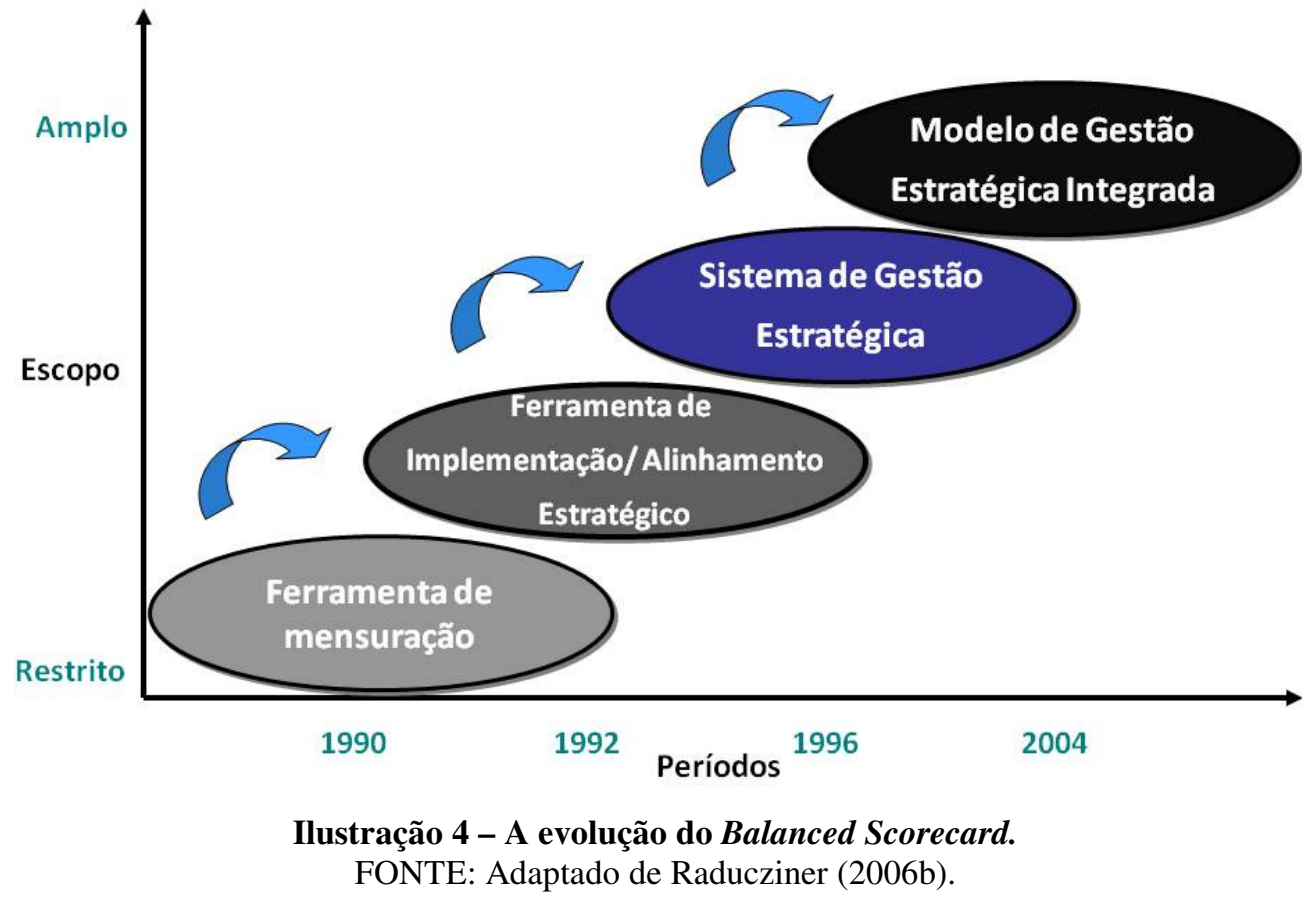

De uma forma geral, segundo Martins e Marquitti (2006), a razão da adoção do BSC vem se modificação, seguindo a evolução do BSC. Inicialmente, tem-se a necessidade de melhorar a medição de desempenho para prover informações relevantes para os tomadores de decisão. Depois a necessidade passa a ser a implementação da estratégia, até tornar a estratégia um trabalho de todos na organização.

A divisão do modelo em quatro perspectivas é um componente importante do BSC para sua correta análise organizacional. As quatro perspectivas comumente utilizadas são: financeira, do cliente, dos processos internos e de aprendizado \& crescimento. Se houver necessidade, é possível adicionar ou substituir alguma dimensão por outra que faça mais sentido à realidade da organização. É o caso de organizações governamentais, sem fins lucrativos e hospitais.

Apresentam-se aqui as perspectivas mais usadas do BSC: 
- A perspectiva de finanças possibilita a identificação dos resultados financeiros da estratégia implementada. O BSC conserva a perspectiva financeira no topo do modelo como conseqüência de todas as outras dimensões, visto que as medidas financeiras são valiosas para sintetizar as consequiências econômicas imediatas de ações consumadas. Exceções para este formato podem ser vistas em BSCs de organizações governamentais ou do terceiro setor, nas quais a dimensão financeira geralmente não é a primeira, ficando a dimensão referente a cliente/usuário/contribuinte em primeiro lugar, além de o caráter financeiro se restringir à captação de recursos e sustentabilidade, em vez de foco em lucratividade e rentabilidade.

- A perspectiva dos clientes permite à administração estabelecer os segmentos e avaliar os desempenhos dos mercados e dos clientes para os quais a empresa atua, em função das expectativas dos clientes e do posicionamento mercadológico da organização.

- A terceira perspectiva, relacionada aos processos internos da empresa, possibilita aos executivos a identificação de pontos críticos nas atividades da empresa em relação aos quais a organização tem de criar diferenciais para agregar valor aos clientes e satisfazer expectativas dos acionistas através dos objetivos financeiros da empresa.

- Por fim, a perspectiva de aprendizado e crescimento facilita a identificação da base ou da infra-estrutura que a organização deve construir para viabilizar o crescimento e a sobrevivência no longo prazo. O objetivo da perspectiva de aprendizado e crescimento é promover a capacitação da empresa a exceder, isto é, apresentar desempenho superior nas perspectivas anteriores.

A ilustração 5, a seguir, resume as quatro perspectivas que fundamentam o BSC, ressaltando ainda as questões-chave que devem ser respondidas em cada uma delas. 


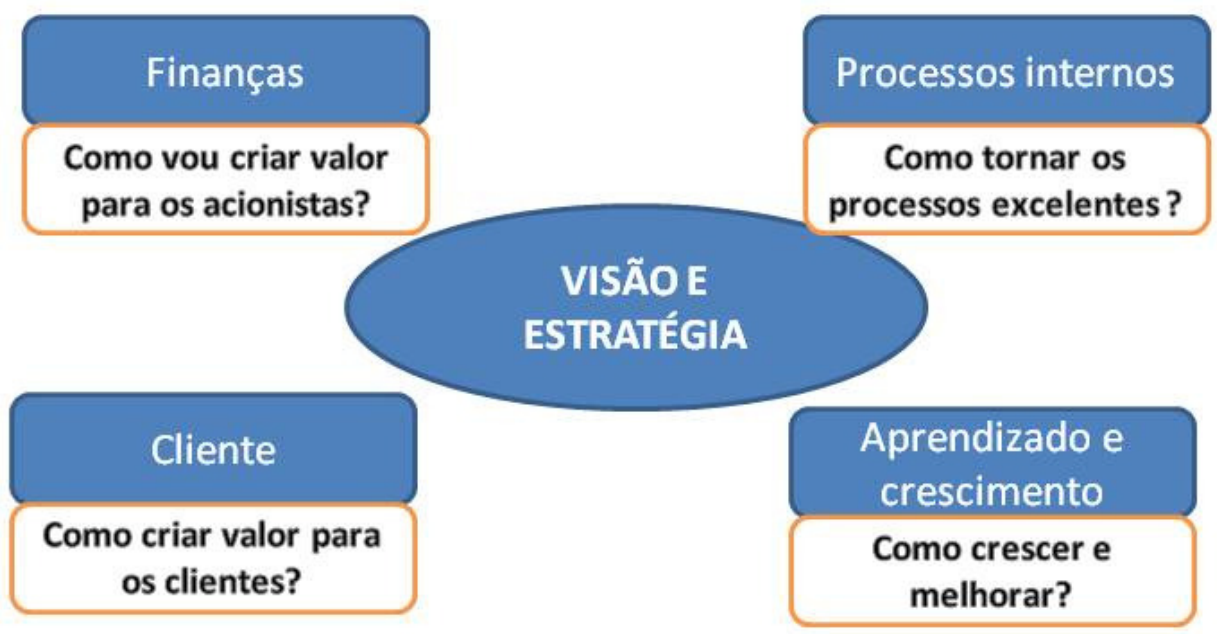

Ilustração 5 - Balanced Scorecard e suas quatro visões. FONTE: Adaptado de Kaplan e Norton (2004).

Madiolo et al (2003) observam que, ao mesmo tempo em que fornece aos dirigentes informações sob quatro perspectivas diferentes, o quadro de indicadores minimiza a sobrecarga de informação, limitando a quantidade de indicadores usados. As empresas raramente sofrem de escassez de medidas. Assim, o quadro de medidas, por outro lado, obriga a direção a fixar-se num pequeno número de indicadores fundamentais. O quadro de indicadores serve de prevenção contra o bom desempenho de uma área em detrimento de outro setor da empresa. Ao obrigar a empresa a considerar em conjunto todas as medidas operacionais, o quadro permite verificar se o aprimoramento de uma área foi obtido à custa de outra. Apesar de destacar que as empresas não devem seguir quantidades fixas, as pesquisas de Niven (2005) indicam que as organizações utilizam em torno de 25 indicadores de desempenho e, cada um ou dois indicadores estão associados a um objetivo estratégico.

As empresas encontram na fase de implementação o momento mais crítico, quando optam por trabalhar com o BSC e o Mapa Estratégico. De acordo com Kaplan e Norton (2004), diversas empresas encontram dificuldades na implementação do BSC, com o uso significativo de recursos humanos e financeiros, sem os resultados desejados. Martins e Marquitti (2006) acrescentam que, para uma mudança efetiva com a adoção do BSC, é necessário que a ferramenta esteja firmemente ligada aos sistemas empresariais, passando a ser o suporte fundamental para a análise do desempenho e tomada de decisão. Além disto, é fundamental determinar as razões pelas quais o BSC deve ser adotado. 
O envolvimento da alta administração é fundamental para o sucesso da implementação do BSC. Na pesquisa realizada por Beber et al (2006), a falta de envolvimento desse público foi indicada como a principal causa de fracasso na implementação do BSC. Uma das possíveis conseqüências deste problema é que muitos altos executivos acabam por delegar todo o processo de implementação do BSC a um nível de gerência intermediária. Muitas vezes esses gerentes não conhecem a fundo as estratégias da organização e seus processos, além de talvez não possuírem a experiência e a força para conduzir o projeto do BSC, já que, na visão de Kaplan (1999), este nível hierárquico não possui nem a autoridade nem o conhecimento dos processos necessários para o sucesso da implementação. Como Kaplan enfatiza, a posição da alta administração deve ser a de dividir funções e responsabilidades, de forma a evitar o isolamento durante a implementação do BSC, além de mostrar o seu envolvimento para toda a organização. Para alcançar o propósito da empresa como um todo, Kaplan (1999) sugere atribuir os scorecards da empresa gradualmente, distribuindo o esforço da implementação e também ajustando e refinando os objetivos e necessidades em todos os setores da empresa.

A definição e composição da equipe a ser encarregada com a implementação do BSC são importantes. Além de possuir alguma experiência ou conhecimento na condução do projeto BSC, deve-se compor uma equipe multifuncional e integrada, de forma a analisar em detalhes a estratégia e os valores da empresa como um todo, que são a base e pré-requisitos para a implementação do BSC, e minimizar as chances de fracasso. Ahn (2001) recomenda que, antes de começar implementar o BSC, os gerentes devem preparar-se profundamente através da leitura ou estudos de livros, artigos e casos a respeito do tema para primeiro se familiarizarem com os conceitos e depois saberem trabalhar com as características, vantagens e desvantagens do BSC.

Outro ponto crítico e importante relatado por Kaplan e Norton (1997) diz respeito às empresas que contratam consultores externos para que fiquem responsáveis pela implementação do BSC. É evidente que a consultoria externa tem seu valor, principalmente pela experiência no assunto adquirida em outras empresas, no entanto, segundo os autores, é necessário tomar cuidado, já que tal circunstância possui um alto risco de produzir um sistema sofisticado, mas que não prioriza as necessidades de gestão do executivo sênior. Em relação a esse aspecto, a alta direção deve possuir seu trabalho estratégico inicial pronto para pode usar os sistemas, tecnologias aplicadas e consultorias para esses sistemas. Ahn (2001) também alerta para este 
ponto, mostrando que a realidade de cada empresa deve ser respeitada quando se trata da implementação de uma ferramenta estratégica.

Costa (2001) e Martins e Marquitti (2006) acrescentam mais alguns itens que devem ser considerados: a determinação da estratégia e objetivos claros para a implementação, para que todos tomem conhecimento e contribuíam de fato para o projeto do BSC. Outro ponto importante destacado pelos autores é o plano de comunicação, para apoiar a implementação, que visa conscientizar todos os níveis da organização a respeito do BSC, informar os conceitos-chave e o andamento do projeto, além de encorajar e motivar os participantes da implementação, tratando assim de eventuais resistências culturais. A relação com outros sistemas gerenciais que a empresa já possui não pode ser subestimada, assim como os bancos de informações básicas para armazenar e avaliar os dados do BSC.

O processo de implementação descrito por Papalexandris et al (2005), baseado em vários autores clássicos, traz uma contribuição de uma visão holística de como o projeto deve ser conduzido. Os autores recomendam sete fases: Preparação do projeto, Entendimento da estratégia da empresa, Identificação dos objetivos e do Mapa Estratégico, Seleção dos melhores indicadores, Operacionalização (definição de metas, iniciativas e orçamentos) e Implementação (início do andamento e revisões). Estas sete fases são apoiadas por atividades que os autores denominam como suporte e que envolvem conceitos de Gestão de Mudança, Gestão de Processos e Projetos, Suporte de Tecnologia da Informação e Gestão de Riscos. Destas etapas, Niven (2005) destaca que o desenho do Mapa Estratégico é etapa crítica do projeto, pois a seleção dos objetivos estratégicos pode gerar desentendimentos entre as equipes, que podem possuir diferentes agendas e metas. Além disto, a subjetividade em estabelecer correlações entre os objetivos estratégicos pode gerar controvérsias.

Costa (2001) destaca ainda que, conforme a evolução e o desempenho da empresa, pode-se chegar à compreensão de que nem toda a empresa deve implantar o BSC. Isto depende também do perfil da organização que deve adotar a idéia e usar de fato a ferramenta. A autora reproduz a opinião de Norton de que o BSC não é apropriado para empresas cujo foco está no corte de custos e na sobrevivência no curto prazo. A teoria do BSC diz respeito a gerir a estratégia que foca no desenvolvimento da empresa no longo prazo. 
De fato, diversos autores apresentam críticas, como seria de se esperar de uma ferramenta comumente utilizada pelas empresas e amplamente citada em livros e artigos. É importante conhecer tais críticas para conhecer melhor o BSC, para aplicá-lo da forma correta e contornar suas limitações.

Mooraj et al (1999) fazem uma ressalva no que tange a implementação, que leva em conta diferentes culturas nas diferentes empresas em que o BSC será adotado. É necessário considerar as diferentes culturas que permeiam cada diferente empresa em que o BSC será implementado. Nisso é importante considerar todos os aspectos da organização, os formalmente descritos e os aspectos informais também, o que resultará que cada BSC é específico da sua empresa, refletindo suas particularidades, além de representar as especificidades na forma de implementar também.

Para Nørreklit (2003), a hipótese da existência de uma relação de causa e efeito entre os indicadores é essencial, pois possibilita que medidas não financeiras sejam empregadas para prever o futuro. Na visão da autora, dado que não existe a variável de tempo, a relação entre os indicadores é considerada apenas lógico - o que cria uma ruptura entre a estratégia planejada e a estratégia de fato realizada por meio das ações. Nørreklit ainda questiona o fato de a ferramenta não ser baseada no ambiente da organização, o que também compromete o objetivo de ser uma ferramenta estratégica. A autora reprova o modelo por não levar em consideração qualquer incerteza em termos de estratégia de risco que pode ameaçar ou invalidar a estratégia presente. Neste caso, entende-se que uma avaliação da estratégia deve ser feita periodicamente e, em caso de mudanças no ambiente, altera-se o BSC, já que os conceitos da ferramenta ensinam que o BSC deve ser implementado a partir de uma estratégia já definida.

Segundo Rampersad (2005), as implementações de BSC tendem a ser insuficientemente comprometidas com o aprendizado e raramente levam as ambições pessoais em consideração. Isso contribui para uma implementação superficial da ferramenta na empresa e para que seu efeito possa ser temporário. Segundo o autor, o melhor desempenho do scorecard depende do alinhamento entre os objetivos organizacionais e os objetivos pessoais dos colaboradores para concretizar as mudanças propostas pelo BSC. Sem esse alinhamento, na experiência do autor, são poucos os funcionários que de fato adotam a idéia do $\mathrm{BSC}$, e, dessa forma, a implementação será feita de forma superficial, e o BSC tenderá ao desuso em pouco tempo. 
Outras críticas do autor dizem respeito à abordagem ainda contábil da ferramenta, em detrimento da visão humana. Rampersad (2006) ainda destaca que a visão essencialmente financeira e que pouco destaca a visão de valores organizacionais pode gerar uma cultura de "o que eu tenho a ver com isso?", contribuindo para o desuso ou fracasso da implementação do BSC. O autor enfatiza também o excesso de objetivos e métricas de desempenho a serem medidas, além da insuficiência de dados disponíveis sobre o atual desempenho da organização, tais como obstáculos para medição de desempenho antes e depois da implementação do BSC. Nesse ponto, é preciso destacar que a literatura de Kaplan e Norton oferece diversos avisos sobre os problemas de um exagero no número de indicadores e objetivos, mas, por outro lado, é interessante essa recomendação de criarem certos controles e indicadores para medir a evolução da empresa antes e depois da implementação do BSC.

Outros pontos destacados das pesquisas de Rampersad (2005 e 2006) podem ser levados em consideração, tais como: o destaque de indicadores antes da implementação do BSC, para avaliar o real impacto causado pela ferramenta, e um maior envolvimento do aspecto humano tanto na implementação como na condução de um BSC - afinal, se as pessoas não estiverem engajadas, o projeto terá poucas chances de dar certo.

Embora criado como um sistema de medição de desempenho, o BSC transformou-se em um sistema de gestão estratégica, conduzindo a implementação, a comunicação e o acompanhamento de toda a estratégia corporativa por meio da gestão de seus objetivos e indicadores e do Mapa Estratégico. Os aspectos apresentados relacionados aos conceitos, características, funcionamento e implementação asseguram que a ferramenta seja utilizada da melhor forma para gerenciar a estratégia de uma organização. Com os conceitos de Mapas Estratégicos e de Balanced Scorecard vistos, passa-se agora às definições de trabalho em grupo.

\subsection{Trabalho em grupo}

De acordo com Casado (2001), numerosas pesquisas realizadas para identificar características do profissional do futuro apontam o trabalho em grupo como um dos itens mais indicados. Lupoli Filho (2006) define grupo sob a ótica da psicologia, como uma entidade 
psicossociológica sujeita a fenômenos específicos tais como coesão, estrutura, liderança, dentre outros.

Para Robbins e Finley (1997), equipes e grupos têm sido componentes-chave da realidade organizacional desde que existem as organizações. Ao longo da história, trabalhar em conjunto tem sido a forma normal de se fazerem as coisas. Os autores definem equipe como "pessoas fazendo algo juntas", sendo que o "algo" não é o que a torna uma equipe, e, sim, o "juntas". A capacidade que as pessoas têm de trabalhar em conjunto é que as faz produzir algo maior do que conseguiriam produzir sozinhas.

Lupoli Filho (2006), citando Aguiar (2000), descreve o que torna um grupo diferente de um simples agregado de pessoas, apesar de ressaltar que esta definição não é algo simples de ser estabelecido:

1. Os membros compartilham de um ou mais objetivos

2. São desenvolvidas normas que estabelecem os limites nos quais as relações interpessoais e as atividades são constituídas

3. Com interação contínua, um conjunto de papéis se estabiliza, e um novo grupo se diferencia dos outros

4. Uma rede de atração interpessoal desenvolve-se na base do "gostar ou não" dos membros do grupo

Lupodi Filho (2006) ainda descreve dois tipos de tendências que consegue discernir na realização de trabalhos em grupo: uma que se dirige a realização da tarefa e outra que parece opor-se à tarefa. Para descrever estas características, Lupodi Filho recorre a Bion, que possui uma terminologia específica sobre o assunto trata-se da Mentalidade Grupal, que reflete a vontade, desejo ou opinião unânimes do grupo, em um dado momento. A mentalidade grupal pode entrar em conflito com os desejos, opiniões ou pensamentos dos indivíduos, produzindo desconforto, mal-estar, entre outras complicações (Grinberg et al, 1973 apud Lupodi Filho, 2006). O termo "Suposto Básico" foi criado para identificar reações que são, muitas vezes, inconscientes e que podem ser opostas às opiniões racionais dos membros do grupo. São três tipos de supostos básicos: 
- Dependência: ocorre quando o grupo possui a convicção de que alguém fornecerá todas as satisfações para as necessidades deste grupo; elege-se alguém de quem o grupo depende de forma absoluta.

- Ataque e fuga: é a convicção do grupo de que existe alguém de quem é necessário fugir ou atacar. Pode ser um membro do grupo excessivamente expansivo, tímido ou ainda que possua alguma característica ameaçadora ao grupo, que, por sua vez, procura desprezá-lo, desacreditá-lo ou atacá-lo.

- Acasalamento: possui o pressuposto de que, quaisquer sejam os problemas ou necessidades do grupo, surgirá um fato que irá resolvê-los.

No caso da dinâmica de grupos, a visão de Lewin (1970 apud Lupoli Filho, 2006), conduziu à elaboração de quatro suposições sobre grupos: os grupos são inevitáveis e onipresentes devido às necessidades individuais de afiliação, reconhecimento, segurança, entre outras obtidas através dos grupos. A segunda suposição diz que os grupos mobilizam poderosas forças, que têm influência decisiva nos indivíduos. A terceira suposição destaca que os grupos podem ter conseqüências boas ou más. E a quarta suposição apresenta que os grupos podem ser muito valiosos e produtivos, se deliberada e conscientemente trabalharem para intensificar as conseqüências positivas.

Apesar das diferenças de definição entre grupos, equipe e times encontradas na literatura, por exemplo, em Casado (2001), Hardingham (2000) e Robbins e Finley (1997), é possível encontrar características comuns a essas diversas formas de trabalho que envolvam um conjunto de pessoas. A este propósito, Hardingham (2000) cita o gasto excessivo de tempo e energia para aprimorar as habilidades de comunicação e interação, afetando os resultados do trabalho. Certos indivíduos ficam constrangidos ou são marginalizados por acharem o trabalho em equipe difícil e contrário ao seu estilo natural. Robbins e Finley (1997) elegem outros problemas, tais como: papéis e necessidades individuais mal resolvidas dentro do grupo, metas confusas, tomada de decisões ruins, conflitos de personalidades, problemas com lideranças, falta de confiança, ferramentas erradas, feedback ou informações insuficientes e sistemas de recompensas mal concebidos.

Lupodi Filho (2006) acrescenta que, na dinâmica de grupo, admite-se que os inevitáveis contatos estabelecidos por membros dos grupos favorecem o aparecimento de vínculos, lutas, 
tensões e conflitos interpessoais. Wright (1991) acrescenta que outras dificuldades surgem da própria dinâmica do grupo na qual a capacidade de persuasão e o prestígio de determinado especialista podem dar peso desproporcional a seus argumentos; a característica e comportamento do grupo tende a abafar posições minoritárias e alguns membros podem registrar participação abaixo do seu potencial; além disso, a lentidão da comunicação verbal limita o número de participantes efetivos e, por conseqüência, a qualidade dos resultados. No caso específico de grupos multidisciplinares, Wright (1991) destaca que as dificuldades são maiores, pois os diferentes perfis dos componentes do grupo podem trazer conceitos, linguagem e abordagens distintas.

Nesta mesma linha, Carew e Parisi-Carew (2007) complementam com as principais razões de fracasso de uma equipe: a falta de diretrizes sólidas para definir tanto o propósito da equipe quanto o modo como esta trabalhará de forma coesa para alcançá-los. Outros aspectos importantes faltam a um grupo que fracassa em seus objetivos: responsabilidade; recursos para concluir o trabalho (incluindo tempo); normas que fomentem a criatividade e excelência; planejamento; apoio das gerências; habilidade para lidar com conflitos; e treinamento em habilidades de trabalho em equipe.

Com esses possíveis problemas do trabalho em grupo, uma ferramenta que minimize estas desvantagens e possibilite a participação de forma igual de todos os envolvidos potencializa as conseqüências positivas que a reunião do grupo ocasiona.

\subsection{Análise e Estruturação de Modelos (AEM)}

$\mathrm{O}$ método AEM foi originalmente desenvolvido como um instrumento para aumentar a eficácia do trabalho em grupo na análise de questões complexas. Com esta técnica e o auxílio do computador, o grupo define uma estrutura hierarquizada de um determinado problema. De acordo com Wright (1991) a AEM foi criada por Warfield a partir de uma necessidade de uma abordagem global para a análise de questões sociais. A AEM foi proposta para lidar e resolver questões complexas que geralmente envolvem muitos elementos ou aspectos multidisciplinares, como uma análise de problemas da sociedade ou como no planejamento de prioridades para cidades (Battelle, 1975; Warfield, 1976). 
Nas décadas de 80/90 o método começou a ser aplicado no Brasil tanto em sua concepção original (Cunha et al, 1996) como em pesquisas que mostram sua aplicação na área de administração de empresas e na eficácia do trabalho em grupo (Wright, 1989, 1991, 1995). Publicações recentes do método mostram suas diversas formas de aplicação: análise da influência entre variáveis (Ilyas et al, 2005, Ravi e Shankar, 2005), aprimoramento da tomada de decisão (Bolaños et al, 2005), priorização de objetivos (PIAPS, 2002), análise de interação entre elementos (Kanazawa et al, 2006; Thakkar et al, 2008, Sagheer et al 2009), análise de riscos (Gorvett e Liu, 2007; Jha e Devaya, 2008), entre outros.

Segundo Warfield (1990), o AEM é uma metodologia que permite aos grupos estruturarem informações complexas com o auxílio do computador, enquanto simultaneamente auxilia a esclarecer a compreensão do problema. De acordo com o autor, o método é útil quando uma questão complexa está sendo estudada e há inter-relações entre os diversos elementos da questão. Um grupo de discussão sobre a questão é necessário para desenvolver o que o autor chama de mapa de relações.

Thakkar et al (2008) complementam esta visão, com a afirmação de que a AEM é útil para identificar e sumarizar as relações entre itens específicos que definem uma questão ou um problema baseado em uma lista de itens que pode ser facilmente aplicada. Os autores, em comparação com outras técnicas de decisão baseada em multicritérios, destacam algumas características relevantes da AEM, tais como a capacidade e habilidade de captar as complexidades dos problemas da vida real.

Para Ravi e Shankar (2005), a metodologia também pode atuar como uma ferramenta para dar direção e ordenar a complexidade das relações entre elementos de um sistema, além da sua aplicação ser um processo de aprendizado sobre o tema em discussão. Os autores afirmam que um das vantagens do modelo AEM é gerar um retrato da estrutura de uma questão complexa ou de um problema em estudo, ser cuidadosamente aplicado em um padrão que emprega gráfico e palavras.

Segundo Warfield (1976 apud Wright 1991), a estrutura hierarquizada, representada graficamente, pode trazer um rápido entendimento e redução da ambigüidade na sua interpretação, além da facilitação da disseminação da informação. Tal estrutura gráfica possui o mesmo objetivo e função de um mapa cognitivo, que Eden et al (1979 apud Rieg e Araújo 
Filho, 2003) definem como uma ferramenta útil para auxiliar a estruturação e situações problemáticas descritas, predominantemente, qualitativas, nas quais é possível entender como os diferentes aspectos se relacionam entre si e pode ser empregado em diversas situações como ferramenta de reflexão e resolução de problemas.

O conceito de mapa cognitivo se assemelha ao da AEM, especialmente pela oportunidade que ele proporciona de refletir acerca de um problema e depois visualizá-lo de forma graficamente estruturada. No entanto, a abordagem própria da AEM torna possível trabalhar com a interação e a visão de um grupo sobre um problema enquanto que, essencialmente, o mapa cognitivo reflete a visão de apenas um cliente.

De acordo com Wright (1989), a técnica AEM é caracterizada por ser útil nas seguintes situações: estruturação de objetivos, definição de prioridades e hierarquização de políticas e diretrizes. Essa técnica permite estruturar um grande número de informações não quantitativas, contribuindo para a análise e tomada de decisão ao nível de políticas e diretrizes, enquanto que os modelos quantitativos em geral não captam muitos dos condicionantes críticos que a situação apresenta (WRIGHT, 1989).

A ferramenta AEM busca extrair do contexto em estudo um conjunto de componentes ou elementos do problema, utilizando, na seqüência, o computador para ordenar, armazenar e fazer inferências lógicas sobre o problema apresentado. Segundo Wright (1989), o modelo resultante é representado por um gráfico direcionado, obtido por meio da aplicação de noções básicas de topologia, somadas ao julgamento humano do grupo e à capacidade que os computadores possuem de processar um grande número de dados e fazer inferências lógicas.

O conjunto de informações necessárias à definição de uma estrutura deste tipo pode ser matematicamente representado por uma matriz binária, e uma operação matemática permite transformá-la de forma a evidenciar, de modo claro, todas as inferências e níveis hierárquicos contidos nas informações originais (Warfield, 1976 apud Wright, 1989). Com estes procedimentos de inferência lógica, o método torna possível identificar relações a partir das respostas dadas e preencher a matriz, de forma que nem todos os itens do problema precisam ser avaliados pelo grupo. Segundo Wright (1995), uma nova abordagem do método AEM, baseada em procedimentos de inferência lógica, abre caminho para a utilização de nuances de relação entre o sim, o não e o talvez, tornando a técnica amplamente aplicável na 
Administração. Esta abordagem do problema de estruturação inclui um procedimento de busca heurística para definir a sequiência de perguntas para coleta de informações.

Quando o contexto do problema está definido, a atuação do grupo que utiliza o método AEM consiste, de acordo com Wright (1995) e Warfield (1990), em extrair um conjunto bem definido de elementos pertinentes. Elementos da questão serão avaliados e inclusos no software. A máquina irá apresentar questões ao grupo que irá discutir a respeito da relação entre os elementos. A seguir, o grupo analisa a existência de uma relação transitiva entre pares de elementos, respondendo a perguntas colocadas pelo computador, que por sua vez faz as inferências lógicas possíveis, produzindo, assim, o mapa estrutural. Ao final da discussão sobre os elementos, o mapa é apresentado para que o grupo examine e discuta sua interpretação. A definição clara dos componentes do problema e de suas relações, assim como a interpretação e o aperfeiçoamento do modelo estrutural são itens de extrema valia para melhorar o entendimento do grupo sobre a questão, sistematizar o raciocínio dos integrantes e facilitar a comunicação sobre o problema.

Segundo Wright (1991), o uso da AEM impõe uma abordagem muito mais estruturada ao trabalho em grupo, com significativas vantagens ao aprendizado. O grupo avança no entendimento de um problema ao discuti-lo de uma maneira estruturada. Deve-se observar que o grupo não precisa ter nenhum conhecimento sobre os procedimentos matemáticos realizados, analisando apenas a relação entre pares de elementos do problema. Por sua vez, o computador faz inferências lógicas com base apenas nas informações fornecidas pelo grupo, minimizando o número de perguntas necessárias para a determinação do modelo estrutural. Para Wright (1995), o modelo estrutural resultante do método facilita o mecanismo de comunicação, a visualização, a interpretação dos modelos e o raciocínio sobre sua estrutura. No decorrer do processo, fica evidente aos participantes que os resultados advêm exclusivamente das informações por eles trazidas, sem qualquer interferência do computador em termos de conteúdo.

Os conceitos vistos trazem a idéia de que o método permite a estruturação de variados formatos de questões, o que torna possível pensar na aplicação desta ferramenta para organizar uma lista de objetivos estratégicos, estruturando um Mapa Estratégico. O pensamento de tal aplicação está apoiado no fato que a construção dos Mapas Estratégicos é 
pouco explorada nos materiais de Kaplan e Norton. A metodologia da pesquisa que tratará deste tema é descrita a seguir. 


\section{ABORDAGEM METODOLOGICA UTILIZADA}

Este item possui o objetivo de delinear a metodologia de pesquisa a ser utilizada para a análise da aplicabilidade do método AEM para a elaboração de Mapas Estratégicos.

\subsection{Método de pesquisa}

No item anterior desde projeto, foi feita a revisão do referencial teórico dos conceitos que permeiam esta pesquisa e seus objetivos. De acordo com Baker (2001), uma vez que definido o que se busca de informação, é possível determinar o método mais apropriado para coletar tais informações. Este item tem o objetivo de listar o método usado nesta pesquisa. Para Marconi e Lakatos (2003), a seleção do instrumental metodológico está diretamente relacionada ao problema estudado. De acordo com as autoras, os métodos e as técnicas devem adequar-se ao problema a ser estudado, às hipóteses levantadas e ao tipo de informações que se entrará em contato.

Segundo Gil (1987), as pesquisas podem ser classificadas em três categorias, com base em seus objetivos gerais:

- Pesquisa exploratória: familiarização com um problema;

- Pesquisa descritiva: descrição das características de uma determinada população ou um determinado fenômeno, ou ainda a relação entre variáveis;

- Pesquisa explicativa: identificação dos fatores que determinam ou contribuem para a ocorrência dos fenômenos estudados. A pesquisa explicativa também é conhecida como causal e, segundo Cooper e Schindler (2003), esse tipo de pesquisa visa descobrir o efeito que uma variável possui sobre outras ou por que certos resultados são obtidos.

Para Gil (1987), as pesquisas explicativas usam quase que exclusivamente a experimentação. Nas ciências sociais, de acordo com este autor, a aplicação deste método reveste-se de muitas dificuldades, razão pela qual se recorre também a outros métodos, sobretudo ao observacional. A maioria das pesquisas desta categoria podem ser classificadas como experimentais e ex-post-facto. 
De acordo com Cooper e Schindler (2003), os experimentos são estudos que envolvem uma intervenção do pesquisador além daquela exigida para mensuração. Kerlinger (1980) complementa tal reflexão, afirmando que esta é a pesquisa em que se estudam as relações entre variáveis dependentes e independentes. A aplicação de uma pesquisa experimental decorre da manipulação da variável independente (ou explanatória) pelo pesquisador e da verificação se a variável dependente é afetada pela intervenção. Segundo Baker (2002), o objetivo deste tipo de pesquisa é identificar e medir relações entre as variáveis, em especial as relações causais. Gil (1987) explica que a diferença básica entre pesquisas experimentais e expost-facto está basicamente em que a manipulação de variáveis independentes não é possível neste segundo tipo de pesquisa, já que a aplicação desta pesquisa é realizada após os fatos terem ocorridos.

Para Kerlinger (1980), um experimento possui duas características básicas:

1. Designação aleatória dos diferentes grupos experimentais. Ou seja, os sujeitos são designados para os grupos experimentais de tal forma que qualquer um pode se tornar membro de qualquer grupo. Cooper e Schindler (2003) complementam com a afirmação de que todas as pessoas pesquisadas devem ter a mesma chance de exposição a todos os níveis da variável independente.

2. Manipulação de variáveis independentes: permite o trabalho do pesquisador de maneiras diferentes com grupos diferentes possibilitando a aplicação do experimento. Cooper e Schindler (2003) detalham esta explicação, afirmando que todos os fatores, com exceção da variável independente, devem ser mantidos constantes e não devem ser confundidos com outra variável que não seja parte da experimentação.

Gil (1987) afirma que, entre as diversas modalidades de pesquisa experimental, as três mais comuns são:

- Experimentos "apenas depois". É um tipo que se subdivide em dois grupos: “experimental”, que recebe a aplicação de um tratamento, segundo Kerlinger (1980), e "de controle". Aplica-se o estímulo apenas no grupo experimental, e procede-se à medição das características de ambos. Estes grupos devem apresentar homogeneidade em relação a todas as características relevantes que seja possível controlar. Como os grupos foram previamente homogeneizados, infere-se que toda variação significativa entre eles será decorrente do estímulo aplicado. Baker (2001) complementa este conceito mostrando que o grupo experimental é exposto à variável independente, que 
hipoteticamente causará um efeito, enquanto que seu conseqüente comportamento ou condição é passível de comparação com o grupo de controle que não foi exposto a tal variável.

- Experimentos “antes-depois" com o mesmo grupo: é constituído por apenas um grupo, que será analisado antes e depois da introdução de um estímulo.

- Experimentos "antes-depois" com dois grupos. Os grupos experimental e de controle são avaliados no início e ao final do experimento, sendo que o estímulo é introduzido apenas no grupo experimental. Baker (2002) destaca que, neste método, é estabelecido um benchmarking para os grupos cujas similaridades podem ser quantificadas e melhor comparadas, já que eles são medidos antes e depois do estímulo. Para Gil (1987), para alguns autores, apenas as pesquisas deste grupo podem ser consideradas rigidamente experimentais, enquanto que as outras duas modalidades seriam "préexperimentais".

Dadas as características detalhadas nos itens a seguir, esta pesquisa se baseia em um experimento "apenas depois".

\subsection{Definição do universo de pesquisa}

De acordo com Kaplan e Norton (1997, 2004), o BSC deve ser usado e elaborado por executivos com o apoio, supervisão e incentivo da alta direção. O universo desta pesquisa, então, são os profissionais de nível executivo - perfil necessário para construir um Mapa Estratégico em uma organização.

\subsection{Definição da amostra de pesquisa}

Segundo Cooper e Schindler (2003), definem como amostras por conveniência aquelas amostragens não-probabilísticas que são irrestritas. Normalmente, usa-se este tipo de amostragem quando não é viável obter uma amostragem probabilística, pois a população não está disponível. Na impossibilidade de usar todo o universo da pesquisa, a amostra desta pesquisa se restringirá aos estudantes de pós-graduação de relevantes escolas de São Paulo. 


\subsection{Estratégia de coleta dos dados: descrição do experimento}

Com a apresentação do método de pesquisa e a definição do universo e da amostra, este item tem o objetivo de fazer a descrição do experimento.

Esta pesquisa considera como variável independente a "Aplicação do método AEM", enquanto que "Elaboração de Mapas Estratégicos" como variável dependente. Estas são as variáveis do experimento, que auxiliam no estudo da aplicabilidade do método AEM na elaboração de Mapas Estratégicos.

De acordo com Gil (1987), é possível definir, a partir do número de variáveis o plano experimental. Neste caso, com a definição de uma única variável independente, o experimento é designado de "mão única" ou one way. O quadro 1, abaixo, mostra como este plano pode ser esquematizado.

Quadro 1 - Plano de experimento sobre a aplicação ou não do método AEM na elaboração de Mapas Estratégicos

\begin{tabular}{|l|l|}
\hline \multicolumn{2}{|c|}{ Aplicação do método AEM (Análise e Estruturação de Modelos) } \\
\hline Aplicam (grupo experimental) & Não aplicam (grupo de controle) \\
\hline \multicolumn{2}{|c|}{ Resultados na variável dependente (elaboração de Mapas Estratégicos). } \\
- Percepção de aprendizagem do indivíduo \\
- Participação/Integração do grupo \\
- Melhorias no processo de construção do Mapa Estratégico \\
\hline
\end{tabular}

FONTE: baseado em Gil (1987).

Foi utilizado um trecho de aproximadamente 1 hora dentro da disciplina de Estratégia Empresarial (ou equivalente) para aplicar o experimento. A designação de cada participante em cada grupo foi feita de forma aleatória, sob a condição de que todos os participantes possuam igual probabilidade de pertencer a qualquer um dos grupos. A organização aleatória também definiu quais foram os grupos experimentais (que usou a AEM para elaborar Mapas Estratégicos) e quais foram os grupos de controle.

Como o experimento foi aplicado em sala de aula simultaneamente para os dois tipos grupos, a abordagem que melhor se encaixa, dentre as modalidades de experimentos, é a "apenas depois" já que todos os grupos produziram os mapas estratégicos que depois foram avaliados, para serem efetuadas comparações entre os grupos de controle e os grupos experimentais. 
O experimento consistia na aplicação de um exercício (Apêndice I) que apresenta aspectos da estratégia de uma empresa ("PROJ Engenharia S/A"), inclusive com a definição de seus objetivos estratégicos. O caso apresenta as informações necessárias para que cada grupo conseguisse produzir seu Mapa Estratégico com os objetivos estratégicos dispostos em uma relação de causa e efeito. O grupo experimental construiu seu Mapa Estratégico por meio de um software concebido com base no processo de Wright (1991). Por sua vez, o grupo de controle elaborou seu Mapa Estratégico de forma livre, ou seja, a partir de seus conhecimentos e das informações do caso, sem nenhuma contribuição adicional.

Após a construção dos Mapas Estratégicos, todos os grupos receberam um questionário (Apêndice II) para preencher. Este questionário colheu a avaliação, por parte do aluno, do processo de construção do Mapa Estratégico (com base nos resultados obtidos com o seu grupo) e coletou percepções individuais acerca da participação, contribuição e aprendizagem do indivíduo.

O quadro 2 foi elaborado para organizar as análises posteriores a aplicação do experimento e, assim, associar as questões de pesquisa aos itens do questionário. Os demais itens do questionário, que não estão associadas diretamente as questões de pesquisa, estão relacionados a informações que deveriam ser colhidas para: a elaboração de perfil do respondente, a medição de interesse no curso e o levantamento da experiência e da dificuldades com os conceitos relacionados ao exercício. Além dos resultados advindos dos questionários o pesquisador procurou fazer observações acerca do nível de participação e interesse de cada grupo durante toda a aplicação do experimento. 
Quadro 2 - Interação entre as questões de pesquisa e os principais elementos do questionário

\begin{tabular}{|c|c|}
\hline Questão & Forma de investigação/ item do questionário \\
\hline $\begin{array}{l}\text { 1. Quais as diferenças entre a } \\
\text { estrutura dos Mapas Estratégicos } \\
\text { construídos com ou sem } \\
\text { aplicação da AEM? }\end{array}$ & $\begin{array}{l}\text {. Comparação entre os Mapas Estratégicos produzidos pelos } \\
\text { grupos (resultado do exercício/experimento) } \\
\text {. Análise da alocação de objetivos nas quatro dimensões do } \\
\text { BSC }\end{array}$ \\
\hline $\begin{array}{l}\text { 2. A aplicação da ferramenta } \\
\text { AEM resulta em alterações no } \\
\text { processo de construção de } \\
\text { Mapas Estratégicos? }\end{array}$ & $\begin{array}{l}\text {. Análise das respostas dos questionários, observações e } \\
\text { comparações entre os dois grupos do experimento. } \\
\text { c. Consegui contribuir com o que considerei } \\
\text { relevante/necessário à discussão } \\
\text { d. Poucos membros (ou um único membro) monopolizaram a } \\
\text { discussão } \\
\text { e. O grupo entrou em consenso prático sobre o conteúdo do } \\
\text { Mapa Estratégico }\end{array}$ \\
\hline $\begin{array}{l}\text { 3. Qual a opinião dos envolvidos } \\
\text { a respeito da aplicação da AEM } \\
\text { na construção de Mapas } \\
\text { Estratégicos? }\end{array}$ & $\begin{array}{l}\text { i. Fiquei satisfeito(a) com o resultado do exercício } \\
\text { k. A ferramenta de estruturação de objetivos (AEM) auxiliou } \\
\text { o processo de construção dos Mapas* } \\
\text { I. Valeu a pena utilizar a ferramenta dentro do tempo } \\
\text { proposto ao exercício * } \\
\text { 6. Qual sua opinião sobre a utilização da AEM neste } \\
\text { exercício?* }\end{array}$ \\
\hline $\begin{array}{l}\text { 4. A percepção da aprendizagem } \\
\text { da estratégia corporativa é mais } \\
\text { evidente nos grupos que } \\
\text { utilizaram ou não a AEM para } \\
\text { construir Mapas Estratégicos? }\end{array}$ & $\begin{array}{l}\text { h. Após a discussão e a construção do Mapa, minha } \\
\text { percepção sobre o entendimento da estratégia descrita do } \\
\text { caso, aumentou } \\
\text { j. A utilização da ferramenta AEM auxiliou-me a } \\
\text { compreender melhor a estratégia descrita no caso }\end{array}$ \\
\hline
\end{tabular}

\subsection{Técnicas de tratamento estatístico dos dados}

Nesta pesquisa, foi empregada a escala de Likert (detalhamento no item a seguir), Cooper e Schindler (2003) afirmam que esta escala produz dados intervalares. De acordo com estes autores, quando uma escala é de intervalo, aplica-se a média aritmética como medida da tendência central e o desvio-padrão para a mensuração da dispersão. Além desses, correlação momento-produto de Pearson, testes $t$, testes $F$ e outros testes paramétricos são os procedimentos estatísticos que podem ser adotados.

\subsection{Escalas de mensuração}

De acordo com Cooper e Schindler (2003), a escala de Likert é a variação mais freqüentemente usada da escala de classificação somatória. Tais escalas consistem em afirmações que expressam atitudes favoráveis ou desfavoráveis em relação ao objeto de interesse. Ou seja, pede-se ao respondente que concorde ou discorde de cada afirmação. Por sua vez, cada resposta recebe uma classificação numérica para refletir seu grau de 
favorecimento de atitude, e esses números podem ser somados para mensurar as atitudes dos respondentes.

\subsection{Modelo teórico da pesquisa}

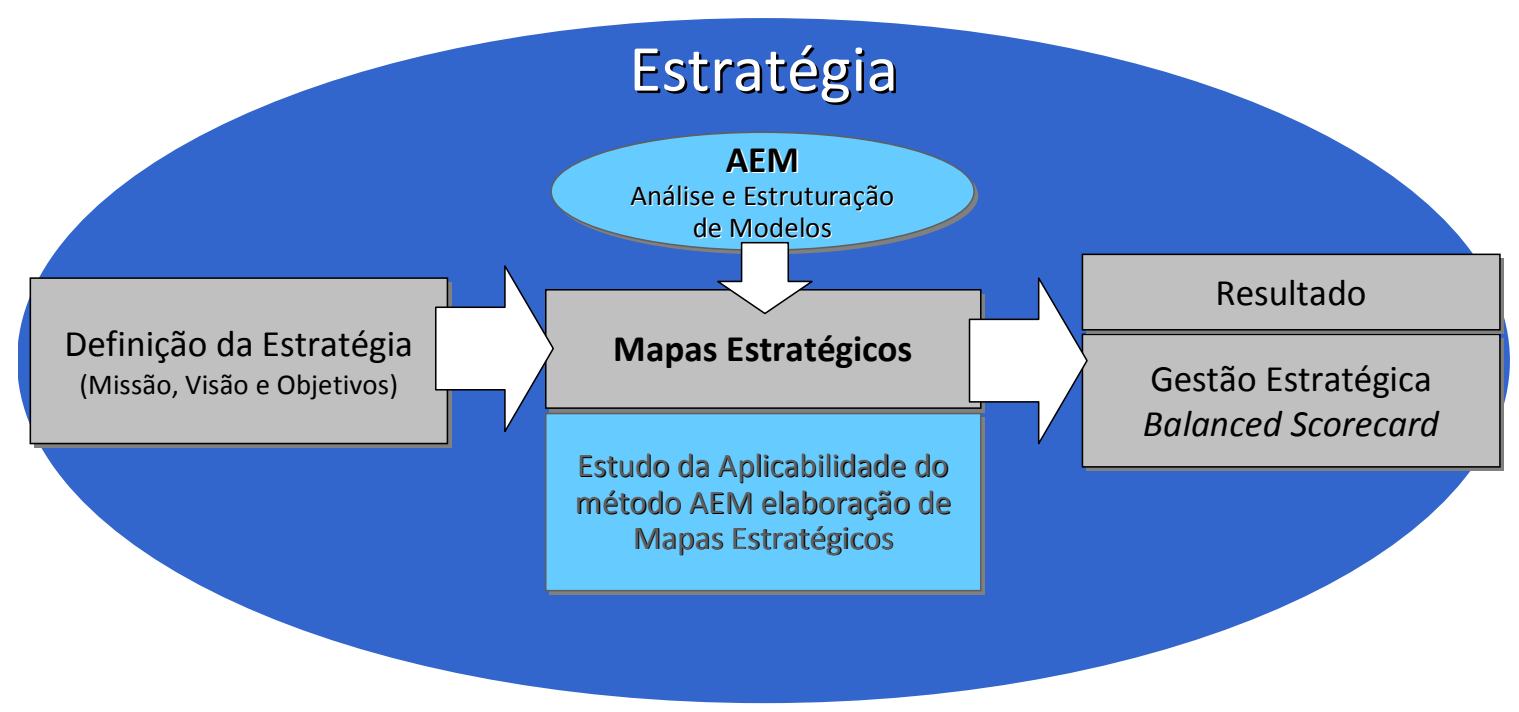

Ilustração 6 - Modelo teórico da pesquisa.

\subsection{Limitações do método de pesquisa}

Não se podem generalizar os resultados desta pesquisa de forma que se garanta que permanecerão os mesmos para todos os tipos de alunos de pós-graduação, tampouco para qualquer posição hierárquica de uma empresa. Para Cooper e Schindler (2003), a generalização de amostragens não-probabilisticas podem representar problemas em relação a interpretação de resultados de pesquisa.

Segundo Kerlinger (1980) os estudos experimentais são sugestivos, embora não conclusivos. Deve-se averiguar se os mesmos resultados são obtidos repetidamente (por meio de replicação).

\subsection{Realização do pré-teste}

Como forma de avaliar a mecânica de pesquisa, o estudo de caso e o questionário, foi realizado em fevereiro de 2009 um pré-teste com uma turma do MBA Gestão Tecnologia da Informação da FIAP (Faculdade de Informática e Administração Paulista). Participaram do 
pré-teste 18 alunos desta turma, como forma de exercitar a construção de Mapas Estratégicos, tema integrante da disciplina de Inteligência de Negócios.

Dada a especialidade do curso, a turma era composta prioritariamente por analistas, coordenadores e gerentes de áreas relacionadas à Tecnologia da Informação, tanto no que diz respeito a sistemas, quanto a infra-estrutura. A média de idade dos alunos que realizaram o pré-teste foi de 29 anos (mediana 30), enquanto a divisão entre gêneros dos participantes apresentou $60 \%$ homens e $40 \%$ mulheres.

Neste pré-teste um grupo de quatro alunos foi selecionado aleatoriamente como grupo experimental, ficando encarregado de resolver o estudo de caso adotando um notebook com o software AEM já preparado para a análise dos objetivos estratégicos. O pesquisador atuou como facilitador, no sentido de fazer a ponte entre o grupo de alunos e software, cadastrando as respostas e colocando os itens para discussão e análise conforme orientação da AEM.

$\mathrm{Na}$ realização do pré-teste, percebeu-se que o tempo gasto para a leitura das informações e início das discussões foi demasiadamente longo em relação ao período disponível para exercício (1 hora), já que alguns grupos de controle não conseguiram completar a construção do Mapa Estratégico.

O pesquisador, exercendo a função de facilitador do grupo experimental, envolveu-se com as atividades deste grupo, procurando prestar auxílio na operação do software para a discussão e resolução do caso. Desta forma, os grupos de controle receberam menos atenção do pesquisador no sentido de que este se encontrava à disposição para tirar eventuais dúvidas e verificar se a resolução do exercício estava corretamente encaminhada.

\subsection{Ajustes a partir dos resultados do pré-teste}

Com a realização do exercício na FIAP, alguns aspectos da pesquisa puderam ser observados e ajustados para possibilitar sua aplicação em um período mais curto. Foram providenciados ajustes no conteúdo do caso para prover aos alunos as informações para a resolução do exercício. Além disso, também se fez necessário o ajuste no papel do pesquisador no período de aplicação da pesquisa, de forma atender todos os grupos igualmente. 
Um dos principais ajustes foi a diminuição do número de páginas do exercício, de cinco para três, focando a descrição do caso em pequenas informações do histórico da empresa, sua experiência, a estratégia adotada e a lista de objetivos estratégicos. O número de objetivos estratégicos também foi diminuído para 15 (em vez) após o exame de qualificação, para enquadrar a realização do exercício em torno de 1 hora.

Também foi adotada a versão Windows do software AEM, que é mais intuitiva e adequada para que os alunos a usassem sozinhos e sem a necessidade do pesquisador para operar o software e atuar como facilitador. Essa alteração de versão do software e mudança na postura do pesquisador abriu a opção de incluir mais grupos experimentais trabalhando em paralelo, além da possibilidade do pesquisador distribuir sua atenção também com os grupos de controle. Com isto abriu-se a possibilidade de poder observar a discussão de todas as categorias de grupos, interagir com todos os grupos, colher opiniões expressas oralmente sobre o exercício e o software, além de acompanhar o preenchimento dos questionários.

Realizou-se um ajuste nas instruções verbais dadas aos grupos, destacando o exemplo de um Mapa Estratégico com as ligações entre os objetivos estratégicos, com destaque para uma instrução de que apenas as relações mais fortes devem ser evidenciadas. Este aviso possuía o intuito de evitar o excesso de ligações que relacionem objetivos estratégicos, para não construir um Mapa Estratégico em que todos os objetivos têm influência sobre todos os objetivos, criando um mapa poluído visualmente e sem uma relação de causa e efeito coerente e interpretável.

Com a mudança na postura do pesquisador em relação aos grupos, que possivelmente influenciou o resultado da aplicação do pré-teste, tanto para o grupo experimental quanto para o grupo de controle, abrindo a possibilidade de se obterem resultados diferentes do obtido, optou-se por não considerar os resultados do pré-teste na análise de resultados do experimento. 


\section{APRESENTACAO DOS RESULTADOS DA PESQUISA}

\subsection{Descrição do Experimento}

O experimento foi realizado entre os meses de abril e junho de 2009, com 110 alunos distribuídos em seis turmas ( cinco de MBA e uma de pós-graduação em gestão estratégica) em diferentes cursos e escolas de São Paulo, escolhidos por conveniência, isto é, em função da possibilidade de acesso aos alunos e concordância dos professores responsáveis.

Na FIA (Fundação Instituto de Administração) o experimento foi realizado em quatro turmas:

- Duas turmas do MBA Executivo Internacional. É um curso voltado a executivos experientes que se preparam para responsabilidades crescentes com uma presidência ou diretoria geral.

- Uma turma do Internacional MBA. Este curso de imersão é voltado a profissionais com três anos ou mais de experiência profissional em uma turma multicultural com metade de alunos brasileiros e metade de alunos estrangeiros.

- Uma turma do Curso de Especialização em Gestão Estratégica: este curso foi realizado com gerentes relacionados a área de vendas de uma indústria farmacêutica.

Tanto no Mackenzie e como na UNIP, o experimento foi realizado em cursos de MBA em Gestão de Negócios, cursos voltados a um perfil heterogêneo de profissionais com o objetivo de prover uma visão geral da área de negócios. A tabela 1, a seguir, apresenta a quantidade de respondentes divididos por turma.

Tabela 1 - Respondentes da pesquisa

\begin{tabular}{|l|l|c|c|c|}
\hline \multicolumn{1}{|c|}{ Instituição } & \multicolumn{1}{c}{ Curso } & \multicolumn{3}{c|}{ Respondentes por turma } \\
\cline { 3 - 6 } & & total & $\begin{array}{c}\text { grupo de } \\
\text { controle }\end{array}$ & $\begin{array}{c}\text { grupo } \\
\text { experimental }\end{array}$ \\
\hline $\begin{array}{l}\text { Fundação Instituto de } \\
\text { Administração - FIA }\end{array}$ & MBA Executivo Internacional - Turma 35 & 19 & 11 & 8 \\
\hline & MBA Executivo Internacional - Turma 36 & 29 & 18 & 11 \\
\hline & International MBA & 14 & 7 & 7 \\
\hline Universidade Paulista - UNIP & Especialização em Gestão Estratégica & 20 & 7 & 13 \\
\hline Universidade Mackenzie & MBA Gestão empresarial & 12 & 6 & 6 \\
\hline & MBA em Gestão de negócios & 16 & 8 & 8 \\
\hline
\end{tabular}


O experimento foi sempre realizado na forma de um estudo de caso (Apêndice I), que apresentava a história, objetivos e estratégia da PROJ Engenharia S/A - uma empresa de gerenciamento de implantação de projetos. A partir da lista de objetivos estratégicos (quadro 3) e das demais informações apresentadas no caso, os alunos deveriam desenhar um Mapa Estratégico dentro do tempo proposto (cerca de uma hora).

Quadro 3- Lista de objetivos estratégicos apresentadas no caso

\begin{tabular}{|c|}
\hline Objetivos Estratégicos da PROJ Engenharia S/A \\
\hline $\begin{array}{l}\text { 1. Alinhar metodologia de gerenciamento às metodologias preconizadas pelos } \\
\text { institutos internacionais }\end{array}$ \\
\hline $\begin{array}{l}\text { 2. Ampliar rede de relacionamento no setor de gerenciamento de } \\
\text { empreendimentos }\end{array}$ \\
\hline 3. Aumentar a participação de mercado em volume e valor \\
\hline 4. Buscar maior retorno sobre o investimento \\
\hline 5. Buscar novas oportunidades em Clientes existentes \\
\hline 6. Buscar novas oportunidades com foco em novos Clientes \\
\hline 7. Cumprir com qualidade o escopo dos contratos atuais \\
\hline 8. Disseminar Cultura e Valores \\
\hline 9. Garantir a satisfação dos Clientes nos contratos existentes \\
\hline $\begin{array}{l}\text { 10. Identificar "pessoal chave" e sucessores, capacitando-os para ocuparem } \\
\text { cargos gerenciais }\end{array}$ \\
\hline $\begin{array}{l}\text { 11. Implementar procedimentos de melhorias contínuas nos processos de } \\
\text { prestação de serviços }\end{array}$ \\
\hline 12. Promover ações de comunicação institucional \\
\hline 13. Promover a gestão de pessoas com foco em capacitação de colaboradores \\
\hline 14. Promover a gestão de pessoas com foco em satisfação de colaboradores \\
\hline 15. Promover a gestão do conhecimento \\
\hline
\end{tabular}

Em três ocasiões, o caso foi incorporado como parte prática de aulas de Estratégia ministradas por outros professores. Na outra parte, no que diz respeito às turmas da UNIP, Mackenzie e o curso de Especialização em Gestão Estratégica da FIA, o próprio pesquisador ministrou palestra sobre Balanced Scorecard, aproveitando o experimento com um dos exercícios relacionados ao tema.

A aplicação do experimento seguiu o mesmo roteiro em todos os casos:

- O ministrante da disciplina abria espaço para um exercício/estudo de caso em grupo para construção de Mapas Estratégicos.

- Seguiu-se uma breve apresentação do exercício, por parte do pesquisador, mostrando o caso, a folha de resposta (a ser entregue uma por grupo) e o questionário (respostas individuais). Neste momento, também era divulgado que os resultados do exercício 
seriam aproveitados nesta pesquisa de mestrado, reforçando o interesse em obter o mapa e os questionários de volta, para análise.

- Quando os grupos de trabalho eram formados, foram selecionados ao acaso um ou dois grupos (dependendo da quantidade de alunos) que eram solicitados a responder ao exercício usando o computador, especificamente o software do método AEM. Para estes grupos, eram fornecidas explicações adicionais sobre o funcionamento do método e a operacionalização do software, além de distribuir os questionários com questões adicionais específicas sobre o método AEM (Apêndice II). Os demais grupos elaboraram seus Mapas Estratégicos no papel, de forma autônoma, apresentando o desenho de seus mapas na folha de respostas (Apêndice III).

- Para todos os grupos (tanto os que usaram papel quanto os que usaram computador) foram enviadas via internet (e-mail ou sites do curso) versões passadas a limpo do resultado do exercício. Todos os mapas construídos pelos grupos estão disponíveis no Apêndice IV.

O grupo experimental que respondia o exercício por meio da AEM trabalhou de acordo com o funcionamento do software. Este grupo recebeu o programa com os objetivos estratégicos já cadastrados pronto para serem analisados. Assim o grupo pode se concentrar diretamente na etapa de análise na qual discutiram a relação entre todos os objetivos estratégicos. A partir da lista fornecida pelo software, os integrantes do grupo deveriam selecionar dois objetivos para discutir a situação da relação entre eles: se não existe ou indicar, por meio de respostas de "sim" ou "não", qual objetivo que contribuía fortemente para a realização do outro objetivo. Apesar de o software sugerir quais dos elementos deveriam ter sua relação discutida naquele momento, o grupo tinha a liberdade para escolher a ordem de quais objetivos gostariam de analisar.

Internamente o software preenchia uma matriz quadrada com as respostas das relações entre os objetivos estratégicos para matematicamente representar a estrutura resultante da discussão. Neste ponto, o conceito de inferência lógica contida na AEM era particularmente útil, uma vez que o software conseguia identificar as relações e os níveis hierárquicos a partir de inferências das respostas já dadas. Desta forma, dependendo das respostas de cada grupo, nem todas as análises entre os objetivos precisaram ser feitas. A ilustração 7 mostra a tela de análise de elementos (objetivos estratégicos) na qual os grupos trabalharam. 


\section{Estruturação de elementos}

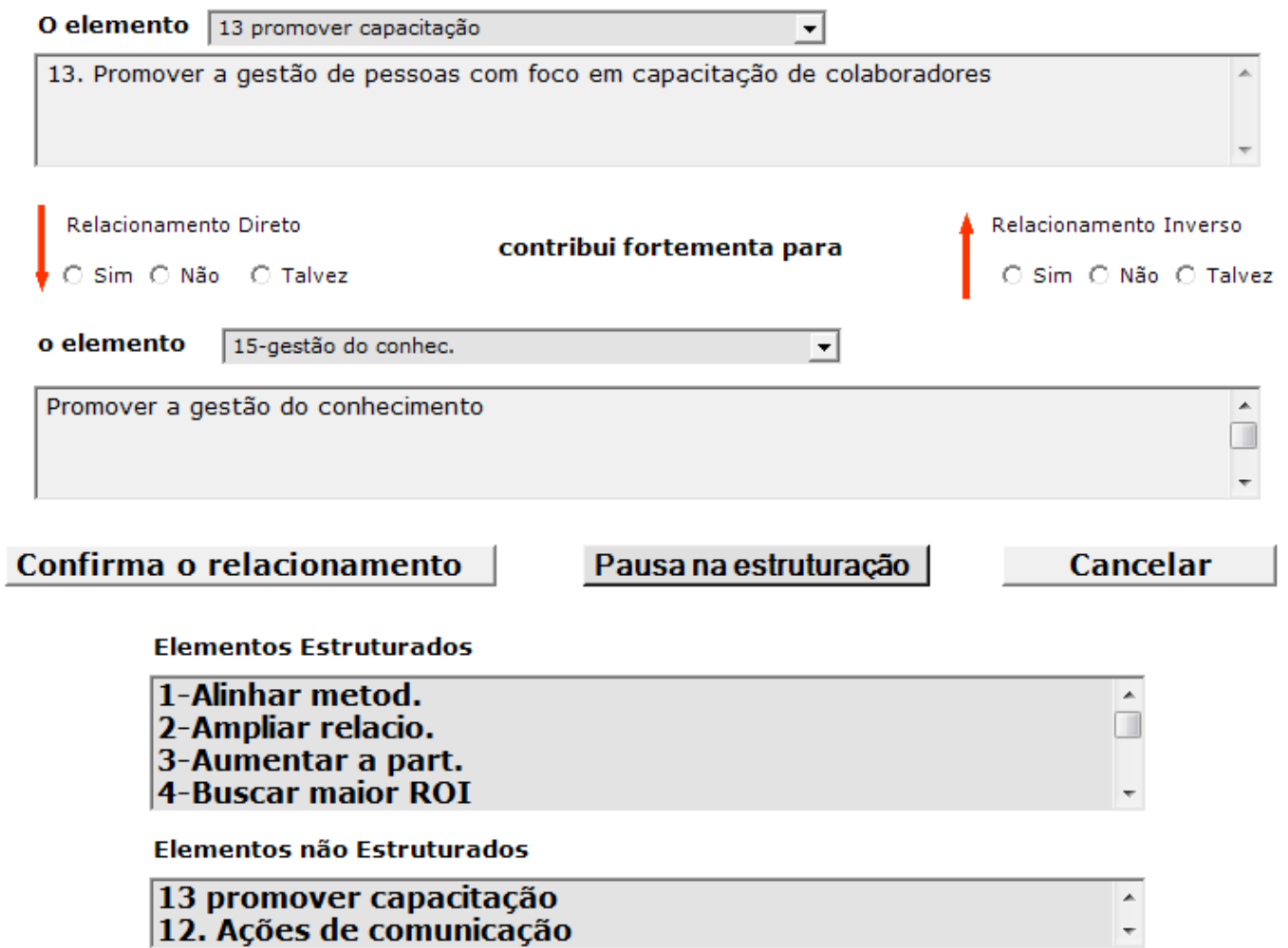

Ilustração 7 - Tela de análise do software da AEM.

Nesta tela do software era disposta a lista de objetivos estratégicos (chamadas no software de elementos) que deveriam ser escolhidos para que a análise pudesse ser realizada. A listagem de objetivos era apresentada duas vezes na parte superior da tela para que os dois objetivos pudessem ser escolhidos para a análise. Na parte inferior da tela o software apresenta outras duas listagens: os elementos estruturados e os não-estruturados, ou seja, os objetivos estratégicos que já passaram pela análise ou não.

Após a análise de todos os objetivos estratégicos era possível visualizar o resultado do exercício que era apresentado em outra tela do software AEM. O resultado era apresentado em texto com a indicação de qual nível o objetivo estratégico faz parte (quanto menor o nível, mais alto o objetivo estará na estrutura) além apresentar quais objetivos se relacionam com os outros. Desta forma, era possível desenhar o Mapa Estratégico com as relações de causa e efeito entre os objetivos estratégicos, conforme apresentado no Apêndice IV. A ilustração 8 apresenta, a seguir, o resultado em texto de uma análise e estruturação de objetivos estratégicos do caso estudado. Em outras opções na tela de resultado era possível visualizar os 
ciclos existentes naquele mapa, a matriz que o software registrava os dados informados pelo grupo, além da matriz com as inferências calculadas pela AEM.

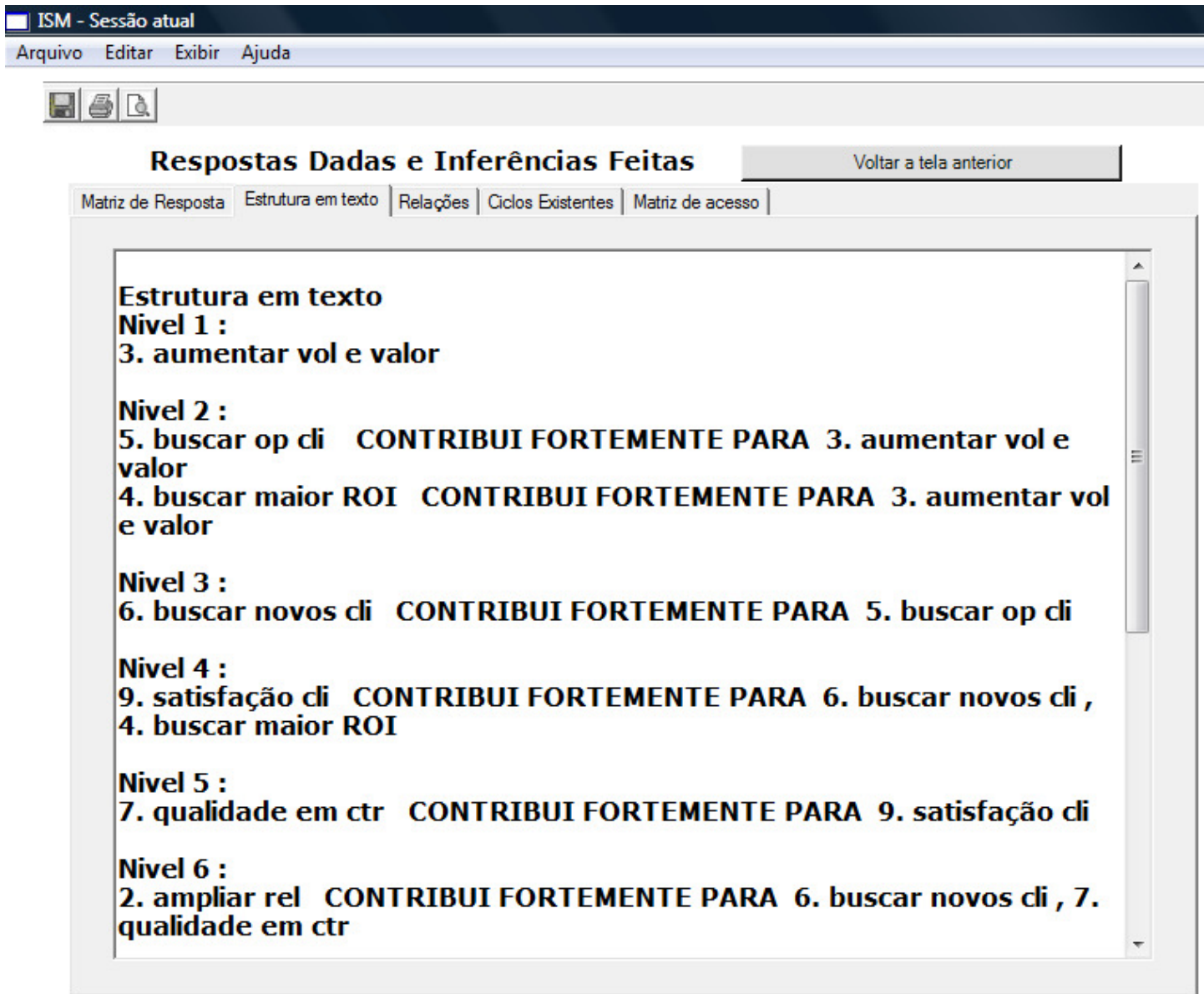

Ilustração 8 - Tela de respostas do software da AEM.

\subsection{Resultados}

Para a análise dos resultados foram consideradas as seis turmas listadas no item anterior. $\mathrm{O}$ resultado coletado no pré-teste não foi levado em conta no cômputo geral já que sofreu ajustes após a sua realização, em especial a posição do pesquisador, que não atuou como facilitador junto ao grupo que operou o software, isto é o grupo experimental. Esta nova postura objetivava uma atuação mais isenta do pesquisador, deixando os grupos trabalhar autonomamente, além de também possibilitar um atendimento mais eficiente aos demais alunos que integravam os chamados grupos de controle, isto é os que resolviam o exercício no papel. 
Os grupos que usavam a ferramenta AEM sempre terminaram o exercício antes dos grupos de controle. Isto provavelmente se deve aos métodos de inteligência artificial que o software possui e que permitiu entender a relação entre objetivos a partir das respostas do grupo, sem a necessidade de colocar este item para ser discutido em grupo. A única exceção neste caso ocorreu no grupo experimental da turma do Mackenzie. Neste caso dos 3 grupos que realizaram o exercício, o grupo experimental foi o segundo a entregar, alguns minutos após o primeiro grupo de controle. Nesta aplicação, o pesquisador registrou um grande interesse do grupo pelo funcionamento do software - o que exigiu um tempo maior de explicações acerca do sistema e dos métodos envolvidos, aumentando o tempo de realização do exercício. Se for descontado o tempo gasto com estas explicações, será possível considerar que o tempo gasto na elaboração do Mapa Estratégico foi menor do que o de ambos os grupos de controle.

A seguir, apresentamos os resultados da pesquisa em dois subitens, o primeiro relacionado às respostas dos questionários enquanto que o seguinte mostra os resultados do exercício: Mapas Estratégicos construídos pelos dois grupos (experimental e de controle).

\subsubsection{Resultados do questionário}

$\mathrm{Na}$ mesma ordem das questões apresentadas no questionário (Apêndice I), segue abaixo o resultado da tabulação das respostas de 57 participantes do grupo de controle, que construiu os Mapas Estratégicos no papel, e 53 do grupo experimental, que aplicou a AEM para a resolução do caso, totalizando os 110 questionários considerados válidos nesta pesquisa.

\section{Perfil dos respondentes}

O primeiro bloco de questões se referia ao perfil do respondente, com questões a respeito de idade, sexo, empresa (opcional), cargo exercido e formação. Quanto ao gênero dos respondentes, temos a seguinte distribuição:

Tabela 2 - Sexo dos respondentes

\begin{tabular}{l|c|c|}
\hline \multicolumn{1}{|c|}{ Sexo dos respondentes } & Masc & Fem \\
\hline Grupo de controle & $73 \%$ & $27 \%$ \\
$\begin{array}{l}\text { Grupo experimental } \\
\text { (AEM) }\end{array}$ & $63 \%$ & $37 \%$ \\
$\begin{array}{l}\text { Total (os dois grupos } \\
\text { juntos) }\end{array}$ & $69 \%$ & $31 \%$ \\
\hline
\end{tabular}


A tabela 2 e o gráfico 1(a seguir) mostram uma quantidade de homens superior à de mulheres em todos o casos. Na verdade, trata-se de uma situação encontrada em todas as escolas e cursos pesquisados. O gráfico 1 mostra que, mesmo com a composição aleatória dos integrantes dos grupos e a definição também aleatória de quais grupos seriam experimentais e quais seriam de controle, a distribuição entre os sexos ocorreu de forma parecida entre os dois grupos, ficando o grupo experimental com uma quantidade um pouco maior de mulheres ( $37 \%$ versus $27 \%$ do grupo de controle).

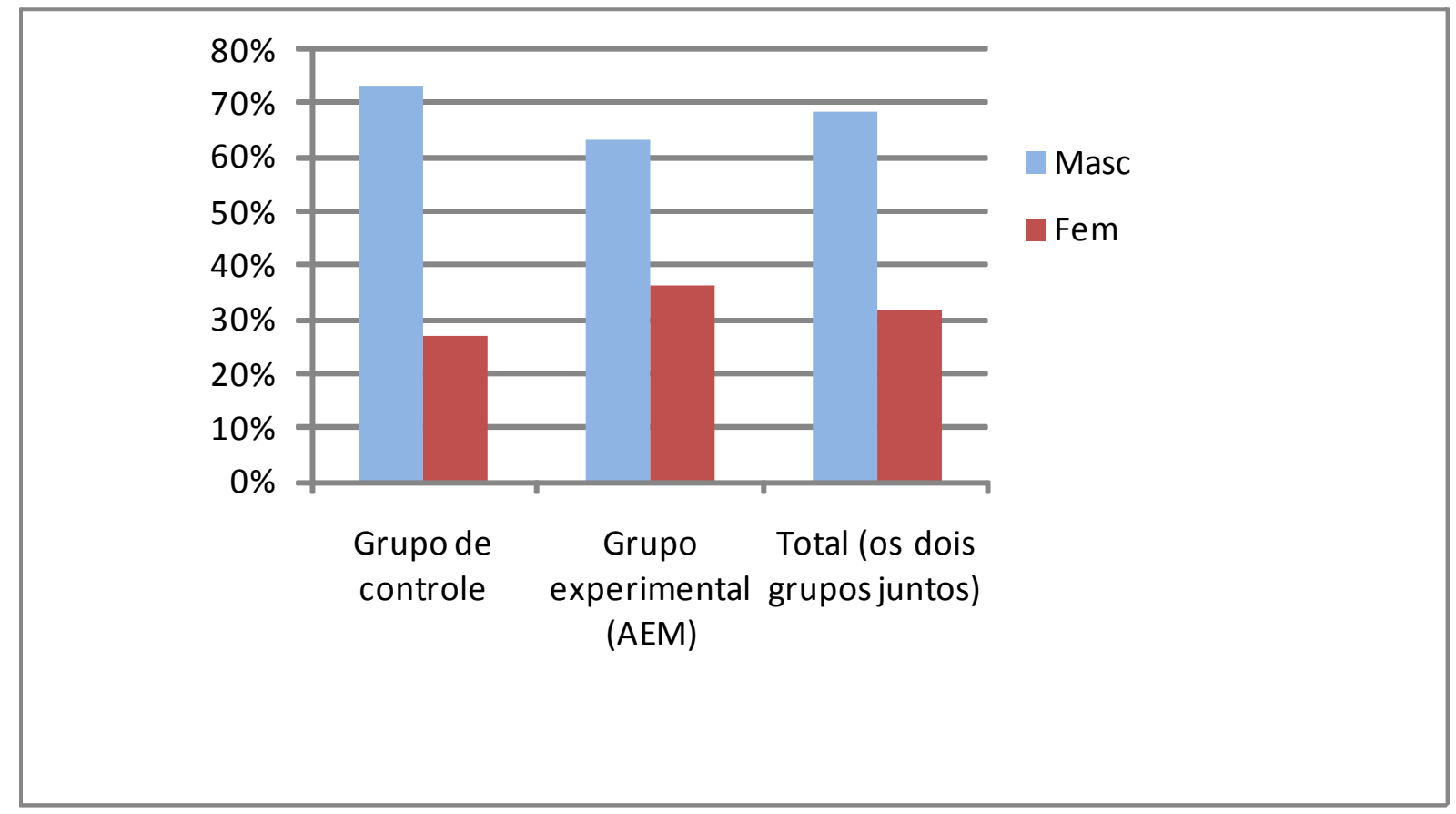

Gráfico 1 - Sexo dos respondentes.

Por sua vez, a tabela 3 e o gráfico 2 apresentam a idade dos respondentes, com os grupos de controle e experimental apresentando idades bem próximas, com medianas e médias ao redor dos 36 anos.

Tabela 3 - Idade dos respondentes

\begin{tabular}{l|c|r|}
\hline \multicolumn{1}{|c|}{ Idade } & Média & \multicolumn{1}{c|}{ Mediana } \\
\hline $\begin{array}{l}\text { Grupo de controle } \\
\text { Grupo experimental } \\
\text { (AEM) }\end{array}$ & 35,82 & 35,50 \\
Total (os dois grupos & 36,12 & 36,00 \\
juntos) & & \\
\hline
\end{tabular}




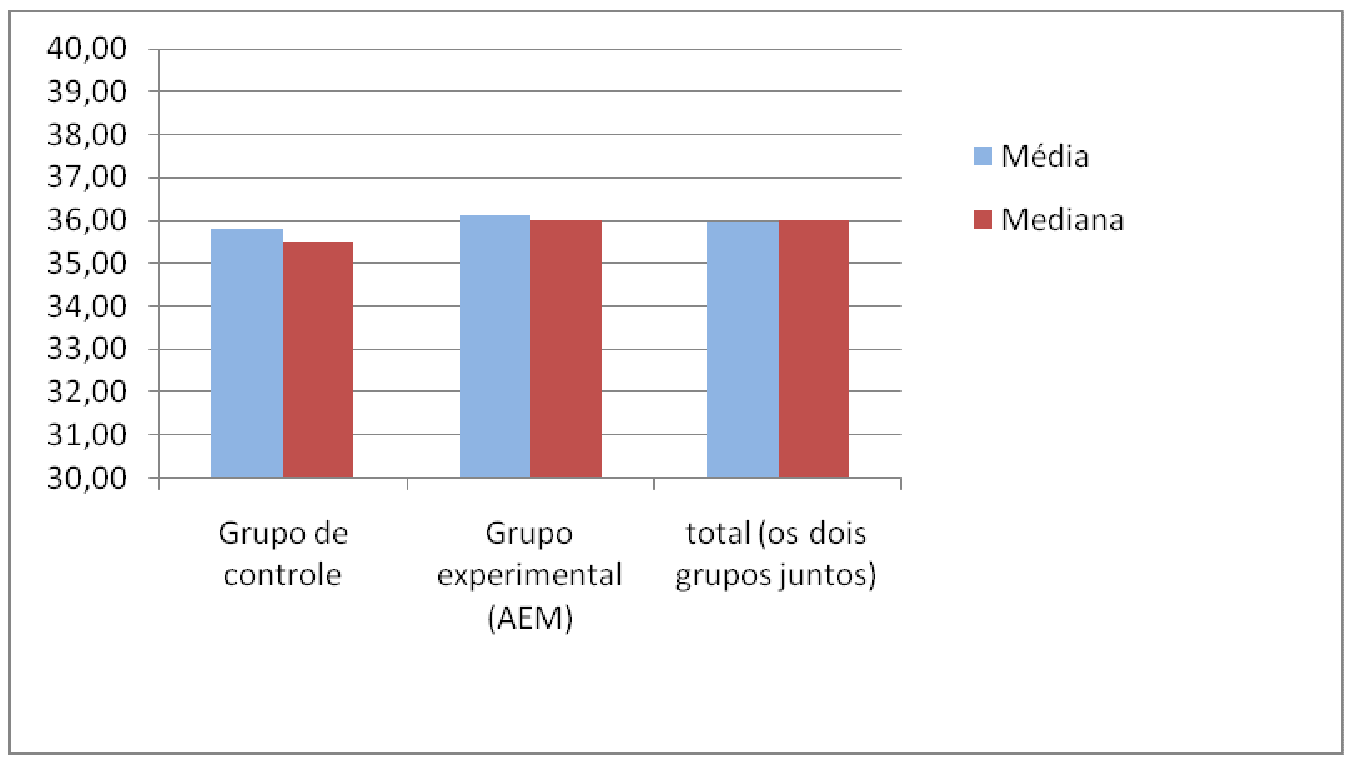

Gráfico 2 - Média e mediana da idade dos respondentes da pesquisa.

Quanto ao cargo dos participantes da pesquisa, não aparecem grandes diferenças entre os grupos, como mostra a tabela 4 e os gráficos 3 e 4 . Nos dois grupos apresentam Gerente como o cargo mais representativo com 39\% (grupo de controle possui 38\%), seguido de Diretor/Gerente geral/Superintendente que nas duas situações aparece com 19\%.

Tabela 4 - Cargo dos respondentes

\begin{tabular}{|l|c|c|c|c|}
\hline \multirow{2}{*}{ Cargo dos respondentes } & \multicolumn{2}{|c|}{ Controle } & \multicolumn{3}{c|}{ AEM } \\
\cline { 2 - 5 } & $\#$ & \% & $\#$ & $\%$ \\
\hline Gerente & 22 & 39 & 20 & 38 \\
\hline $\begin{array}{l}\text { Diretor/ Gerente geral/ } \\
\text { superintendente }\end{array}$ & 11 & 19 & 10 & 19 \\
$\begin{array}{l}\text { coordenador/analista/ } \\
\text { assistente }\end{array}$ & 7 & 12 & 9 & 17 \\
\hline \begin{tabular}{l|l|l|l|} 
outros \\
não informou
\end{tabular} & 10 & 18 & 6 & 11 \\
\hline $\begin{array}{l}\text { Presidente/proprietário/ } \\
\text { diretor geral }\end{array}$ & 6 & 10 & 5 & 9 \\
\hline \multicolumn{1}{|c|}{ soma } & $\mathbf{5 7}$ & $\mathbf{1 0 0}$ & $\mathbf{5 3}$ & $\mathbf{1 0 0}$ \\
\hline
\end{tabular}




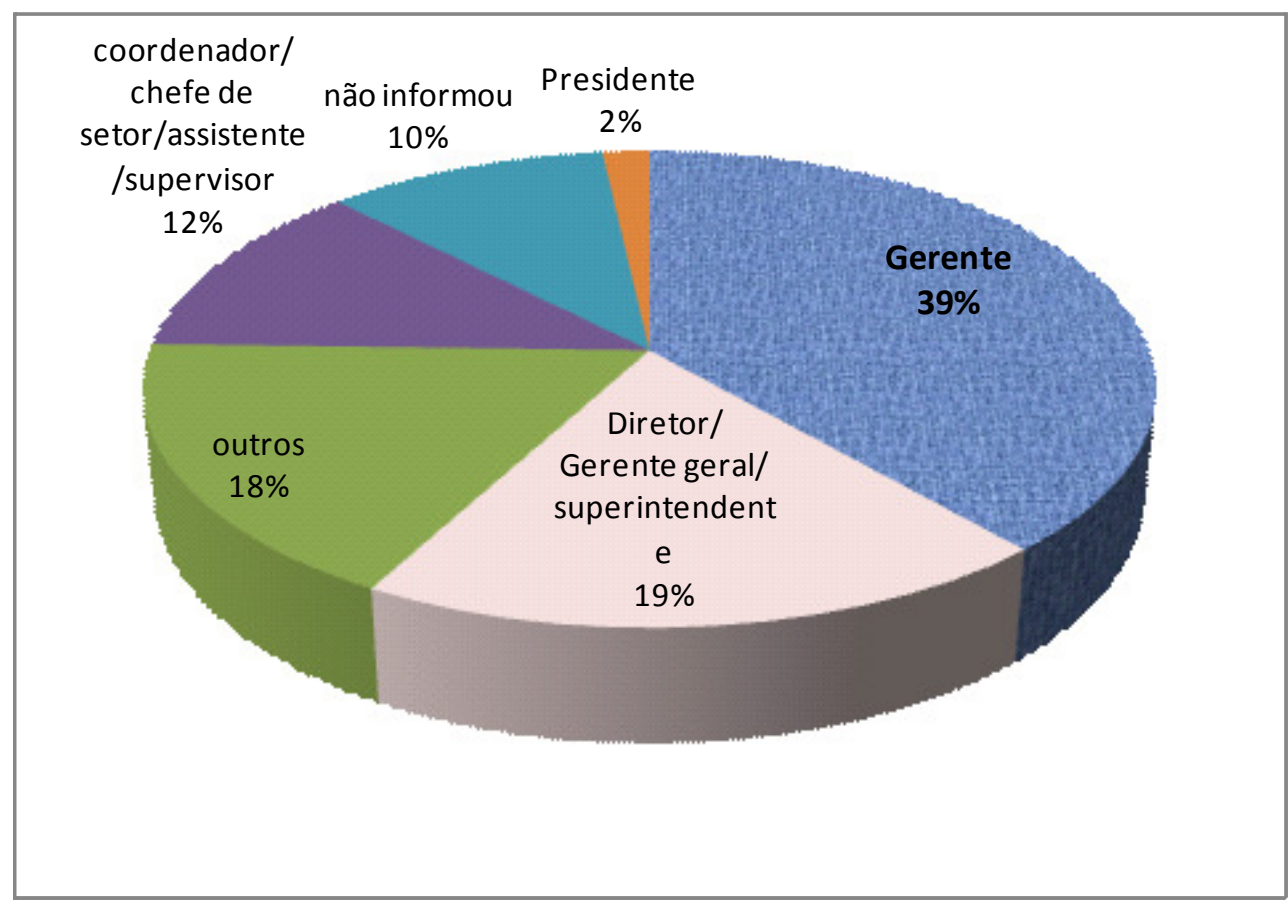

Gráfico 3 - Cargos dos respondentes do grupo de controle.

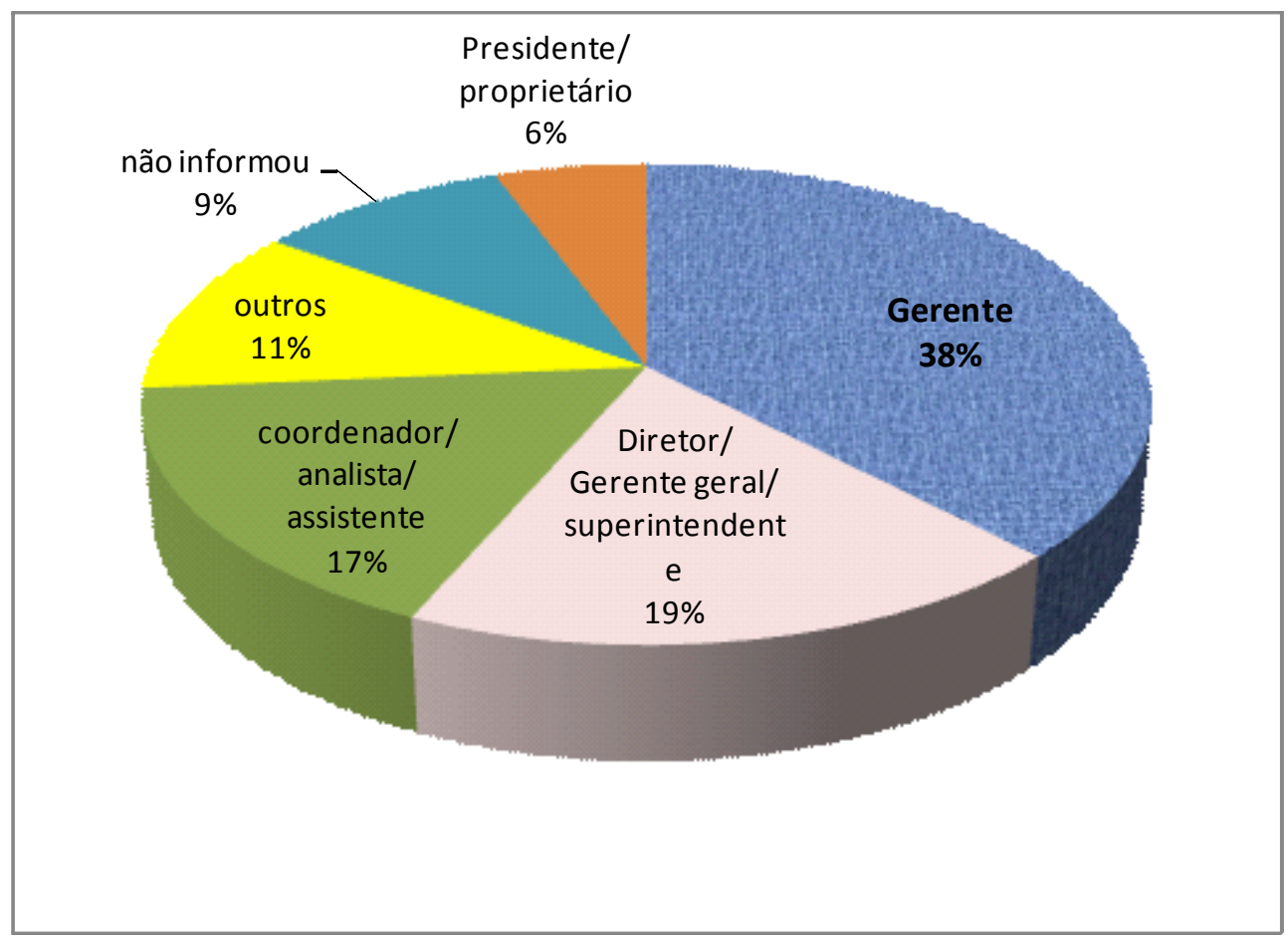

Gráfico 4 - Cargos dos respondentes do grupo experimental. 


\section{Questão 1 - Principal objetivo no curso}

O objetivo desta e da próxima questão estava em medir o interesse do aluno pelo curso e pela disciplina. Foi a maneira encontrada de registrar tal interesse, para posteriormente avaliar se este aspecto poderia influenciar o resultado do exercício, já que o mesmo poderia sofrer algum tipo de influência devido à motivação dos respondentes.

Verifica-se na tabela 5 que não houve influência de aspectos motivacionais, já que para os dois grupos o grande objetivo para a realização do MBA é aprender novas técnicas e teorias, o que foi apontado por mais de $90 \%$ de cada grupo, informações que se destacam também no Gráfico 5.

Tabela 5 - Objetivos ao fazer o curso

\begin{tabular}{|c|c|c|}
\hline 1. Objetivo do MBA & $\begin{array}{l}\text { Grupo de } \\
\text { controle }\end{array}$ & $\begin{array}{c}\text { Grupo } \\
\text { experimental } \\
(\mathrm{AEM})\end{array}$ \\
\hline $\begin{array}{l}\text { Obter o título de } \\
\text { Especialista }\end{array}$ & $1,75 \%$ & $3,85 \%$ \\
\hline $\begin{array}{l}\text { Aprender novas técnicas } \\
\text { e teorias }\end{array}$ & $92,98 \%$ & $92,31 \%$ \\
\hline Outros & $5,26 \%$ & $3,85 \%$ \\
\hline
\end{tabular}

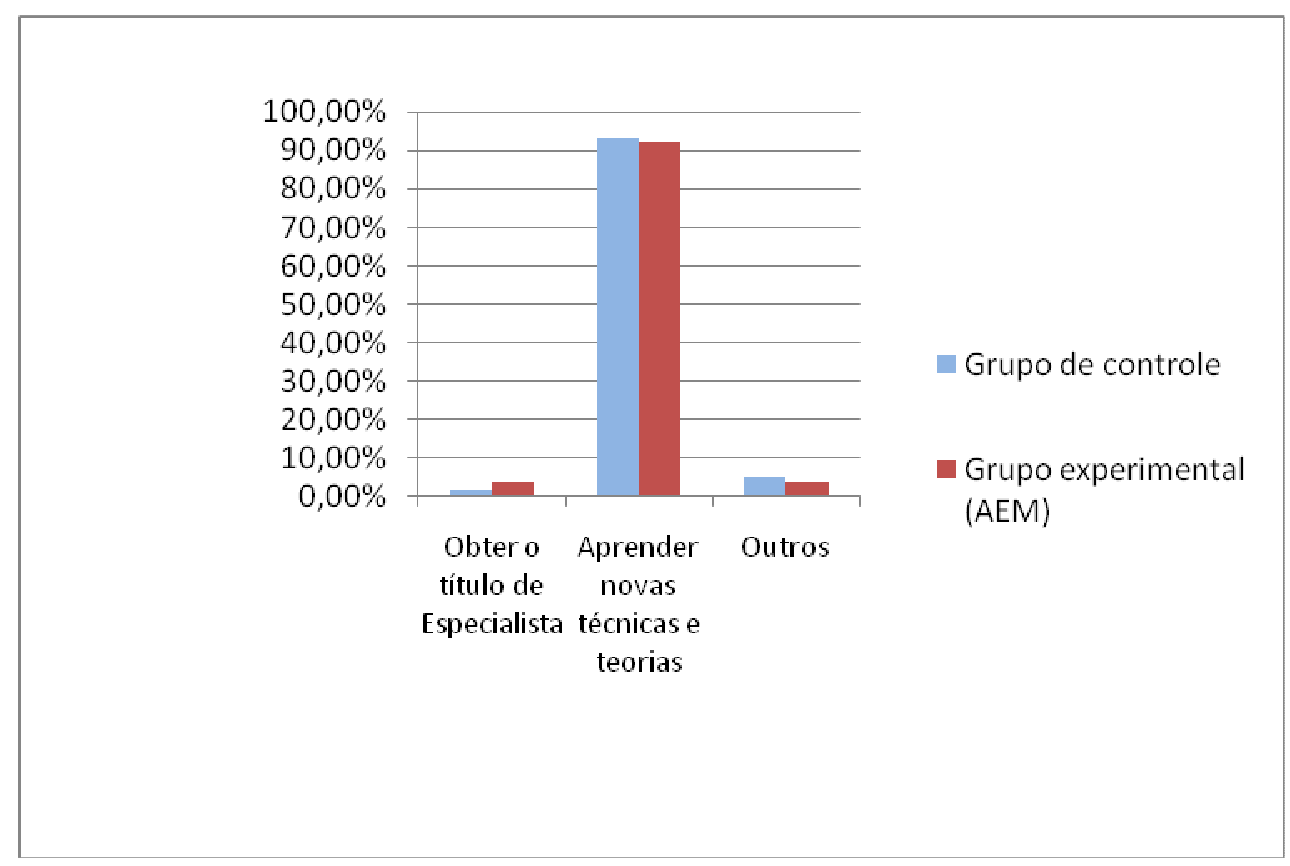

Gráfico 5 - Objetivos no curso MBA.

Entre os que escolheram o item "outros", os indivíduos tanto no grupo experimental quanto no grupo de controle especificaram aspectos relacionados ao aumento de conhecimento, 
ampliação da rede de relacionamento (isto é, networking), desenvolvimento de carreira e crescimento pessoal e profissional.

\section{Questão 2 - Interesse na disciplina}

Nesta questão, considera-se que houve um interesse elevado pela disciplina relacionada ao tema, no caso, Estratégia Competitiva, Gestão Estratégica ou outro nome similar, dependendo da escola. Mais de $90 \%$ dos respondentes de ambos os grupos declararam que seu interesse na disciplina é explorar mais o assunto e usar seus conceitos de profissionalmente, como se pode verificar na tabela e no gráfico 6.

Tabela 6 - Nível de interesse na disciplina de estratégia

\begin{tabular}{l|r|r|}
\hline $\begin{array}{l}\text { 2. Interesse na disciplina } \\
\text { de Estratégia }\end{array}$ & $\begin{array}{c}\text { Grupo de } \\
\text { controle }\end{array}$ & $\begin{array}{c}\text { Grupo } \\
\text { experimental } \\
\text { (AEM) }\end{array}$ \\
\hline $\begin{array}{l}\text { Cumprir o programa } \\
\text { obrigatório do curso e ser } \\
\text { aprovado na disciplina }\end{array}$ & $0,00 \%$ & $3,85 \%$ \\
$\begin{array}{l}\text { Explorar mais este } \\
\text { assunto e utilizar seus } \\
\text { conceitos } \\
\text { profissionalmente }\end{array}$ & $98,25 \%$ & \\
Outros & & $94,23 \%$ \\
\hline
\end{tabular}

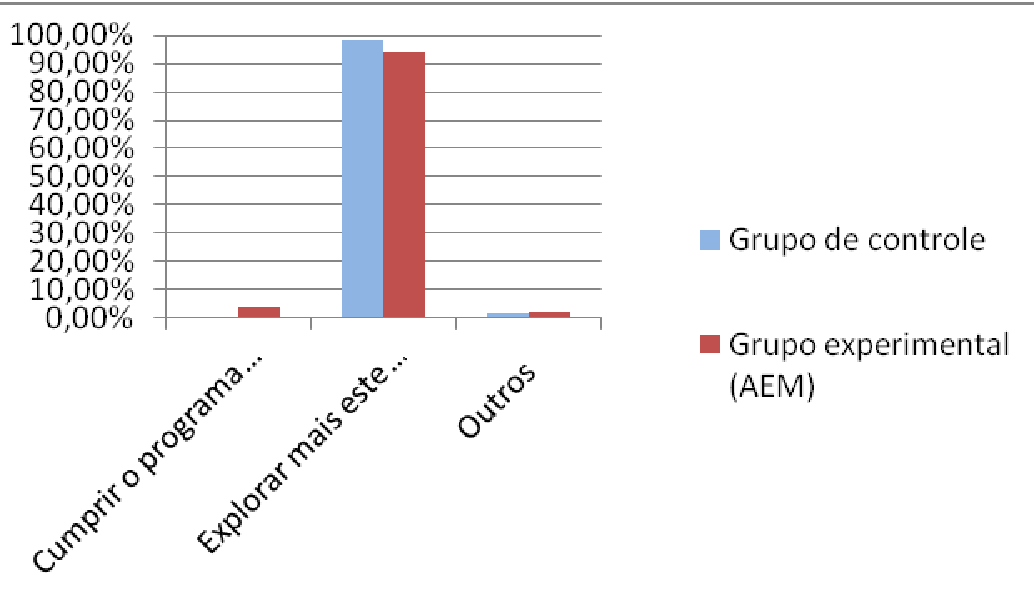

Gráfico 6 - Interesse na disciplina de estratégia. 
Os dois comentários relacionados a "outros" se referem a "manter-se atualizado" e a "desafiar os conceitos já assimilados e adquirir outros".

\section{Questão 3 - Conhecimento e experiência sobre o tema}

A tabela e o gráfico 7 mostram que a escolha aleatória dos grupos fez com que o grupo experimental possuísse uma porcentagem cerca de $10 \%$ maior de pessoas que não tiveram contato anterior com os conceitos relacionados ao exercício (Mapa Estratégico/Balanced Scorecard). Por sua vez, o grupo de controle obteve uma porcentagem maior de pessoas que já conheciam o tema por meio de leituras ou outros contatos informais $(31,58 \%)$, enquanto o grupo experimental apresentou 19,23\% de respondentes que já tiveram acesso ao tema por meio de contatos informais.

Se agruparmos outros dois itens, nos quais se verifica a experiência profissional e a capacitação formal dos respondentes em relação às ferramentas, nota-se que a distribuição das porcentagens é mais equilibrada nestes quesitos. O grupo de controle possui $21,05 \%$ dos participantes que já receberam treinamento formal ou já trabalham com o tema, chamando a atenção os 12,28\% dos respondentes que trabalham, enquanto que, no grupo experimental, $23,08 \%$ dos participantes trabalham com o tema ou já receberam alguma capacitação formal sobre o assunto, destacando os $17,31 \%$ dos respondentes que já fizeram cursos sobre o tema.

Tabela 7 - Conhecimento sobre os temas

\begin{tabular}{|c|c|c|}
\hline $\begin{array}{c}\text { 3.Conhecimento e } \\
\text { interesse sobre BSC e } \\
\text { Mapas Estratégicos }\end{array}$ & $\begin{array}{l}\text { Grupo de } \\
\text { controle }\end{array}$ & $\begin{array}{c}\text { Grupo } \\
\text { experimental } \\
\text { (AEM) }\end{array}$ \\
\hline $\begin{array}{l}\text { Teve contato pela } 1^{\text {a }} \text { vez } \\
\text { neste curso ou palestra }\end{array}$ & $47,37 \%$ & $57,69 \%$ \\
\hline $\begin{array}{l}\text { Conhece o tema por meio } \\
\text { de leituras ou contatos } \\
\text { informais }\end{array}$ & $31,58 \%$ & $19,23 \%$ \\
\hline $\begin{array}{l}\text { Já fez } \\
\text { curs os/treinamentos } \\
\text { sobre o tema }\end{array}$ & $8,77 \%$ & $17,31 \%$ \\
\hline $\begin{array}{l}\text { Trabalha com a } \\
\text { ferramenta e tem } \\
\text { capacitação teórica e } \\
\text { prática }\end{array}$ & $12,28 \%$ & $5,77 \%$ \\
\hline
\end{tabular}




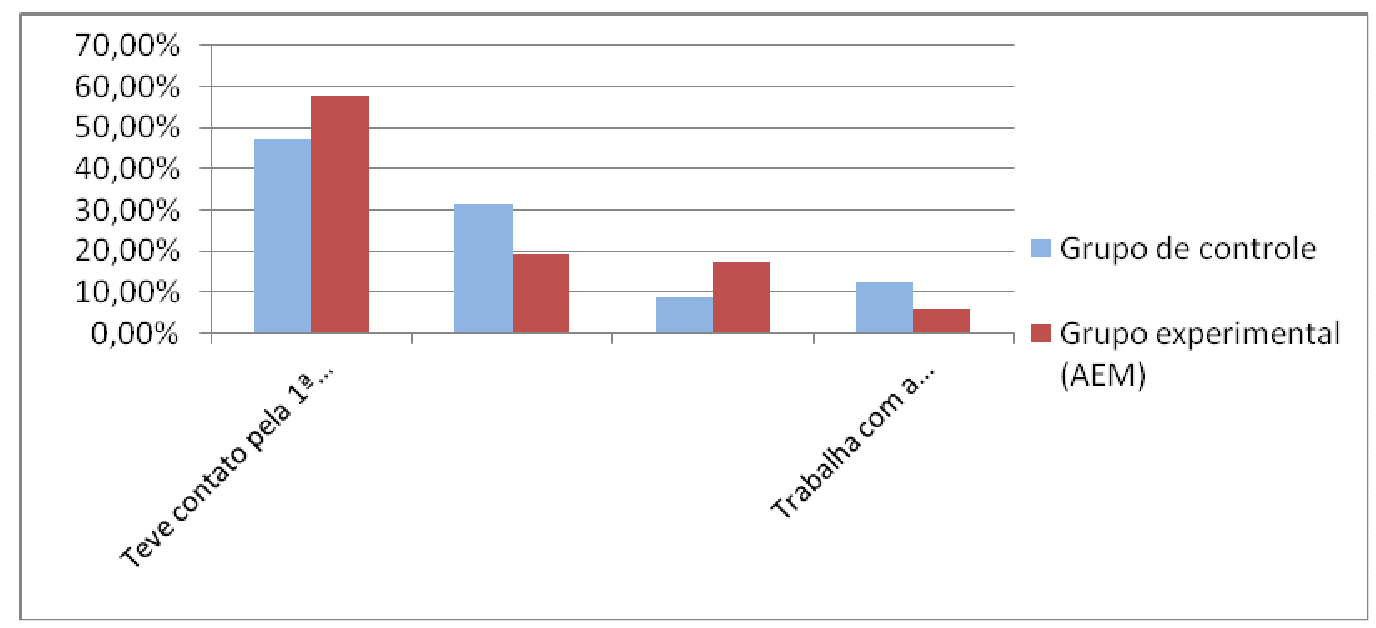

Gráfico 7 - Conhecimento sobre o tema.

\section{Questão 4 - Adoção das ferramentas pela empresa onde o respondente trabalha}

Analisando o grupo de controle na tabela e no gráfico 8, vemos que 35,7\% dos respondentes afirmaram que a organização onde trabalha adotam o BSC, o Mapa Estratégico ou ambas as ferramentas. Por sua vez, o Grupo Experimental, apesar da porcentagem mais baixa quando se analisa individualmente o item "utiliza ambos", possui uma porcentagem maior, com 43,14\% (com as três respostas agrupadas) e também possui uma quantidade de respondentes maior que afirmaram que as respectivas empresas empregam ou o BSC ou Mapa Estratégico.

Chama atenção nos dois grupos a alta porcentagem do item "não sei" - praticamente 1/3 de cada grupo assinalou esta opção. Uma vez que muitos participantes ficaram conhecendo os conceitos de Mapa Estratégico e de BSC pela primeira vez pouco antes de resolver o exercício, entendem-se duas possibilidades: que o respondente não tenha acesso à informações sobre a estratégia empresarial da organização onde trabalha e por isso não sabe informar se a empresa adota as ferramentas ou se é o caso de o respondente possuir acesso à estratégia empresarial sem, no entanto, conhecer as ferramentas empregadas. Após a realização da aula e do exercício, o aluno saberá identificar se os conceitos apresentados em sala de aula estão sendo adotados pela empresa onde trabalha. 
Tabela 8 - Adoção das ferramentas pela empresa na qual cada respondente trabalha

\begin{tabular}{|l|r|r|}
\hline $\begin{array}{c}\text { 4. A organização onde } \\
\text { você trabalha utiliza } \\
\text { Mapa Es tratégico ou } \\
\text { BSC? }\end{array}$ & $\begin{array}{c}\text { Grupo de } \\
\text { controle }\end{array}$ & $\begin{array}{c}\text { Grupo } \\
\text { experimental } \\
\text { (AEM) }\end{array}$ \\
\hline Utiliza ambos & $21,43 \%$ & $15,69 \%$ \\
\hline Somente o Mapa & $1,79 \%$ & $11,76 \%$ \\
Somente o BSC & $12,50 \%$ & $15,69 \%$ \\
\hline Nenhum dos dois & $33,93 \%$ & $31,37 \%$ \\
\hline Não sei & $30,36 \%$ & $25,49 \%$ \\
\hline
\end{tabular}

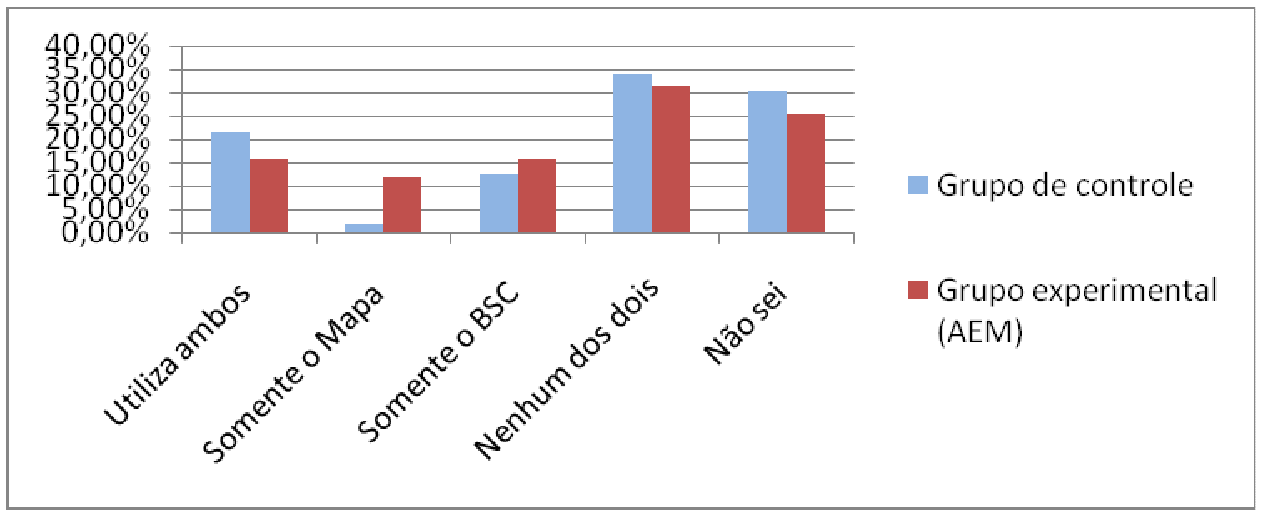

Gráfico 8 - Adoção do BSC ou Mapa pela empresa onde o respondente trabalha.

\section{Questão 5 - experiência individual na construção do Mapa Estratégico ou do BSC}

As porcentagens se equivalem em termos de experiência com a construção do BSC ou do Mapa. A grande maioria (mais de 70\%) de ambos os grupos nunca participou da construção das ferramentas. Dos que possuíam experiência nestes assuntos, vale destacar a maior experiência do grupo experimental com a construção de Mapas Estratégicos (17,31\%, contra $5,26 \%$ do grupo de controle) enquanto que o grupo de controle possui pessoas com maior experiência em construir BSC (10,53\% versus $1,92 \%$ do experimental)

Tabela 9 - Participação na construção de BSC ou Mapa

\begin{tabular}{|l|r|r|}
\hline $\begin{array}{c}\text { 5. Já participou da } \\
\text { construção de um Mapa } \\
\begin{array}{c}\text { Estratégico ou de um } \\
\text { BSC antes? }\end{array}\end{array}$ & $\begin{array}{c}\text { Grupo de } \\
\text { controle }\end{array}$ & $\begin{array}{c}\text { Grupo } \\
\text { experimental } \\
\text { (AEM) }\end{array}$ \\
\hline Sim, de ambos & $8,77 \%$ & $7,69 \%$ \\
\hline Somente do Mapa & $5,26 \%$ & $17,31 \%$ \\
\hline Somente do BSC & $10,53 \%$ & $1,92 \%$ \\
\hline Não, nenhum dos dois & $75,44 \%$ & $73,08 \%$ \\
\hline
\end{tabular}




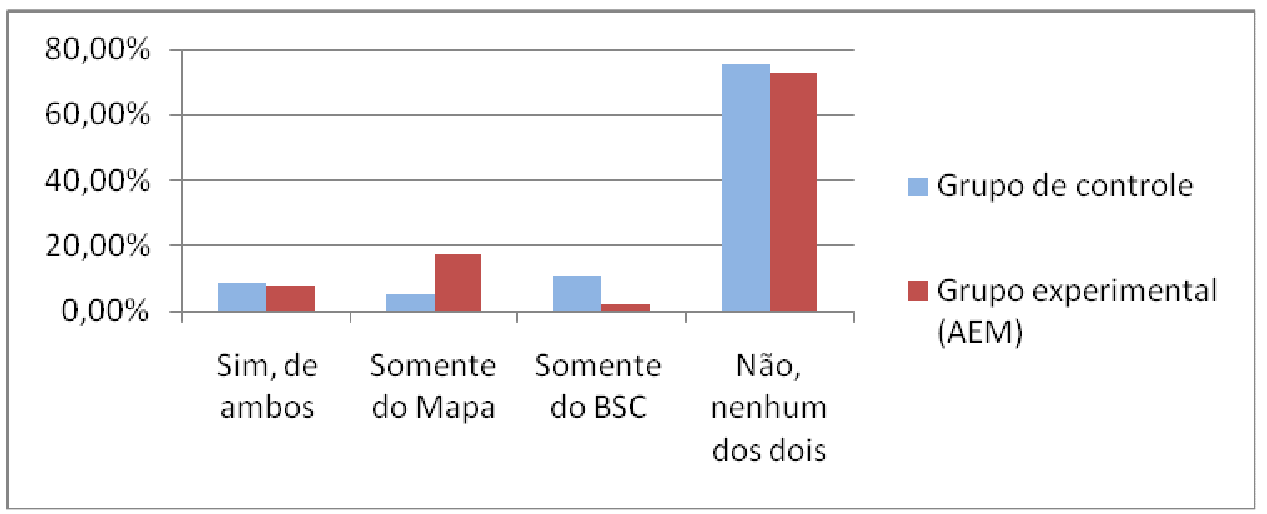

Gráfico 9 - Participação na construção de BSC ou Mapa.

Terminada as questões relacionadas ao perfil dos respondentes, verificam-se agora as questões relacionadas ao experimento propriamente dito. Estas questões são baseadas em uma série de afirmações relacionadas de a) a i) para o grupo de controle e de a) a l) para o grupo experimental. A diferença entre as questões de um questionário e as de outro decorre de 3 itens que cobrem especificamente o uso da ferramenta AEM e foram avaliadas apenas pelo grupo experimental.

\section{Item a) - Dificuldade de resgatar conceitos em estratégia para usá-los no exercício}

Os grupos apresentaram opiniões semelhantes ao avaliar a dificuldade em relembrar os conceitos de estratégia para empregá-las no exercício. Pouco mais de 60\% de cada grupo discordam (total ou parcialmente) desta afirmação. Uma análise mais retida revela que o grupo experimental foi um pouco mais enfático em discordar totalmente (24,53\% versus $19,30 \%)$.

\begin{tabular}{|c|c|c|}
\hline $\begin{array}{l}\text { a. Tive dificuldade em } \\
\text { resgatar os conceitos de } \\
\text { es tratégia para utilizar } \\
\text { neste exercício }\end{array}$ & $\begin{array}{l}\text { Grupo de } \\
\text { controle }\end{array}$ & $\begin{array}{c}\text { Grupo } \\
\text { experimental } \\
(\mathrm{AEM})\end{array}$ \\
\hline Discordo totalmente (1) & $19,30 \%$ & $24,53 \%$ \\
\hline $\begin{array}{l}\text { Dis cordo parcialmente } \\
\text { (2) ou mais discordo que } \\
\text { concordo }\end{array}$ & $42,11 \%$ & $37,74 \%$ \\
\hline $\begin{array}{l}\text { Nem concordo nem } \\
\text { dis cordo }(3)\end{array}$ & $14,04 \%$ & $13,21 \%$ \\
\hline $\begin{array}{l}\text { Concordo parcialmente } \\
\text { (4) ou mais concordo que } \\
\text { discordo }\end{array}$ & $19,30 \%$ & $16,98 \%$ \\
\hline Concordo totalmente (5) & $5,26 \%$ & $7,55 \%$ \\
\hline
\end{tabular}




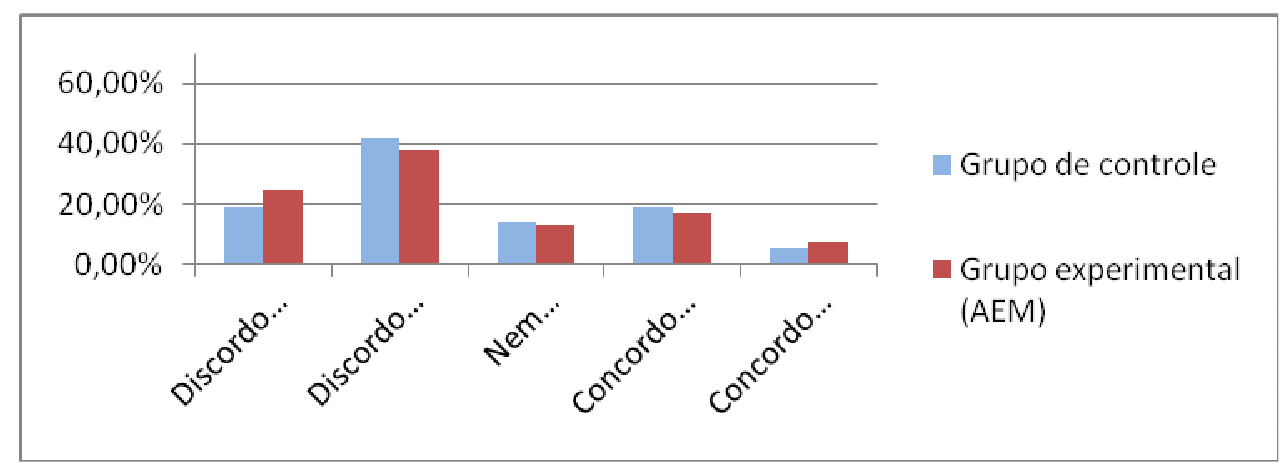

Gráfico 10 - Dificuldade para resgatar conceitos de estratégia.

\section{Item b - Opinião sobre interação do grupo para a conclusão do exercício}

Nesse item, obteve-se a confirmação, pelos próprios participantes, de que, para a conclusão do exercício, era necessária (e importante) a interação do grupo. Os dois grupos concordaram totalmente em aproximadamente de $60 \%$ das respostas. Se somarmos as respostas dos que concordaram parcial ou totalmente, obteremos uma concordância ao redor de $90 \%$ dos respondentes de ambos os grupos.

Tabela 11 - Interação entre os participantes

\begin{tabular}{|l|c|r|}
\hline $\begin{array}{l}\text { b. A interação e troca de } \\
\text { idéias do grupo } \\
\text { contribuiu para a } \\
\text { conclusão do exercício }\end{array}$ & $\begin{array}{c}\text { Grupo de } \\
\text { controle }\end{array}$ & $\begin{array}{c}\text { Grupo } \\
\text { experimental } \\
\text { (AEM) }\end{array}$ \\
\hline $\begin{array}{l}\text { Discordo totalmente (1) } \\
\text { Discordo parcialmente } \\
\text { (2) ou mais discordo que } \\
\text { concordo }\end{array}$ & $1,75 \%$ & $5,66 \%$ \\
\hline $\begin{array}{l}\text { Nem concordo nem } \\
\text { discordo (3) }\end{array}$ & $5,26 \%$ & $3,77 \%$ \\
\hline $\begin{array}{l}\text { Concordo parcialmente } \\
\text { (4) ou mais concordo que } \\
\text { discordo }\end{array}$ & $3,51 \%$ & $0,00 \%$ \\
\hline Concordo totalmente (5) & $24,56 \%$ & $32,08 \%$ \\
\hline
\end{tabular}

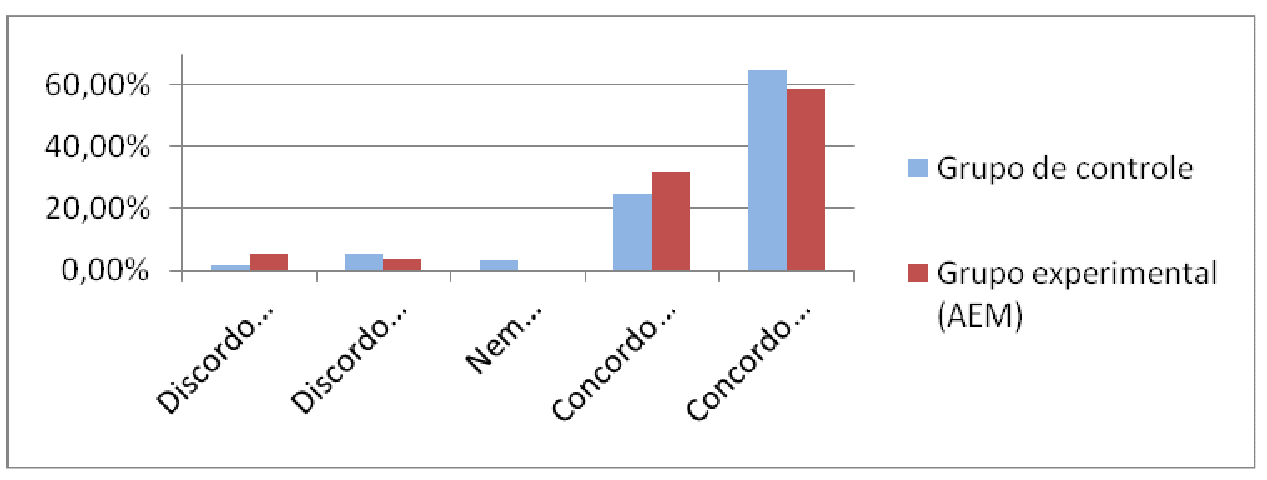

Gráfico 11 - Interação entre os participantes. 


\section{Item c - Opinião sobre contribuição individual}

$\mathrm{Na}$ questão que versa sobre a contribuição individual do que o respondente considerou importante para a discussão em grupo, revelou-se uma concordância (total e parcial) de mais de $80 \%$ de respondentes dos dois grupos com esta afirmação. O número de respondentes que concordaram totalmente com a afirmação foi 7,5\% maior no grupo de controle do que no outro grupo já que o grupo de controle apresentou $49,12 \%$ versus $41,51 \%$ do grupo experimental. No outro extremo das respostas, vemos que $1,75 \%$ do grupo de controle discordam totalmente, e a mesma porcentagem apresentam os que discordam parcialmente. Para o grupo experimental, as porcentagens são um pouco maiores, sendo que os membros deste grupo que discordam totalmente da afirmação chegaram a 3,77\%, ao passo que os membros que discordam parcialmente alcançaram 7,55\%.

Tabela 12 - Contribuição individual

\begin{tabular}{|l|c|r|}
\hline $\begin{array}{c}\text { c. Cons egui contribuir } \\
\text { com o que considerei } \\
\text { relevante/necessário à } \\
\text { discussão }\end{array}$ & $\begin{array}{c}\text { Grupo de } \\
\text { controle }\end{array}$ & $\begin{array}{c}\text { Grupo } \\
\text { experimental } \\
\text { (AEM) }\end{array}$ \\
\hline $\begin{array}{l}\text { Discordo totalmente (1) } \\
\text { Discordo parcialmente } \\
\text { (2) ou mais discordo que } \\
\text { concordo }\end{array}$ & $1,75 \%$ & $3,77 \%$ \\
\hline $\begin{array}{l}\text { Nem concordo nem } \\
\text { discordo (3) }\end{array}$ & $1,75 \%$ & $7,55 \%$ \\
\hline $\begin{array}{l}\text { Concordo parcialmente } \\
\text { (4) ou mais concordo que } \\
\text { discordo }\end{array}$ & $3,51 \%$ & $3,77 \%$ \\
Concordo totalmente (5) & $43,86 \%$ & $43,40 \%$ \\
\hline
\end{tabular}

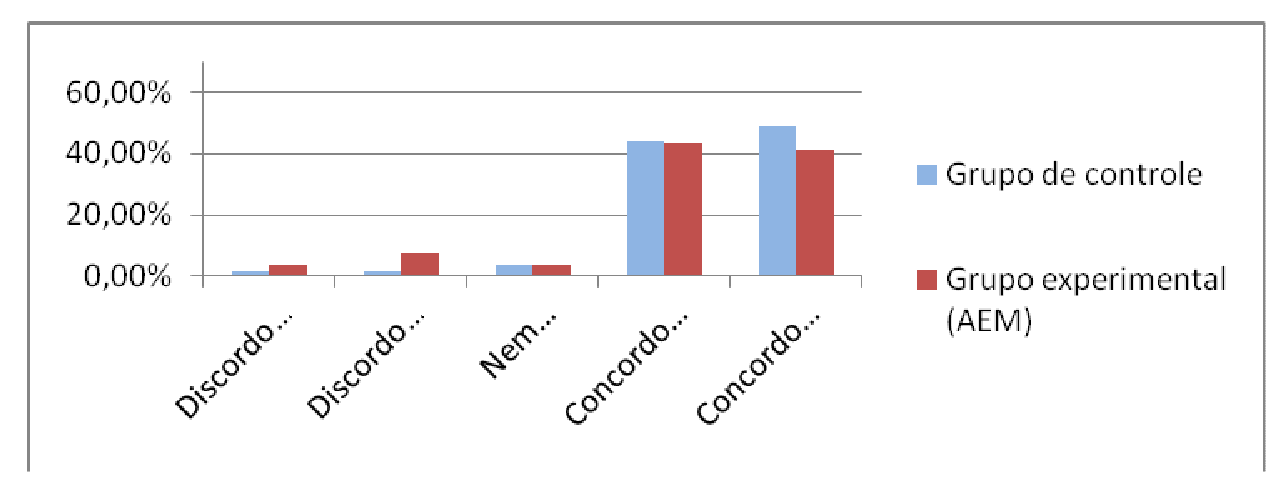

Gráfico 12 - Contribuição individual. 


\section{Item d - Opinião sobre a centralização da discussão em poucos indivíduos}

Os dados mostram que os respondentes do grupo experimental concordaram mais com a situação de que não houve a monopolização da discussão por parte de uma minoria dos membros do grupo. Em termos da ausência de discussão ou da centralização do exercício em poucos membros, os respondentes do grupo experimental foram mais enfáticos em mostrar que $60 \%$ discordam totalmente da afirmação de que a discussão foi monopolizada por poucos membros, enquanto que, no grupo de controle, $45 \%$ discordaram totalmente ao passo que $25 \%$ discordaram parcialmente. No outro extremo, um total de aproximadamente $21 \%$ dos respondentes do grupo de controle concordou em algum grau com a afirmação, enquanto que, no grupo experimental, a porcentagem dos que concordaram que houve a monopolização da discussão por poucos participantes somou pouco mais de $11 \%$ dos respondentes, evidenciando que, segundo a opinião dos respondentes do grupo de controle, teria havido uma centralização maior da discussão.

Tabela 13 - Monopolização da discussão

\begin{tabular}{|l|r|r|}
\hline $\begin{array}{c}\text { d. Poucos membros (ou } \\
\text { um único membro) } \\
\text { monopolizaram a } \\
\text { discussão }\end{array}$ & $\begin{array}{c}\text { Grupo de } \\
\text { controle }\end{array}$ & $\begin{array}{c}\text { Grupo } \\
\text { experimental } \\
\text { (AEM) }\end{array}$ \\
\hline $\begin{array}{l}\text { Discordo totalmente (1) } \\
\text { Discordo parcialmente } \\
\text { (2) ou mais discordo que }\end{array}$ & 45,61\% & $60,38 \%$ \\
concordo & $28,07 \%$ & $15,09 \%$ \\
\hline $\begin{array}{l}\text { Nem concordo nem } \\
\text { discordo (3) }\end{array}$ & $5,26 \%$ & $13,21 \%$ \\
\hline $\begin{array}{l}\text { Concordo parcialmente } \\
\text { (4) ou mais concordo que } \\
\text { discordo }\end{array}$ & $10,53 \%$ & $7,55 \%$ \\
\hline \begin{tabular}{l} 
Concordo totalmente (5) \\
\hline
\end{tabular} & $10,53 \%$ & $3,77 \%$ \\
\hline
\end{tabular}

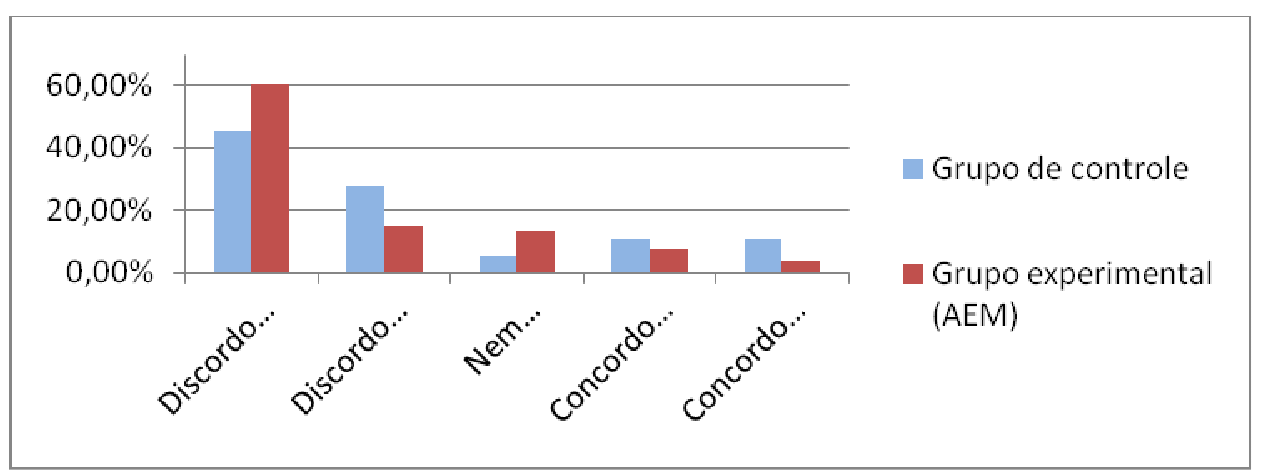

Gráfico 13 - Monopolização da discussão. 
Das questões apresentadas até então, esta é a primeira diferença mais notável entre os dois grupos em relação às suas respectivas opiniões, com o grupo experimental apresentando uma posição mais enfática de que não houve centralização da discussão do exercício por um ou alguns membros do grupo.

\section{Item e - Acordo sobre a forma de construir o mapa}

Analisando as opiniões sobre se houve acordo entre os integrantes do grupo para a definição do Mapa Estratégico, o grupo de controle foi mais enfático em concordar, já que 57,14\% de seus respondentes concordaram totalmente com a afirmação. Somando esta porcentagem com a dos que mais concordam do que discordam, temos $91 \%$ de respostas concordantes com aquela afirmação. No grupo experimental, somando os grupos que concordam totalmente e os que concordam parcialmente, temos um agrupamento de pouco mais de $60 \%$ dos respondentes.

Tabela 14 - Acordo sobre o mapa

\begin{tabular}{|l|r|r|}
\hline $\begin{array}{l}\text { e. O grupo entrou em um } \\
\text { acordo prático sobre a } \\
\text { definição do formato do } \\
\text { Mapa }\end{array}$ & $\begin{array}{c}\text { Grupo de } \\
\text { controle }\end{array}$ & $\begin{array}{c}\text { Grupo } \\
\text { experimental } \\
\text { (AEM) }\end{array}$ \\
\hline $\begin{array}{l}\text { Discordo totalmente (1) } \\
\begin{array}{l}\text { Discordo parcialmente } \\
\text { (2) ou mais discordo que }\end{array}\end{array}$ & $3,57 \%$ & $11,54 \%$ \\
concordo & $1,79 \%$ & $5,77 \%$ \\
\hline $\begin{array}{l}\text { Nem concordo nem } \\
\text { discordo (3) }\end{array}$ & $3,57 \%$ & $21,15 \%$ \\
\hline $\begin{array}{l}\text { Concordo parcialmente } \\
\text { (4) ou mais concordo que } \\
\text { discordo }\end{array}$ & $33,93 \%$ & $38,46 \%$ \\
\hline \begin{tabular}{l} 
Concordo totalmente (5) \\
\hline
\end{tabular} & $57,14 \%$ & $23,08 \%$ \\
\hline
\end{tabular}

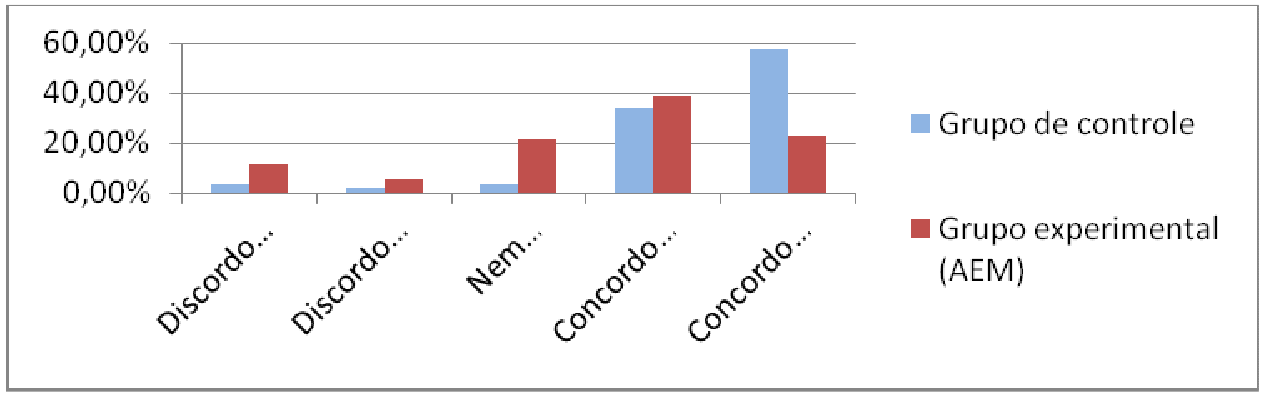

Gráfico 14 - Acordo sobre o formato do mapa.

A partir desta questão, pode-se observar que: 
a) Os grupos de controle e experimental não puderam observar o resultado final um do outro. Portanto, a análise da satisfação é "interna" ao grupo, sem comparações mais estruturadas entre uma forma de trabalho e outra.

b) Cabe ressaltar que, em função da limitação de tempo e do software (em especial, para a geração da estrutura final), não se realizou uma etapa final de visualização no exercício dos grupos experimentais para análise e retoques da estrutura de objetivos. Os grupos experimentais não tiveram a oportunidade de visualizar a estrutura acabada antes de responder ao questionário.

A experiência com AEM em outras aplicações (Wright 1989,1991,1995) mostra que o grau de entendimento e satisfação do exercício cresce após a visualização, revisão e finalização da estrutura final. As estruturas revisadas estão apresentadas no Apêndice IV.

\section{Item f - Aprovação da forma que o grupo resolveu o exercício}

Observando as respostas para o item que contém a afirmação de que o respondente concorda como os objetivos estratégicos foram distribuídos, nota-se que o grupo de controle possui, somados o porcentual dos que concordam parcialmente e o dos que concordam totalmente, mais $85 \%$ dos respondentes. O percentual de respondentes do grupo experimental que concordam (parcial ou totalmente) com esta afirmação também é alto, chegando a quase $80 \%$ (mais precisamente, 79,25\%).






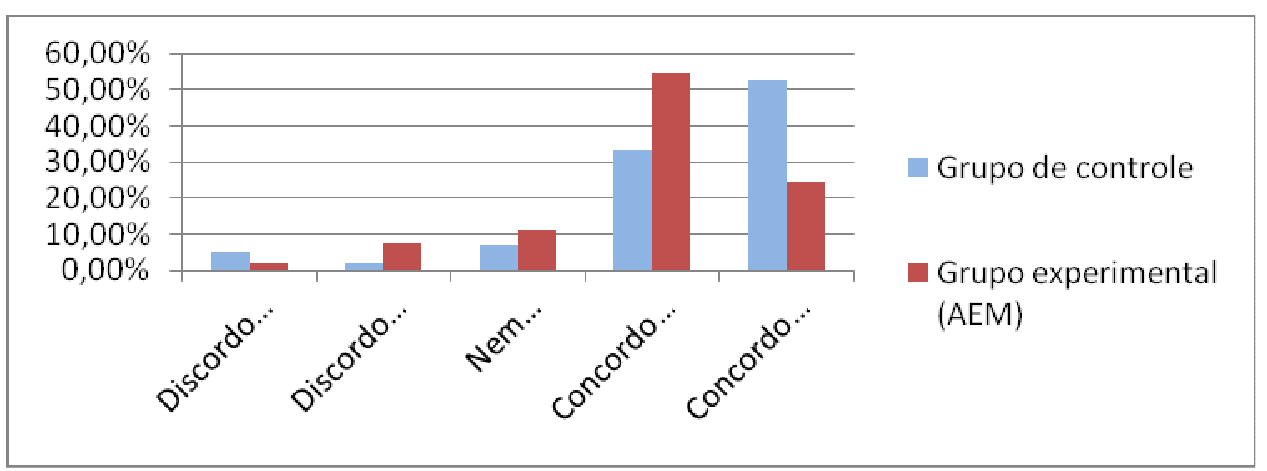

Gráfico 15 - Distribuição dos objetivos entre as dimensões.

É interessante notar que as porcentagens quase que se invertem quando se analisam os dois grupos e apenas os itens 4 e 5 (concordância parcial ou total). Mais precisamente, a maioria do grupo de controle concorda totalmente com a afirmação enquanto que a maioria do grupo experimental concorda parcialmente (isto é, mais concorda que discorda) da afirmação. Essa inversão pode estar relacionada com a mecânica do exercício em função da aplicação da AEM, que, na prática, o software não pergunta qual dimensão do BSC o objetivo deve ser alocado mas, em vez disso, com base nas discussões e decisão do grupo, estrutura as relações entre os objetivos, isto é, apresenta tanto aqueles objetivos que contribuem fortemente para com os outros quanto os objetivos resultantes que recebem mais do que contribuem. Para estruturar os objetivos neste exercício, o grupo tinha em mente o modelo das dimensões do BSC e buscou de estruturar os objetivos seguindo esta orientação, mesmo que implicitamente. Uma vez que o grupo experimental de fato não assinalou o ponto preciso no qual cada objetivo ficaria de acordo com as dimensões, pode ter acontecido que cada respondente se sentisse pouco à vontade para afirmar que concorda totalmente com a distribuição dos objetivos entre as dimensões.

\section{Item g - Resultado do exercício perante a opinião do grupo}

Tomando como base apenas aqueles que concordam totalmente com a afirmação de que o mapa refletiu a opinião do grupo, temos o grupo de controle com uma porcentagem maior $(52,63 \%)$ do que o grupo experimental $(18,87 \%)$. Se analisarmos o total de respondentes que concordam total ou parcialmente, vemos que o grupo de controle ainda possui as maiores porcentagens $(85,96 \%)$, mas com uma diferença (entre a concordância total e a concordância parcial) menor em comparação com a do grupo experimental (71,70\%). Uma porcentagem relevante $(22,64 \%)$ de respondentes do grupo experimental indicou uma posição neutra (nem concordância, nem discordância) em relação à afirmação. 
Tabela 16 - Opinião do grupo refletida no Mapa Estratégico

\begin{tabular}{|l|c|r|}
\hline $\begin{array}{l}\text { g. O Mapa Es tratégico } \\
\text { refletiu a opinião do } \\
\text { grupo sobre o exercício }\end{array}$ & $\begin{array}{c}\text { Grupo de } \\
\text { controle }\end{array}$ & $\begin{array}{c}\text { Grupo } \\
\text { experimental } \\
\text { (AEM) }\end{array}$ \\
\hline $\begin{array}{l}\text { Discordo totalmente (1) } \\
\text { Discordo parcialmente } \\
\text { (2) ou mais dis cordo que } \\
\text { concordo }\end{array}$ & $1,75 \%$ & $0,00 \%$ \\
\hline $\begin{array}{l}\text { Nem concordo nem } \\
\text { discordo (3) }\end{array}$ & $3,51 \%$ & $5,66 \%$ \\
\hline $\begin{array}{l}\text { Concordo parcialmente } \\
\text { (4) ou mais concordo que } \\
\text { discordo }\end{array}$ & $33,33 \%$ & $22,64 \%$ \\
\hline Concordo totalmente (5) & $52,63 \%$ & $52,83 \%$ \\
\hline
\end{tabular}

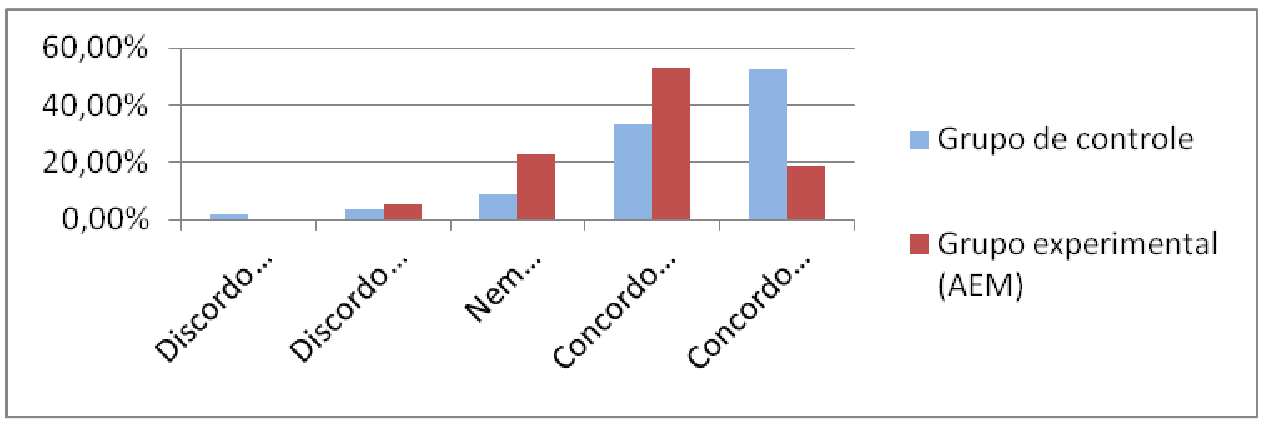

Gráfico 16 - Opinião do grupo refletida no Mapa Estratégico.

Ocorre uma distribuição parecida com a da questão anterior no que se refere às maiores porcentagens do grupo de controle em responder "concordo totalmente" enquanto o grupo experimental se destaca com respostas "concordo parcialmente". Tal semelhança pode ser explicada do mesmo modo que o item anterior. Um alto número de respondentes do grupo experimental afirmou que concorda parcialmente com a opinião final do grupo sobre o exercício. Essa opinião pode ter sido motivada pelo retorno recebido com o uso do software da AEM, que não possui a melhor interface gráfica para apresentar um Mapa Estratégico. Conforme descrito no capítulo anterior, o resultado no software era em primeiro lugar apresentado ao grupo e, em uma segunda etapa, o mapa foi passado a limpo e, por fim, enviado pela internet aos grupos. É razoável imaginar que, se houvesse mais tempo para apresentar para os alunos, ainda em sala de aula, o mapa passado a limpo, a porcentagem dos que concordam totalmente poderia maior. 


\section{Item $h$ - Percepção sobre o entendimento da estratégia}

No caso do item no qual o respondente avalia se após a execução do exercício é possível compreender melhor a estratégia apresentada no caso, podemos observar novamente que o grupo de controle possui a maior faixa de respondentes que concordaram totalmente, com quase $50 \%$ das respostas. Se analisarmos os totais de todos os respondentes que concordaram (parcial e totalmente) observaremos $80 \%$ dos respondentes do grupo de controle ante $64 \%$ do grupo experimental, concordando que a execução do exercício contribui para um melhor entendimento da estratégia descrita no caso.

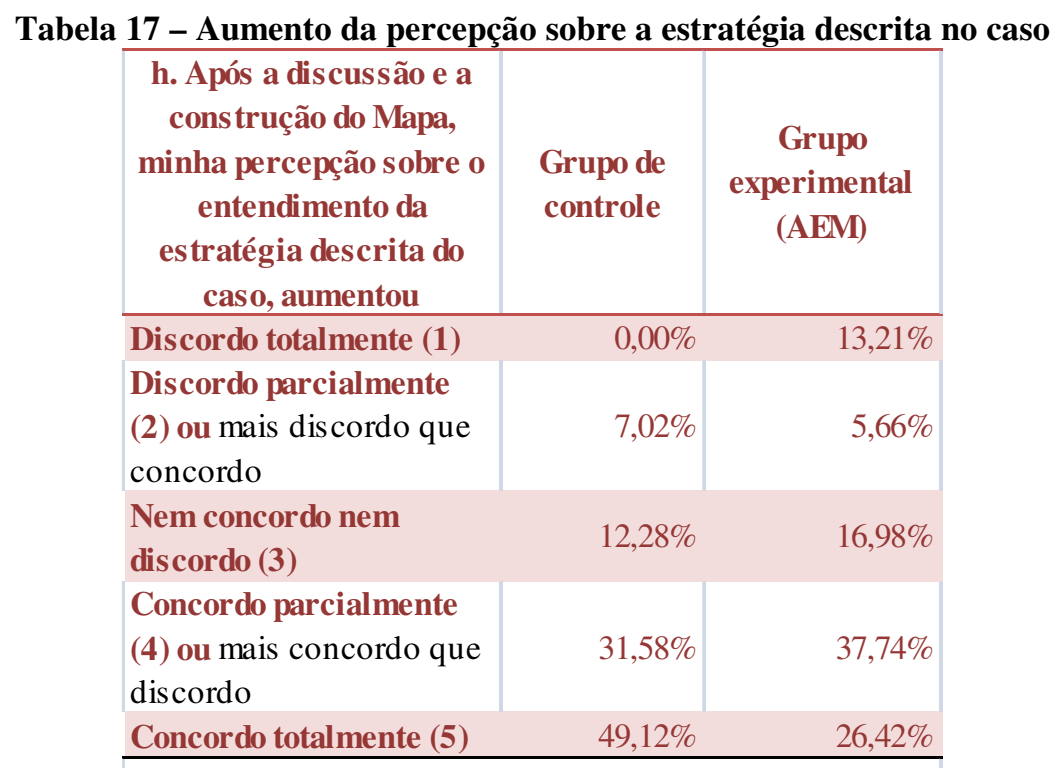

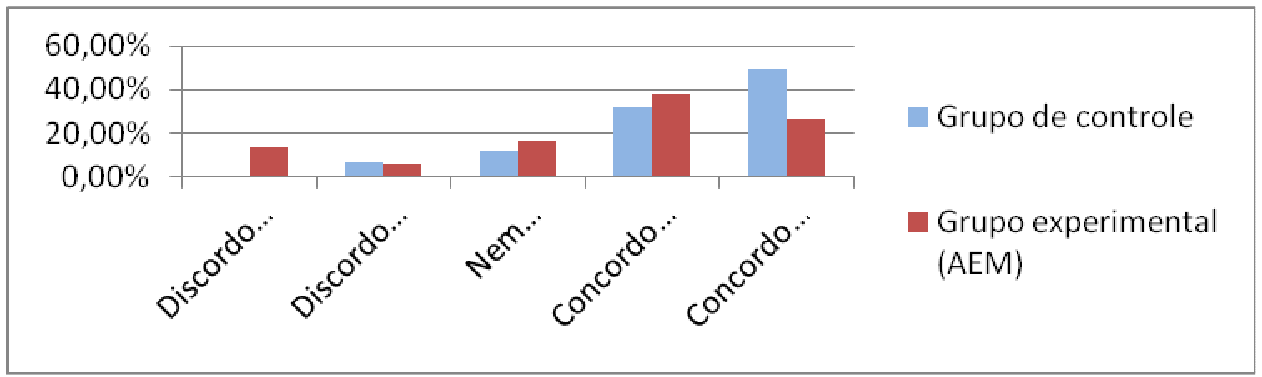

Gráfico 17 - Aumento da percepção sobre a estratégia descrita no caso.

\section{Item i - Satisfação individual com o resultado do exercício}

No item que analisa a satisfação individual com o exercício, novamente observamos uma maior porcentagem das respostas dos que concordam totalmente, com $43 \%$ do grupo de controle apresentando essa resposta enquanto que $20,75 \%$ dos respondentes do grupo de controle concordaram totalmente. Agrupando as respostas de quem concorda total e 
parcialmente, observamos que o grupo de controle ainda possui um grupo maior de satisfeitos com o resultado do exercício, mas com uma diferença menor entre os grupos, já que o grupo de controle apresenta essa resposta em $82,46 \%$ dos respondentes, enquanto que no grupo experimental, $67,92 \%$ oferecem essa opinião.

De acordo com comentários dos participantes do exercício, esta falta de satisfação total com o exercício está relacionada com a falta de retorno mais satisfatório do software. Esta informação pode explicar também a porcentagem de 16,98\% de participantes do grupo experimental que discordam (total ou parcialmente) do resultado do exercício.

Tabela 18 - Satisfação com o resultado do exercício

\begin{tabular}{|l|r|r|}
\hline $\begin{array}{l}\text { i. Fiquei satisfeito(a) com } \\
\text { o resultado do exercício }\end{array}$ & $\begin{array}{c}\text { Grupo de } \\
\text { controle }\end{array}$ & $\begin{array}{c}\text { Grupo } \\
\text { experimental } \\
\text { (AEM) }\end{array}$ \\
\hline $\begin{array}{l}\text { Discordo totalmente (1) } \\
\begin{array}{l}\text { Discordo parcialmente } \\
\text { (2) ou mais discordo que }\end{array}\end{array}$ & $0,00 \%$ & $7,55 \%$ \\
concordo & $1,75 \%$ & $9,43 \%$ \\
\hline $\begin{array}{l}\text { Nem concordo nem } \\
\text { discordo (3) }\end{array}$ & $15,79 \%$ & $15,09 \%$ \\
\hline $\begin{array}{l}\text { Concordo parcialmente } \\
\text { (4) ou mais concordo que } \\
\text { discordo }\end{array}$ & $38,60 \%$ & $47,17 \%$ \\
\hline \begin{tabular}{l} 
Concordo totalmente (5) \\
\hline
\end{tabular} & $43,86 \%$ & $20,75 \%$ \\
\hline
\end{tabular}

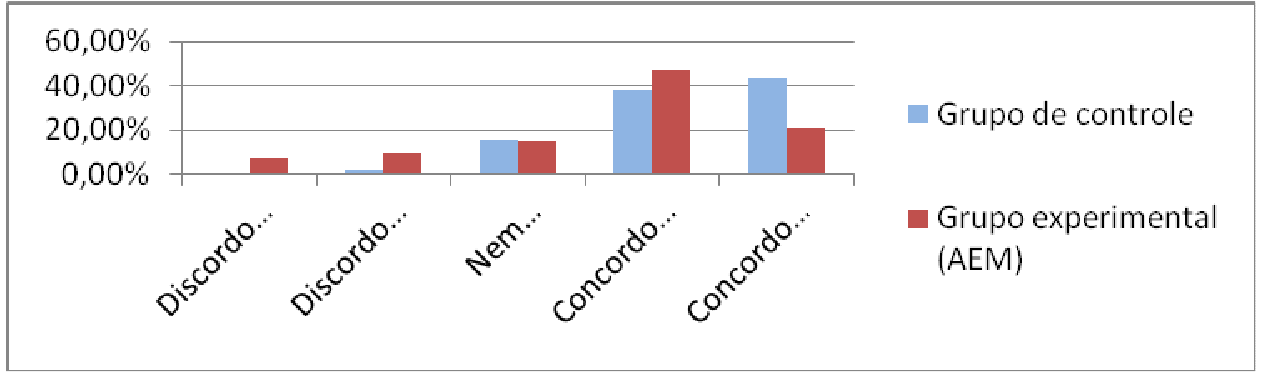

Gráfico 18 - Satisfação com o resultado do exercício.

As questões seguintes foram apresentadas apenas ao grupo experimental, pois o objetivo foi coletar opiniões daqueles que usaram a AEM. A seguir são listados os resultados. 


\section{Item j - Emprego da ferramenta AEM no exercício, para um entendimento melhor da estratégia descrita no caso.}

Dos respondentes do grupo experimental temos um grupo de $54,72 \%$ que concorda (ao menos que parcialmente) que a adoção da ferramenta contribui para compreender a estratégia do caso. No outro extremo, $16,98 \%$ dos respondentes discordam (total ou parcialmente) da afirmação.

Tabela 19 - Utilização da AEM na compreensão da estratégia do caso

\begin{tabular}{|c|c|}
\hline $\begin{array}{c}\text { j. A utilização da } \\
\text { ferramenta AEM auxiliou- } \\
\text { me a compreender } \\
\text { melhor a es tratégia } \\
\text { descrita no caso }\end{array}$ & $\begin{array}{c}\text { Grupo } \\
\text { experimental } \\
\text { (AEM) }\end{array}$ \\
\hline Discordo totalmente (1) & $9,43 \%$ \\
\hline $\begin{array}{l}\text { Dis cordo parcialmente } \\
\text { (2) ou mais dis cordo que } \\
\text { concordo }\end{array}$ & $7,55 \%$ \\
\hline $\begin{array}{l}\text { Nem concordo nem } \\
\text { discordo }(3)\end{array}$ & $28,30 \%$ \\
\hline $\begin{array}{l}\text { Concordo parcialmente } \\
\text { (4) ou mais concordo que } \\
\text { discordo }\end{array}$ & $37,74 \%$ \\
\hline Concordo totalmente (5) & $16,98 \%$ \\
\hline
\end{tabular}

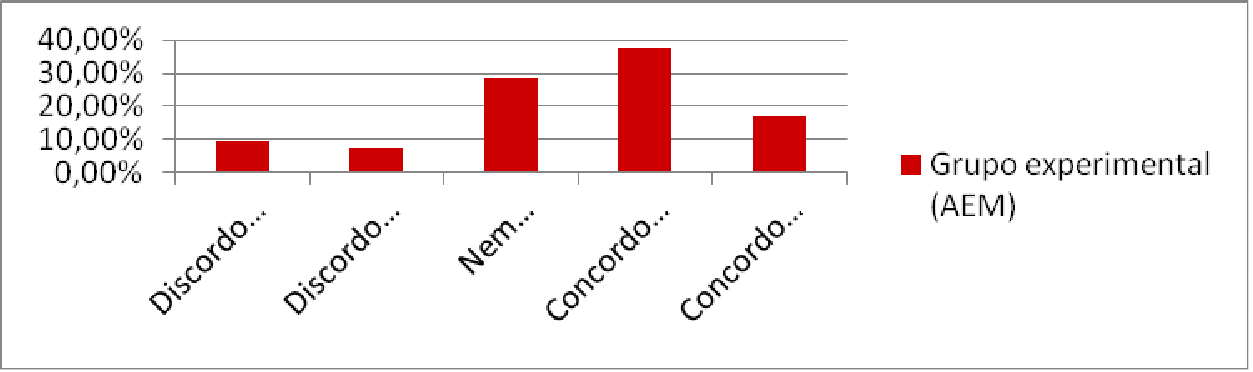

Gráfico 19 - Utilização da AEM na compreensão da estratégia do caso. 


\section{Item k - Auxílio da AEM no processo de construção dos Mapas}

A respeito da afirmação de que a ferramenta auxiliou o processo de construção de Mapas Estratégicos, um total de $67,92 \%$ dos respondentes esteve de total ou parcialmente de acordo, sendo que a distribuição é uniforme, com um total de 33,96\% tanto para quem concorda parcialmente quanto para quem concorda totalmente. A opinião neutra totaliza $18,87 \%$ das respostas enquanto que as opiniões discordantes somam $13,21 \%$

\begin{tabular}{|c|c|}
\hline $\begin{array}{c}\text { k. A ferramenta de } \\
\text { es truturação de objetivos } \\
(\mathrm{AEM}) \text { auxiliou o } \\
\text { processo de construção } \\
\text { dos Mapas }\end{array}$ & $\begin{array}{c}\text { Grupo } \\
\text { experimental } \\
\text { (AEM) }\end{array}$ \\
\hline Discordo totalmente (1) & $5,66 \%$ \\
\hline $\begin{array}{l}\text { Dis cordo parcialmente } \\
\text { (2) ou mais discordo que } \\
\text { concordo }\end{array}$ & $7,55 \%$ \\
\hline $\begin{array}{l}\text { Nem concordo nem } \\
\text { discordo }(3)\end{array}$ & $18,87 \%$ \\
\hline $\begin{array}{l}\text { Concordo parcialmente } \\
\text { (4) ou mais concordo que } \\
\text { discordo }\end{array}$ & $33,96 \%$ \\
\hline Concordo totalmente (5) & $33,96 \%$ \\
\hline
\end{tabular}

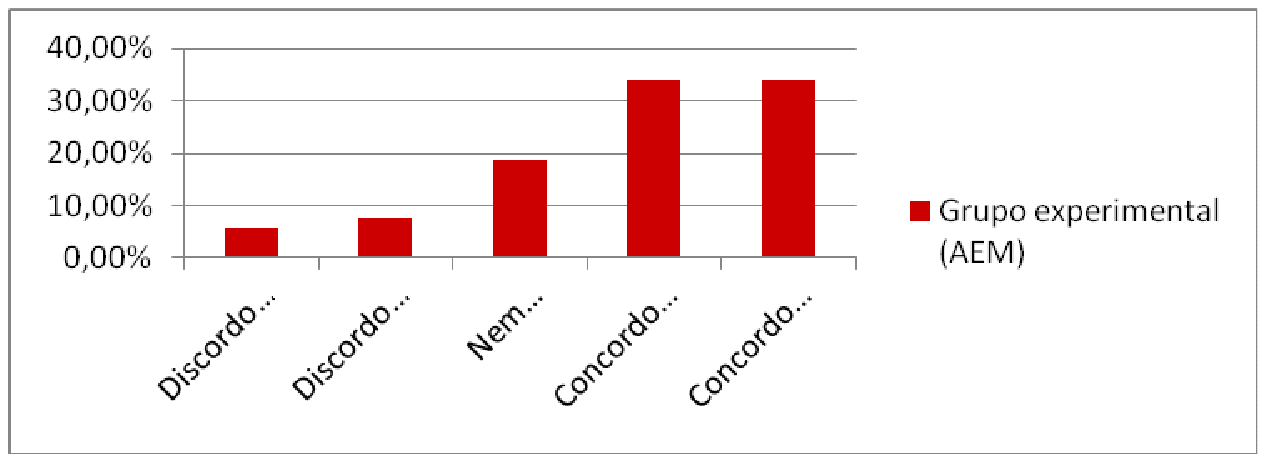

Gráfico 20 - Auxílio da ferramenta no processo. 


\section{Item I - Opinião sobre o uso da ferramenta no exercício}

No que diz respeito a satisfação em utilizar a ferramenta, no tempo proposto para resolver o exercício, temos que $73,58 \%$ dos respondentes concordaram (parcial ou totalmente) com a afirmação. Ainda temos 16,98\% de respondentes que se posicionam de forma neutra (nem concorda nem discorda) enquanto que as posições de discordância juntas somaram 9,43\%.

\begin{tabular}{|c|c|}
\hline $\begin{array}{l}\text { I. Valeu a pena utilizar a } \\
\text { ferramenta dentro do } \\
\text { tempo proposto ao } \\
\text { exercício }\end{array}$ & $\begin{array}{c}\text { Grupo } \\
\text { experimental } \\
\text { (AEM) }\end{array}$ \\
\hline Discordo totalmente (1) & $3,77 \%$ \\
\hline $\begin{array}{l}\text { Discordo parcialmente } \\
\text { (2) ou mais discordo que } \\
\text { concordo }\end{array}$ & $5,66 \%$ \\
\hline $\begin{array}{l}\text { Nem concordo nem } \\
\text { dis cordo }(3)\end{array}$ & $16,98 \%$ \\
\hline $\begin{array}{l}\text { Concordo parcialmente } \\
\text { (4) ou mais concordo que } \\
\text { discordo }\end{array}$ & $35,85 \%$ \\
\hline Concordo totalmente (5) & $37,74 \%$ \\
\hline
\end{tabular}

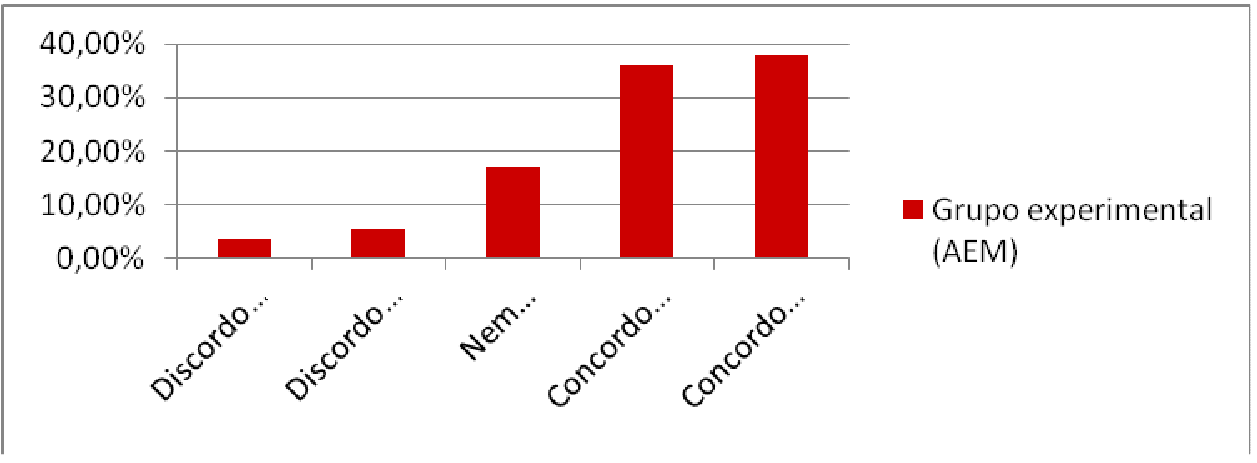

Gráfico 21 - Opinião sobre o uso da ferramenta. 


\section{Questão 6 - Avaliação do uso da AEM no exercício}

A opinião dos respondentes se mostrou positiva em relação ao uso da AEM no exercício. Elas totalizam como "muito boa" em 44,23\% dos casos. Agrupando os dois primeiros itens da escala o total é de 78,85\% de avaliação positiva do emprego da ferramenta. Quanto aos demais itens: "razoável" ficou com $11,54 \%$, enquanto que 9,62\% responderam "ruim".

Tabela 22 - Avaliação do uso da AEM

\begin{tabular}{|c|c|}
\hline $\begin{array}{l}\text { 6. Qual sua opinião s obre } \\
\text { a utilização da AEM neste } \\
\text { exercício? }\end{array}$ & $\begin{array}{c}\text { Grupo } \\
\text { experimental } \\
\text { (AEM) }\end{array}$ \\
\hline $\begin{array}{l}\text { Muito boa, auxiliou a } \\
\text { fazer o exercício com } \\
\text { mais qualidade do que } \\
\text { faríamos sem a } \\
\text { ferramenta }\end{array}$ & $44,23 \%$ \\
\hline $\begin{array}{l}\text { Média, ajudou a fazer o } \\
\text { exercício sem grandes } \\
\text { vantagens em relação aos } \\
\text { outros grupos }\end{array}$ & $34,62 \%$ \\
\hline $\begin{array}{l}\text { Razoável, tentou orientar } \\
\text { a condução do trabalho } \\
\text { sem grande sucesso }\end{array}$ & $11,54 \%$ \\
\hline Ruim, explique: & $9,62 \%$ \\
\hline
\end{tabular}

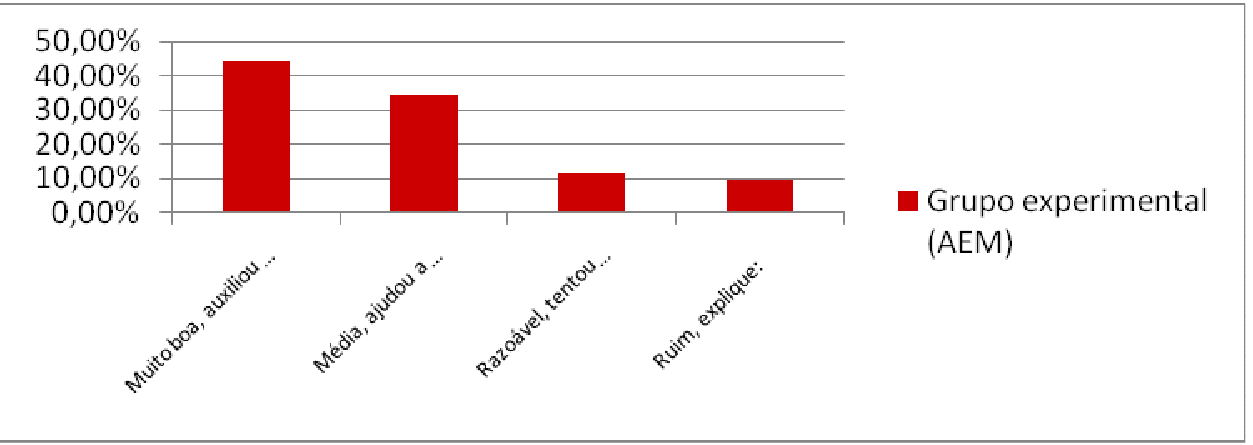

Gráfico 22 - Avaliação do uso da AEM.

Dentre os 9,62\% dos participantes que responderam "ruim", cinco especificaram as razões para marcar esta opção. Uma crítica apresentada diz respeito à restrição de opções para discussão e avaliação oferecidas pelo software, o que, segundo o respondente, limita a discussão por não ser possível escolher o que discutir na ordem e hora que se quiser. Os demais comentários estão relacionados ao que os respondentes chamaram de falta de visualização do resultado, isto é, eles apontaram como um empecilho para a discussão não ver o resultado do que está sendo discutido. Um desses comentários consiste em sugerir que o 
mapa no software deveria ser visualizado à medida que os itens vão sendo discutidos. Outra crítica refere-se à interface do software que poderia ser melhor: "O programa precisa ser melhor estruturado/completado", escreveu um dos participantes.

Além das críticas elaboradas pelos respondentes que não gostaram do método AEM, algumas recomendações podem ser feitas ao software AEM com base nas opiniões dos grupos experimentais como um todo, assim como a partir de observações do pesquisador:

- Forma de apresentação do resultado mais limpa, desenhando o mapa após o processamento da matriz interna para evitar o desenho de linhas redundantes na saída gráfica.

- Possibilidade de os alunos avaliarem a construção do mapa on-line enquanto discutem. Criar uma tela menor que durante a estruturação já seja possível visualizar o mapa sendo construído.

- Dar mais destaque à relação escolhida para a discussão. Retirar o termo "relacionamento direto" perto dos botões de resposta na tela de estruturação. Muitas vezes era por este termo, e não pela relação escolhida, que os alunos se pautavam para discutir.

\section{Questão 7 (para o grupo experimental) - Outros métodos para construir Mapas}

\section{Estratégicos (questão 6 do grupo de controle)}

Esta questão foi apresentada como forma de coletar conceitos ou ferramentas que pudessem ser utilizadas para construir Mapas Estratégicos e desta forma efetuar alguma comparação com a AEM. No caso dos participantes do grupo experimental poucos participantes fizeram sugestões, que foram: workshop, "trabalho em grupo obtendo o consenso", árvore de decisão do cliente, "sim, manualmente ou através de sistemas", Positional Selling (software no qual o respondente comenta que é bastante parecido no estabelecimento de posicionamento de estratégias) e fazer no Excel.

Nenhuma das sugestões apresentou outro método de construção de Mapas Estratégicos com algum grau de detalhe que pudesse efetuar alguma comparação. Vale ressaltar que sugestões como workshop ou trabalho em grupo, no fundo são procedimentos semelhantes ao que os alunos vivenciaram para resolver o exercício e, infelizmente, os comentários não trouxeram informações adicionais para entender a diferença desses termos para o que foi executado em 


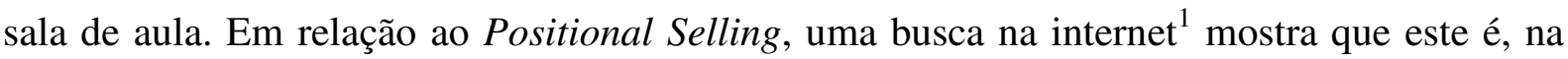
verdade, um sistema relacionado a vendas, equipe de vendas e logística. Vale ressaltar que a questão 8 do questionário do grupo experimental, que justamente, questionava o respondente sobre vantagens essa ferramenta citada possuía em comparação com a AEM não obteve nenhuma resposta.

No caso do grupo de controle, esta questão também não recebeu sugestões de ferramentas que poderiam trabalhar como um método de apoio a construção de mapas estratégicos. Para descrever os modelos utilizados para resolver o exercício no papel, a grande maioria respondeu que utilizou a intuição, o material de aula ou simplesmente responderam que não utilizaram método algum.

Este item relatou as opiniões tecidas pelos grupos de controle e experimental por meio de um questionário individual aplicado ao final do exercício. Até aqui, algumas constatações podem ser feitas com base nestas opiniões, especialmente em relação a aprovação do software AEM pelo grupo que o utilizou, conforme apresenta a tabela 23 .

\footnotetext{
${ }^{1}$ http://www.carew.com ou ainda http://www.intercultural.srv.br/tpv.html\#ps acessados em 14/07/2009.
} 
Tabela 23 - Consolidação das opiniões

\begin{tabular}{|c|c|c|c|c|c|c|c|c|}
\hline \multirow[b]{2}{*}{ Item } & \multicolumn{4}{|c|}{ Grupo de controle } & \multicolumn{4}{|c|}{ Grupo Experimental } \\
\hline & $\begin{array}{c}\text { opção mais } \\
\text { votada }\end{array}$ & $\%$ & $\begin{array}{l}\text { agrupamento } \\
\text { de } 2 \text { opções }\end{array}$ & $\begin{array}{l}\text { soma } \\
\text { das } \%\end{array}$ & $\begin{array}{c}\text { opção mais } \\
\text { votada }\end{array}$ & $\%$ & $\begin{array}{l}\text { agrupamento } \\
\text { de } 2 \text { opções }\end{array}$ & $\begin{array}{l}\text { soma } \\
\text { das } \%\end{array}$ \\
\hline $\begin{array}{l}\text { a. Tive dificuldade em } \\
\text { resgatar os conceitos } \\
\text { de estratégia para } \\
\text { utilizar neste exercício }\end{array}$ & $\begin{array}{l}\text { Discordo } \\
\text { parcialmente } \\
\text { (2) ou mais } \\
\text { discordo que } \\
\text { concordo }\end{array}$ & $42,11 \%$ & $\mathrm{DP}+\mathrm{DT}$ & $61,40 \%$ & $\begin{array}{l}\text { Discordo } \\
\text { parcialmente } \\
\text { (2) ou mais } \\
\text { discordo que } \\
\text { concordo }\end{array}$ & $37,74 \%$ & $\mathrm{DP}+\mathrm{DT}$ & $62,26 \%$ \\
\hline $\begin{array}{l}\text { b. A interação e troca } \\
\text { de idéias do grupo } \\
\text { contribuiu para a } \\
\text { conclusão do exercício }\end{array}$ & $\begin{array}{l}\text { Concordo } \\
\text { totalmente } \\
\text { (5) }\end{array}$ & $64,91 \%$ & $\mathrm{CT}+\mathrm{CP}$ & $89,47 \%$ & $\begin{array}{l}\text { Concordo } \\
\text { totalmente (5) }\end{array}$ & $58,49 \%$ & $\mathrm{CT}+\mathrm{CP}$ & $90,57 \%$ \\
\hline $\begin{array}{l}\text { c. Consegui contribuir } \\
\text { com o que considerei } \\
\text { relevante/necessário } \\
\text { à discussão }\end{array}$ & $\begin{array}{l}\text { Concordo } \\
\text { totalmente } \\
\text { (5) }\end{array}$ & $49,12 \%$ & $\mathrm{CT}+\mathrm{CP}$ & $92,98 \%$ & $\begin{array}{l}\text { Concordo } \\
\text { parcialmente } \\
\text { (4) ou mais } \\
\text { concordo que } \\
\text { discordo }\end{array}$ & $43,40 \%$ & $\mathrm{CP}+\mathrm{CT}$ & $84,91 \%$ \\
\hline $\begin{array}{l}\text { d. Poucos membros } \\
\text { (ou um único } \\
\text { membro) } \\
\text { monopolizaram a } \\
\text { discussão }\end{array}$ & $\begin{array}{l}\text { Discordo } \\
\text { totalmente } \\
\text { (1) }\end{array}$ & $45,61 \%$ & DT+DP & $73,68 \%$ & $\begin{array}{l}\text { Discordo } \\
\text { totalmente (1) }\end{array}$ & $60,38 \%$ & DT+DP & $75,47 \%$ \\
\hline $\begin{array}{l}\text { e. } O \text { grupo entrou em } \\
\text { um acordo prático } \\
\text { sobre a definição do } \\
\text { formato do Mapa }\end{array}$ & $\begin{array}{l}\text { Concordo } \\
\text { totalmente } \\
\text { (5) }\end{array}$ & $57,14 \%$ & $\mathrm{CT}+\mathrm{CP}$ & $91,07 \%$ & $\begin{array}{l}\text { Concordo } \\
\text { parcialmente } \\
\text { (4) ou mais } \\
\text { concordo que } \\
\text { discordo }\end{array}$ & $38,46 \%$ & $\mathrm{CP}+\mathrm{CT}$ & $61,54 \%$ \\
\hline $\begin{array}{l}\text { f. Concordo como o } \\
\text { grupo distribuiu os } \\
\text { objetivos entre as } \\
\text { dimensões do mapa }\end{array}$ & $\begin{array}{l}\text { Concordo } \\
\text { totalmente } \\
\text { (5) }\end{array}$ & $52,63 \%$ & $\mathrm{CT}+\mathrm{CP}$ & $85,96 \%$ & $\begin{array}{l}\text { Concordo } \\
\text { parcialmente } \\
\text { (4) ou mais } \\
\text { concordo que } \\
\text { discordo }\end{array}$ & $54,72 \%$ & $\mathrm{CP}+\mathrm{CT}$ & $79,25 \%$ \\
\hline $\begin{array}{l}\text { g. O Mapa Estratégico } \\
\text { refletiu a opinião do } \\
\text { grupo sobre o } \\
\text { exercício }\end{array}$ & $\begin{array}{l}\text { Concordo } \\
\text { totalmente } \\
(5)\end{array}$ & $52,63 \%$ & $\mathrm{CT}+\mathrm{CP}$ & $85,96 \%$ & $\begin{array}{l}\text { Concordo } \\
\text { parcialmente } \\
\text { (4) ou mais } \\
\text { concordo que } \\
\text { discordo }\end{array}$ & $52,83 \%$ & $\mathrm{CP}+\mathrm{CT}$ & $71,70 \%$ \\
\hline $\begin{array}{l}\text { h. Após a discussão e a } \\
\text { construção do Mapa, } \\
\text { minha percepção } \\
\text { sobre o } \\
\text { entendimento da } \\
\text { estratégia descrita do } \\
\text { caso, aumentou }\end{array}$ & $\begin{array}{l}\text { Concordo } \\
\text { totalmente } \\
\text { (5) }\end{array}$ & $49,12 \%$ & $\mathrm{CT}+\mathrm{CP}$ & $80,70 \%$ & $\begin{array}{l}\text { Concordo } \\
\text { parcialmente } \\
\text { (4) ou mais } \\
\text { concordo que } \\
\text { discordo }\end{array}$ & $37,74 \%$ & $\mathrm{CP}+\mathrm{CT}$ & $64,15 \%$ \\
\hline $\begin{array}{l}\text { i. Fiquei satisfeito(a) } \\
\text { com o resultado do } \\
\text { exercício }\end{array}$ & $\begin{array}{l}\text { Concordo } \\
\text { totalmente } \\
\text { (5) }\end{array}$ & $43,86 \%$ & $\mathrm{CT}+\mathrm{CP}$ & $82,46 \%$ & $\begin{array}{l}\text { Concordo } \\
\text { parcialmente } \\
\text { (4) ou mais } \\
\text { concordo que } \\
\text { discordo }\end{array}$ & $47,17 \%$ & $\mathrm{CP}+\mathrm{CT}$ & $67,92 \%$ \\
\hline
\end{tabular}

O grupo experimental, em comparação com o grupo de controle apresentou um destaque em relação a descentralização da discussão, aspecto que não foi tão destacado pelo grupo de 
controle. As questões relacionadas a aprendizagem e a concordância quanto ao resultado do exercício, por sua vez, mostram que o grupo de controle foi mais enfático em concordar com estes elementos em relação ao exercício, apesar do grupo experimental também ter recebido aprovações quanto a concordância. Os questionamentos realizados apenas com o grupo experimental mostram uma avaliação positiva da ferramenta AEM por quem a utilizou, apesar de todas as ressalvas já citadas. Esses resultados até aqui mostram uma avaliação positiva da AEM, mas indica que melhorias direcionadas a seu software possibilitariam uma avaliação melhor do grupo experimental de forma a destacá-lo do grupo de controle.

\subsubsection{Análise dos Mapas Estratégicos elaborados}

Como produto final do exercício, cada grupo deveria entregar, além do questionário individual, o Mapa Estratégico com a resposta do caso. Todos os mapas recebidos foram passados a limpo para um mesmo formato e devolvidos posteriormente, por via eletrônica, aos respondentes. Este trabalho de padronização visual dos mapas foi necessário para a padronização do layout e possibilitar uma melhor análise. Todos os mapas foram passados a limpo com seu conteúdo integral. O pesquisador apenas organizou horizontalmente os itens de forma a melhorar a visualização das relações entre um objetivo e outro, no caso dos mapas feitos no papel, e interpretou a distribuição de objetivos nas dimensões do BSC sem interferir no conteúdo ou nas relações entre os objetivos estratégicos definidos pelos grupos.

\section{Mapas Estratégicos produzidos pelos grupos de controle}

Os grupos de controle tinham autonomia para produzir seus mapas no papel da forma que lhes conviesse. O que foi observado é que, intuitivamente, estes grupos produziam o mapa em duas grandes fases: na primeira, o grupo classificava cada objetivo estratégico segundo as quatro dimensões do BSC. Após esta classificação, os objetivos eram colocados na folha de resposta (Apêndice III) e, então, os grupos realizavam nova discussão para identificar quais as relações a serem destacados entre os objetivos estratégicos, de forma a caracterizar o Mapa Estratégico.

As ilustrações 9 e 10, a seguir, representam exemplos dos 11 Mapas Estratégicos construídos pelos grupos de controle. 


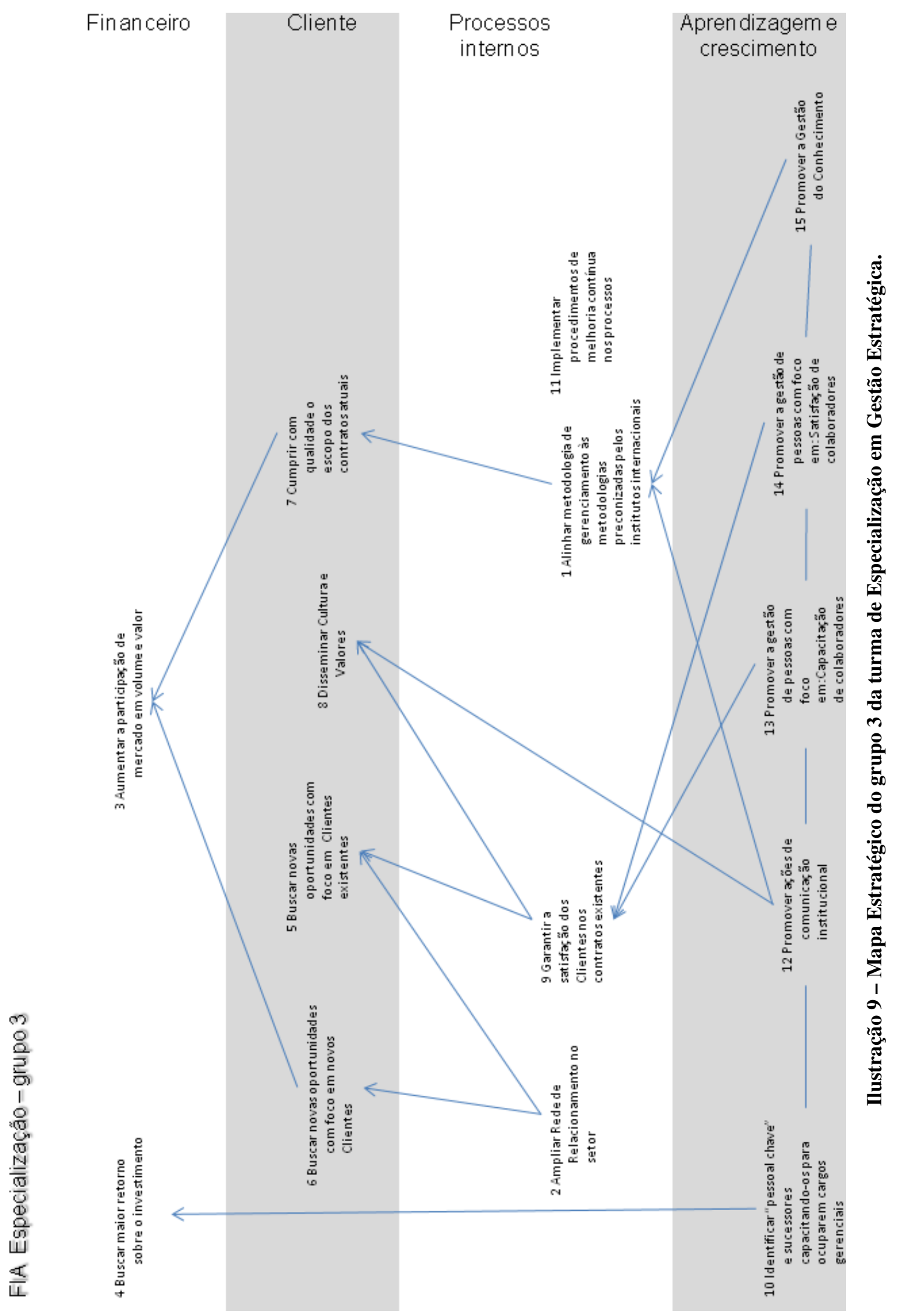




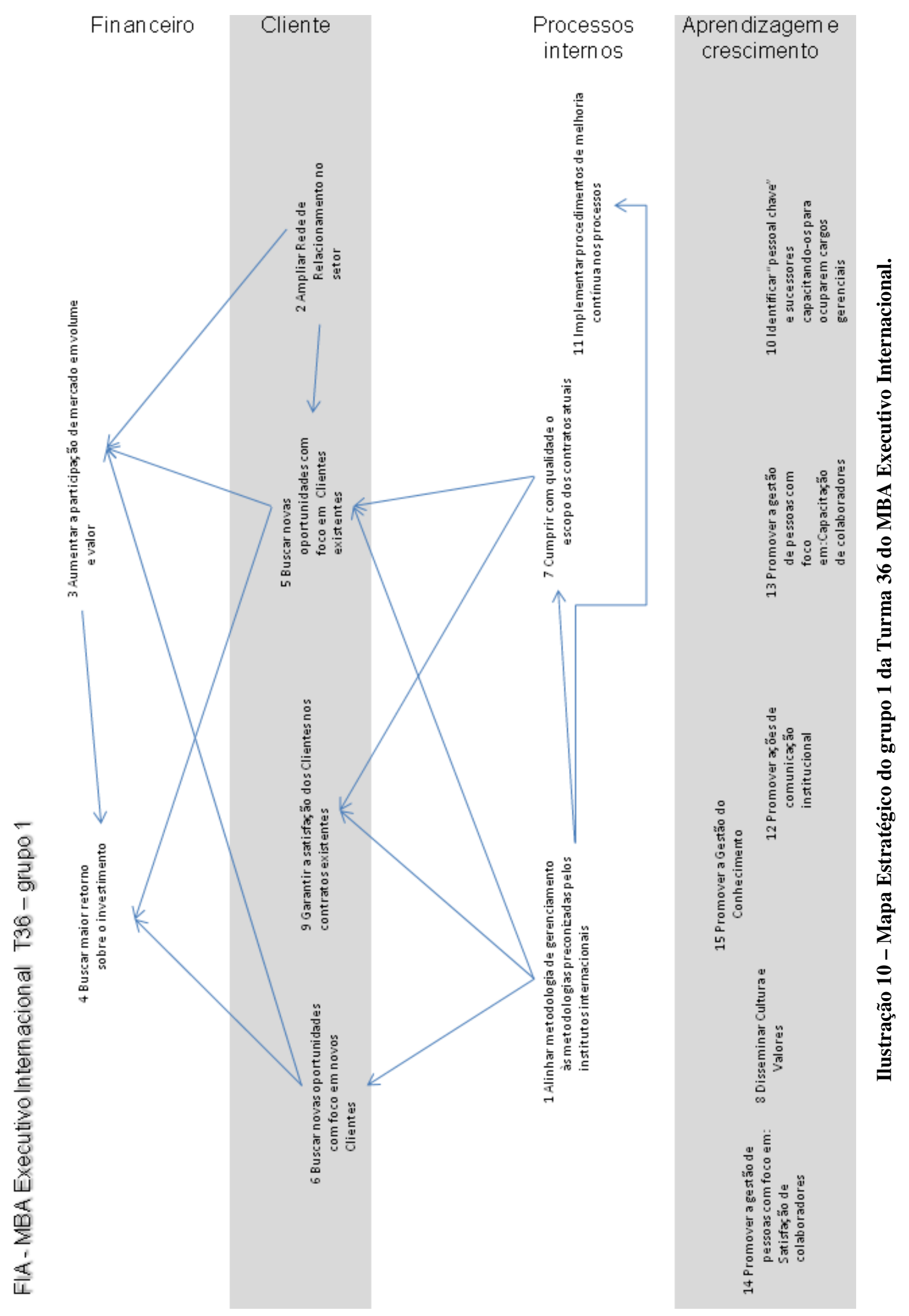


É possível apresentar algumas observações a partir da leitura desses dois mapas e dos demais disponíveis no Apêndice IV. A partir dos 11 mapas entregues, em 5 se podem notar objetivos estratégicos sem ligações com os demais objetivos, quebrando a seqüência de causa e efeito que os elementos deveriam possuir e deixando de mostrar tanto a relação deste objetivo com os demais quanto a sua ligação com a estratégia da empresa descrita no caso.

Em relação à quebra das ligações de causa e feito, notam-se ainda objetivos, situados nas dimensões intermediárias do Mapa Estratégico, que não recebem influência de nenhum outro e contribuem para os objetivos acima. De maneira semelhante, existem alguns casos de objetivos estratégicos que fazem a ligação direta entre uma dimensão de base e as dimensões de topo, sem evidenciar as possíveis relações com os objetivos estratégicos, que se situam em dimensões mais intermediárias no mapa.

A partir dos 11 Mapas Estratégicos produzidos pelos grupos de controle, é possível desenhar um mapa geral, apresentando as porcentagens das dimensões nas quais os objetivos foram mais alocados pelos respondentes, conforme se pode ver na ilustração 11, a seguir. Ao observar a ilustração, nota-se que os itens $\mathbf{2}$, “ampliar rede de relacionamento do setor", e $\mathbf{1 2}$, "promover ações de comunicação institucional”, geraram mais dúvidas entre os grupos, com respectivamente $55 \%$ e $45 \%$ dos grupos optando por alocá-los na dimensão de cliente, sendo que os demais grupos colocaram estes objetivos na dimensão de processos internos. 


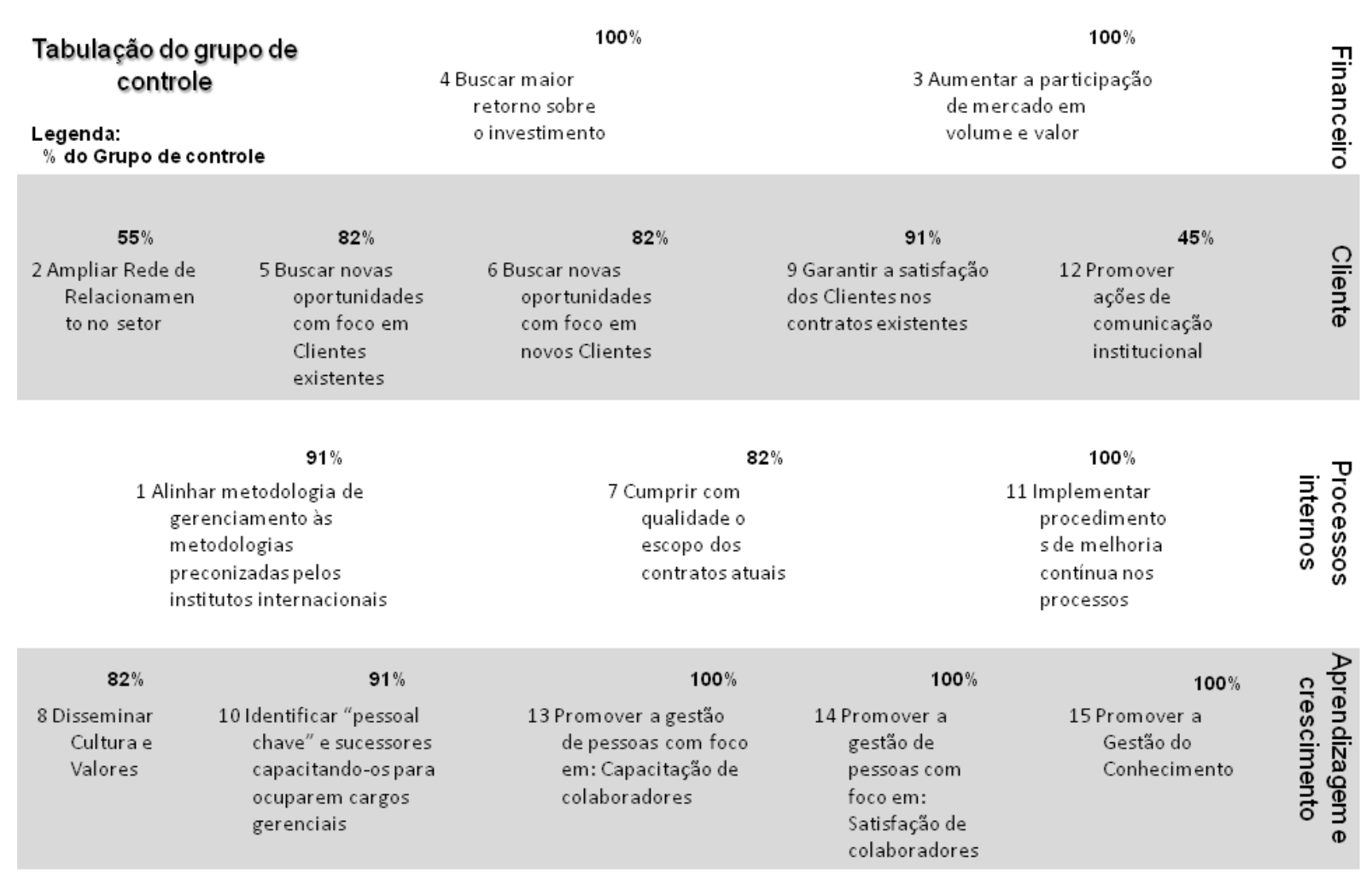

Ilustração 11 - Mapa Estratégico resumo dos grupos de controle.

\section{Mapas Estratégicos produzidos pelos grupos experimentais}

Os mapas elaborados pelos grupos que usaram a AEM (grupos experimentais), ao contrário do grupo de controle, não tinham a indicação explícita de quais eram as dimensões em que estavam alocando os objetivos. Uma vez que a AEM mostra a relação e a influência de um objetivo estratégico para o outro, a ferramenta cria uma estrutura destes objetivos. Para permitir que comparações fossem efetuadas entre os mapas construídos pelos dois grupos, o pesquisador retirou o desenho da estrutura da AEM e o enquadrou nas dimensões do BSC sem descaracterizar as relações indicadas pelo grupo e, portanto, sem desfazer a estrutura. No caso dos ciclos (relação de reforço mútuo entre dois ou mais objetivos) que apareceram nas estruturações, o pesquisador realizou a distribuição dos objetivos estratégicos pelas dimensões, interpretando a condição mais adequada para cada Mapa Estratégico.

As ilustrações 12 e 13 trazem exemplos de dois mapas construídos pelos grupos que empregaram a AEM, representando os dez mapas produzidos pelos grupos experimentais. Todos os mapas produzidos por estes grupos estão disponíveis no Apêndice IV. 


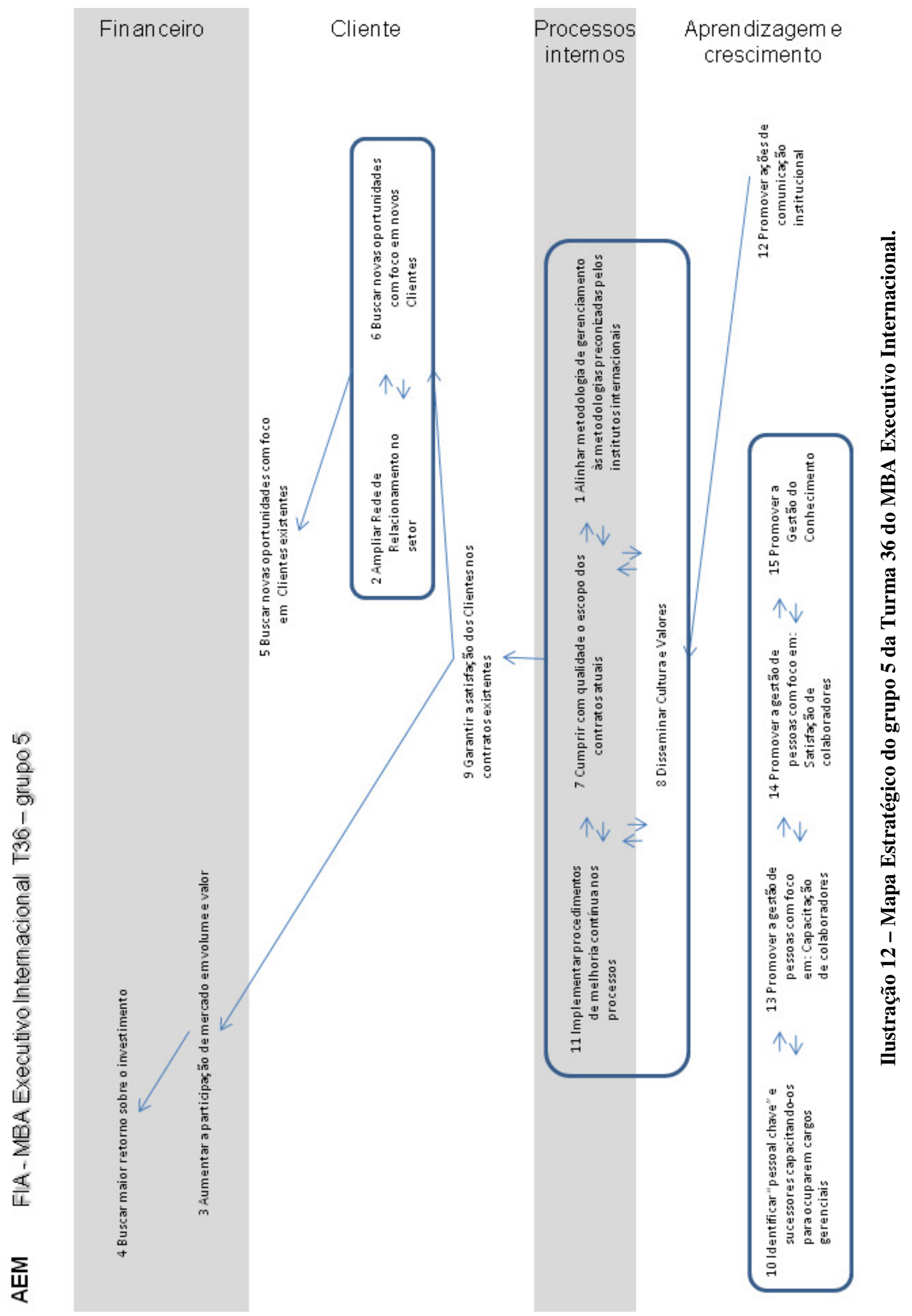




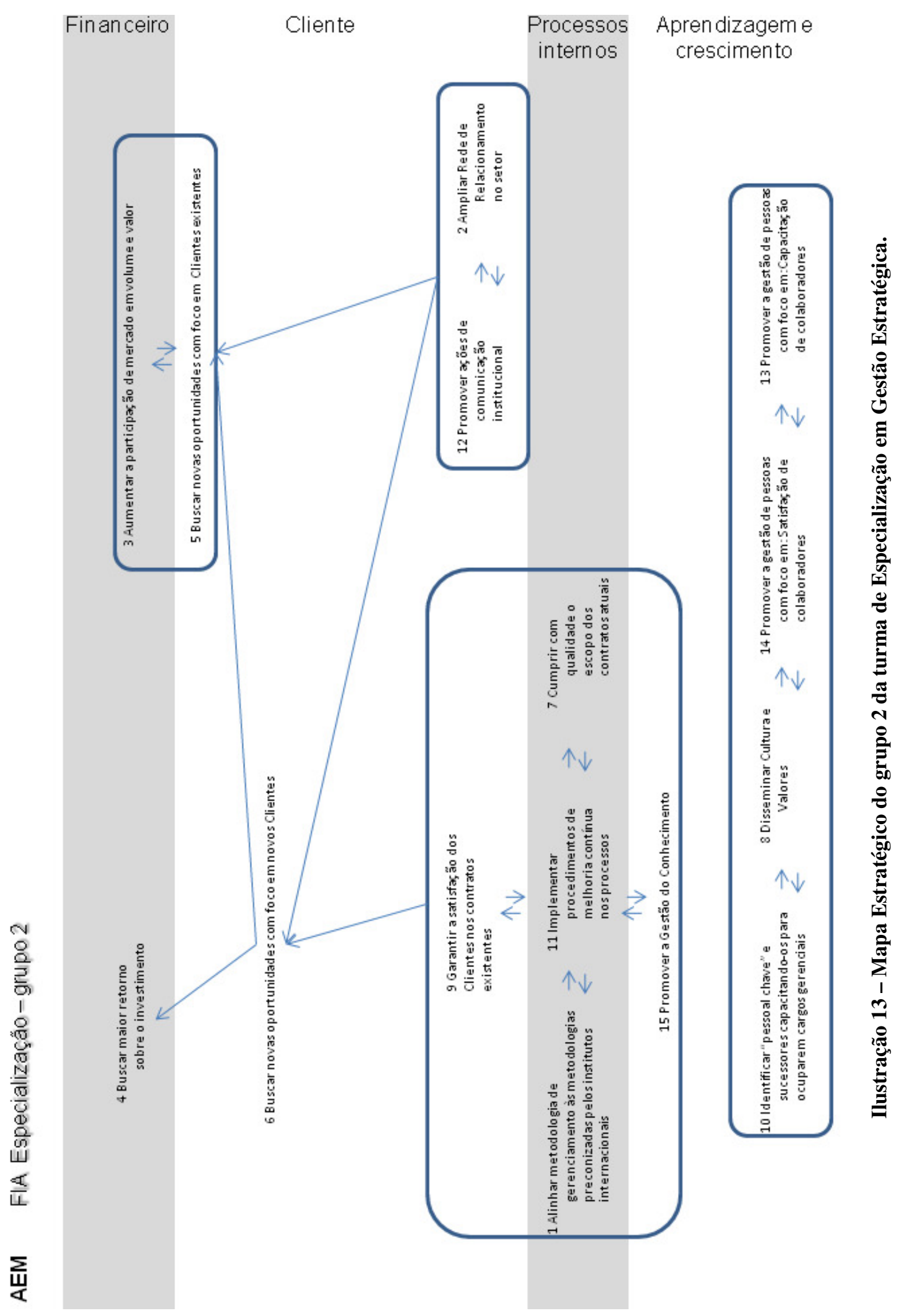


Alguns pontos podem ser destacados a partir da análise dos Mapas produzidos pelos grupos experimentais com o auxílio do software AEM. Uma característica presente em todos os mapas construídos pelos grupos experimentais é a presença de ciclos entre dois ou mais objetivos. Esse aspecto reforça a idéia de que nem sempre todos objetivos atuam individualmente de maneira a construir uma árvore de relação direta de um item influenciando o outro tal como ocorre na representação usual do Mapa Estratégico. Alguns objetivos estão tão ligados a outros que chegam a estabelecer uma relação de reforço mútuo, na qual não é possível identificar um objetivo mais forte da relação, mas, sim, que existe um ciclo com relações mútuas de influência (agrupamento de objetivos estratégicos) que, por sua vez, é influenciado por objetivos que vêm da base do mapa e influenciam objetivos estratégicos que estão no topo do mapa.

O fato de os Mapas Estratégicos trazerem ciclos em sua concepção contribuiu para que se forme um visual mais organizado, o que facilita sua compreensão quando se compara aos quinze objetivos estratégicos postados individualmente. Esta forma mais organizada mostra de forma mais clara quais os objetivos estratégicos de base e quais os resultantes para a implementação e realização da estratégia empresarial contida no caso e estruturada pelo grupo. Além disso, se o mapa está apresentado de uma forma que facilita seu entendimento, isto contribui para o entendimento da estratégia empresarial contido no mapa.

Outro aspecto que se destaca nestes mapas é que, mesmo dentro das dimensões do BSC, foi possível identificar relações de causa e feito entre os objetivos estratégicos, mostrando que a AEM contribuiu para estruturar relações dentro de cada dimensão entre objetivos de base, que influenciam os demais, e objetivos que são resultantes desta influência exercida pela relação dos objetivos que fazem parte da base do Mapa Estratégico.

Analisando os 10 Mapas Estratégicos produzidos pelos grupos experimentais, torna-se possível traçar um novo mapa geral, que classifica os objetivos segundo as dimensões que mais foram alocados por cada grupo. Observando a ilustração 14, nota-se que o item 12, “promover ações de comunicação institucional”, gerou mais dúvidas entre os grupos. Neste caso houve um empate de $40 \%$ entre os grupos que decidiram alocá-lo na dimensão de processos internos e aprendizado \& crescimento, enquanto que os $20 \%$ restantes colocou esse objetivo na dimensão de clientes. 


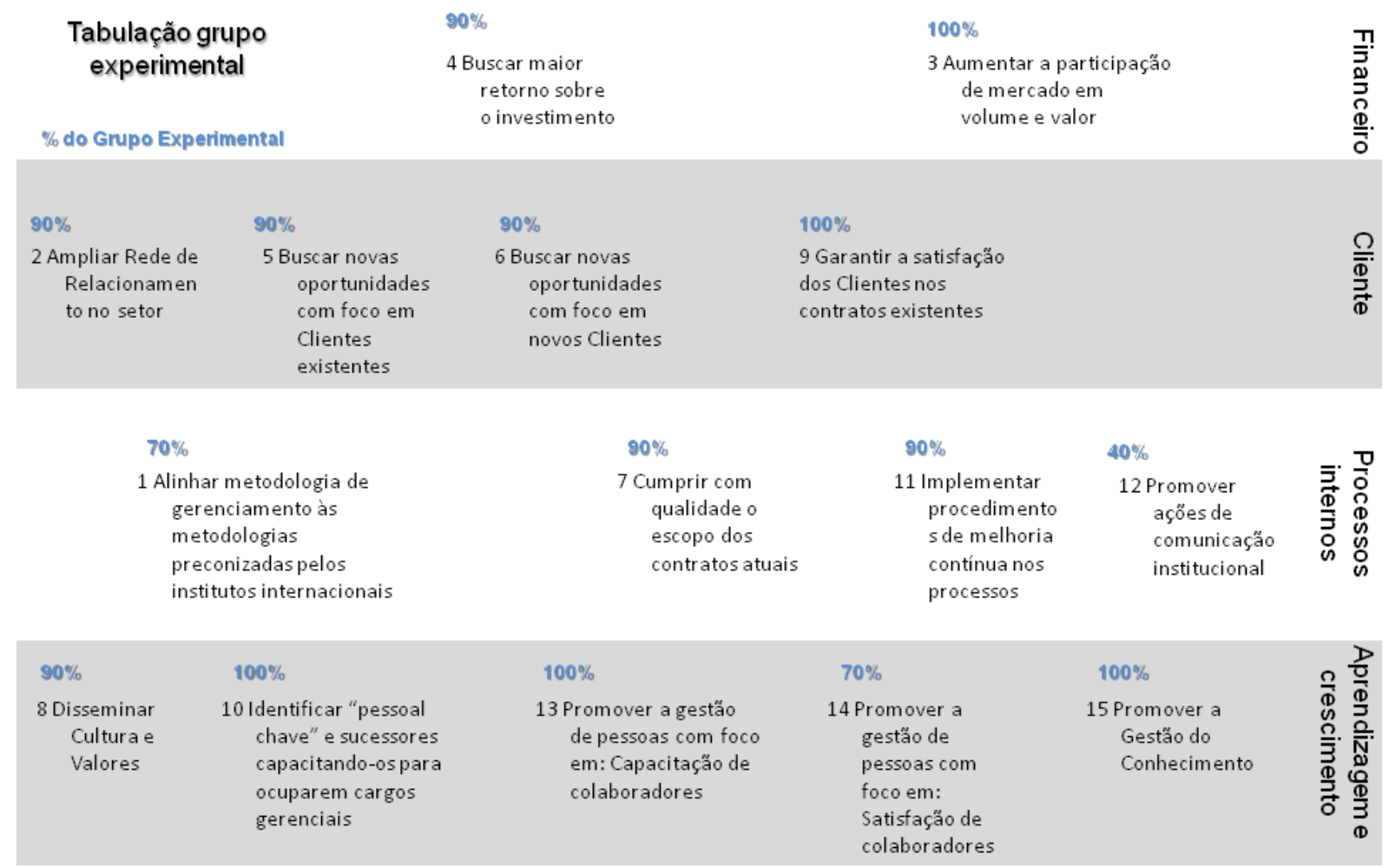

Ilustração 14 - Mapa Estratégico resumo dos grupos experimentais.

O que se pode notar na comparação entre os mapas do grupo de controle e do grupo experimental (disponíveis no Apêndice IV), é que as relações e a influência entre os mapas de um e outro estão mais explícitas e evidentes no grupo experimental. Nos mapas deste grupo verifica-se uma relação de causa e efeito entre um objetivo e outro, além de diversos casos de ciclos com um elemento influenciando o outro e vice-versa. No caso dos grupos de controle, muitos grupos apenas listaram os objetivos dentro de uma das quatro dimensões do BSC, sem estabelecer subníveis dentro de uma dada dimensão e raramente evidenciando relações laterais ou ciclos. É possível verificar 05 mapas com objetivos não conectados entre si, ou ainda, com objetivos relacionados, mas sem uma linha de influência que mostre objetivos estratégicos desde a dimensão de aprendizagem \& crescimento, passando por processos internos, clientes, até resultar, em sua chegada à dimensão financeira.

É possível ver, até mesmo em mapas completos e resolvidos pelos grupos de controle que alguns objetivos não são influenciados por nenhum outro, o que impossibilita visualizar a estratégia a partir da seqüencia de causa e efeito dos objetivos, quebrando a grande proposta de Kaplan e Norton, de mostrar claramente as relações de causa e efeito entre os componentes de uma estratégia. Todos os mapas estão disponíveis no Apêndice IV. 


\section{CONCLUSÕES E RECOMENDAÇÕES}

Esta pesquisa investigou a aplicação da Análise e Estruturação de Modelos (AEM) no apoio a construção de Mapas Estratégicos. Como forma de operacionalizar esta pesquisa, realizou-se um experimento com uma amostra por conveniência de 110 alunos de escolas de pósgraduação localizadas na cidade de São Paulo.

O experimento consistiu na realização de um exercício em forma de estudo de caso real, de uma empresa de engenharia consultiva, cujo nome foi mantido em sigilo, onde participantes de MBA que deveriam, a partir das informações dispostas no caso, elaborar o Mapa Estratégico da empresa estudada. Para a realização do experimento os alunos se dividiram em dois grupos de trabalho, classificados da seguinte forma:

- Os grupos de controle, que elaboraram seus Mapas Estratégicos no papel e possuíam autonomia para trabalhar da forma que considerarem a melhor.

- Grupos experimentais, que usaram o método AEM automatizado em um software para realizar esta mesma tarefa.

Ambos os grupos deveriam devolver ao pesquisador um questionário com as impressões individuais acerca do exercício e de aspectos relacionados ao processo de sua resolução.

\subsection{Diferenças entre os Mapas Estratégicos construídos pelos dois grupos}

Quatro questões de apoio foram apresentadas como forma de auxiliar a investigação da questão principal de pesquisa, que está direcionada para o resultado da aplicação do método AEM na concepção e construção de Mapas Estratégicos. A primeira destas questões consistia em indagar a respeito entre, de um lado, a estrutura do Mapa Estratégico construída com a AEM e, de outro, a do Mapa montada sem aplicação desse recurso. De um modo geral, foi verificado que, no grupo experimental, os 10 Mapas construídos com o apoio da AEM apresentam uma visão de causa e efeito mais completa, envolvendo todos os objetivos estratégicos em uma estrutura compatível com o BSC. Esta estrutura, que forma o mapa, apresenta a relação entre, de um lado os objetivos alocados na dimensão de aprendizagem e crescimento e, de outro lado, os objetivos das dimensões seguintes (processos internos e cliente), influenciando os objetivos financeiros que estão no topo do mapa. Assim apresenta- 
se uma seqüência lógica entre as relações de objetivos, refletindo a estratégia da empresa descrita no caso, segundo a opinião dos grupos.

Já nos grupos de controle, que trabalhavam autonomamente sem o uso da AEM, em alguns casos de relações de causa e efeito entre alguns objetivos do Mapa Estratégico não foram explicitados. Os Mapas Estratégicos elaborados no papel pelos grupos de controle trazem uma construção um pouco diferente, não apresentando uma estrutura em que os objetivos se relacionassem em ciclos por influência mútua. Em vez disso, os objetivos aparecem mais soltos, sem relacionamentos e apresentando redundâncias entre as relações de objetivos. Esta configuração ocorre principalmente por algumas ligações diretas efetuadas entre objetivos na base que, por sua vez, ligam-se, diretamente aos objetivos no topo, sem passar pelas dimensões intermediárias do mapa para criar a relação de causa e efeito característico do conceito de Mapas Estratégicos. Em alguns casos, ao contrário das redundâncias causadas por várias relações entre variáveis, foram dispostos em 5 mapas estratégicos, objetivos desconectados do restante do mapa, ou seja, sem ligação alguma com os demais objetivos estratégicos apresentados no caso.

O uso da AEM propiciou, portanto, uma explicitação maior e mais abrangente das relações existentes entre os diferentes objetivos da empresa, segundo a estruturação feita pelos grupos experimentais, pois o software exige que a análise seja feita de maneira completa, "perguntando" aos usuários sobre a existência ou não de relações, ou fazendo inferências lógicas válidas sobre os mesmos.

Em termos de alocação de objetivos nas dimensões do mapa, a ilustração 15, a seguir, apresenta a comparação entre os grupos de controle e experimental, apresentando os percentuais dos objetivos nas dimensões mais alocadas pelos dois grupos. De modo geral, a distribuição ente objetivos e dimensões apresenta resultado semelhante, apresentando diferenças apenas pontuais entre os dois conjuntos de mapas. 


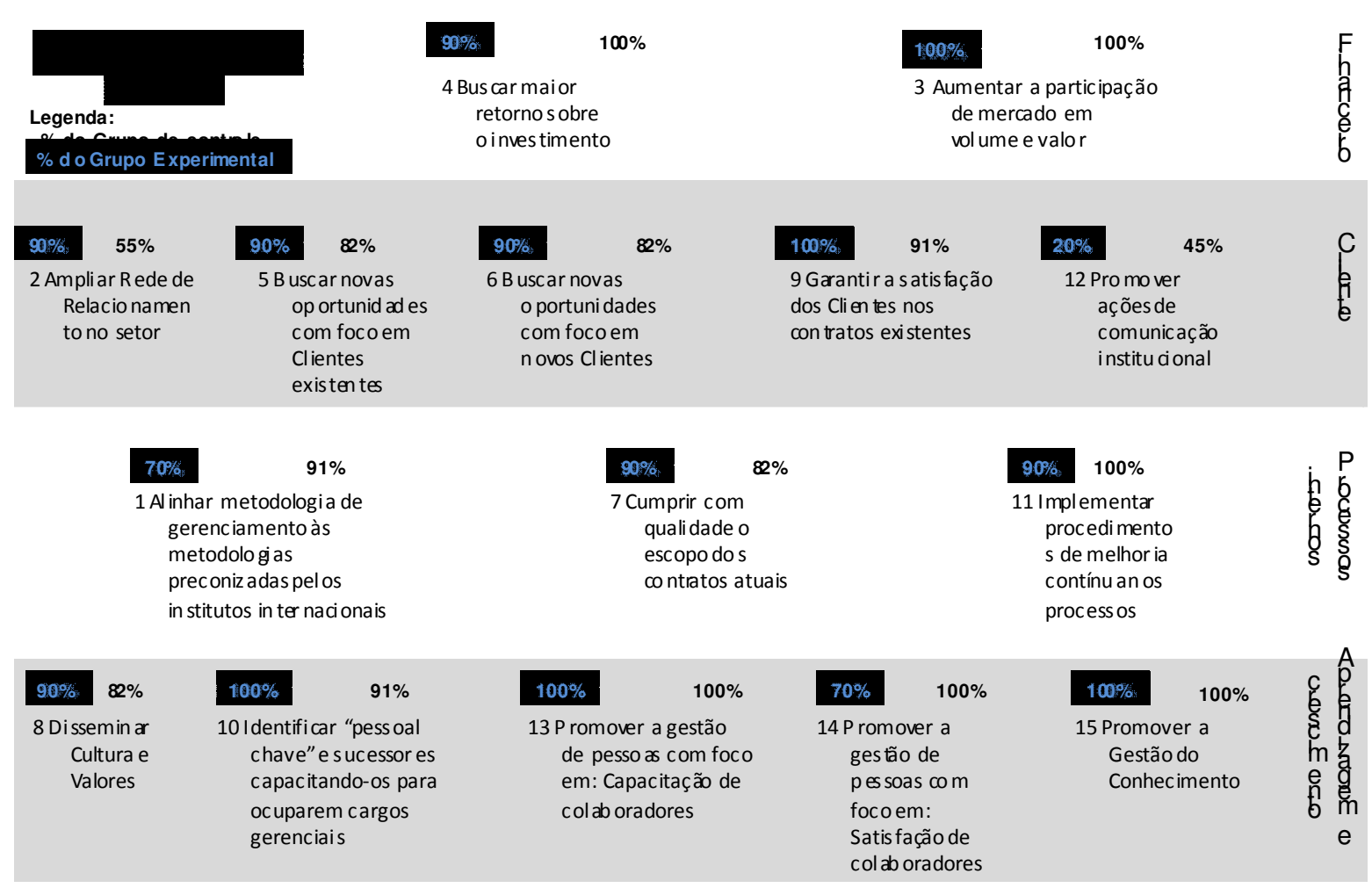

Ilustração 15 - Mapa Estratégico tabulado dos dois grupos.

A ilustração apresenta mapas bem parecidos, com apenas pequenas diferenças entre as tabulações dos dois grupos. No grupo de controle há uma dispersão de opiniões, sobre a posição correta para assinalar dos objetivos 2 e 12, que estão em sua maioria, na dimensão de Cliente mas para quatro grupos de que deveriam fazer parte de Processos Internos. Nos grupos experimentais, a maior dúvida também está relacionada ao item 12, que foi alocado em três dimensões distintas: visão do cliente, visão de processos internos e também na dimensão de aprendizagem e crescimento.

Com a semelhança apontada na distribuição entre objetivos e dimensões pelos dois grupos, as diferenças mais relevantes são encontradas na forma em que os Mapas Estratégicos foram construídos e apresentam as relações entre os objetivos. De um lado, no grupo de controle, os desenhos de mapas aparecem mais desorganizados em termos de relações entre os objetivos, já que alguns possuem relações em redundância entre itens, enquanto que outros objetivos sequer recebem indicações se são influenciados por algum objetivo ou se influenciam outro. Do outro lado, nos grupos experimentais, são observados mapas mais organizados, no sentido de que apresentam uma visão mais estruturada de causa e feito e relações entre seus objetivos. Alguns objetivos dispostos em ciclo contribuem para uma visão mais limpa, detalhada e organizada do mapa, contribuindo para facilitar sua apresentação e seu entendimento. 
A existência de um ciclo entre dois ou mais objetivos aponta para o fato de que a realização de um objetivo do ciclo contribui fortemente para a realização de outro objetivo do mesmo ciclo, ou seja, há um reforço mútuo para a realização dos objetivos daquele ciclo.

\subsection{Conclusões sobre o processo de construção de Mapas Estratégicos}

A segunda questão de pesquisa trata do processo de construção de Mapas Estratégico. A esse respeito pode-se afirmar que a ferramenta AEM propõe um roteiro definido de discussão, que pode auxiliar os grupos que assim desejarem. Este apoio é dado pela ferramenta na condução da reunião, já que a AEM auxilia na indicação de quais elementos devem ser analisados e discutidos, oferecendo as opções de escolha para o grupo de discussão na maioria das vezes e indicando os elementos da discussão que faltam ser analisados em outras. Por outro lado, os recursos de inferência lógica permitem que algumas análises entre elementos não precisem ser realizadas, pois a inteligência artificial do software consegue inferir algumas relações entre objetivos a partir das respostas dadas pelo grupo ao longo do exercício. Esta forma de trabalho, mais estruturada e sistemática, assegura que o grupo analise todos os elementos de um problema (neste caso, todos os objetivos estratégicos), o que, por sua vez, o que garante a mesma oportunidade de análise para todos os itens do problema, passo a passo. Quanto aos grupos que elaboraram seus mapas no papel, pode-se observar que o trabalho era definido em duas grandes etapas: a primeira consistia em enquadrar os objetivos segundo as dimensões do BSC no mapa e, em seguida, estabelecer as relações entre os objetivos tendo de estabelecer essas relações ao mesmo tempo em que se observa o mapa como um todo, sem contar com mecanismos mais estruturados para analisar objetivo por objetivo.

Outro resultado importante é que, conforme comentado no capítulo quatro, todos os grupos experimentais que usaram a AEM concluíram o trabalho em um tempo útil de estruturação em grupo menor do que os grupos de controle. Ou seja, o processo realizado com o auxílio do software foi mais rápido e completo ao aplicar-se a AEM.

O processo de trabalho da AEM possui um aspecto adicional, no que diz respeito a exigir respostas do grupo a cada etapa de discussão, criando um processo mais estruturado para a discussão em grupo. As opiniões da questão d) do questionário nos levam a crer que esta forma de trabalho possui vantagens em relação à forma desestruturada de discussão do grupo 
de controle. A análise desta questão mostra que $60 \%$ dos respondentes do grupo experimental discordaram totalmente da afirmação de que houve centralização da discussão em poucos indivíduos, enquanto que, no grupo de controle, houve um percentual de $45 \%$ de respondentes que discordam totalmente. Deve-se acrescentar, ainda, que $21 \%$ dos respondentes do grupo de controle concordaram em algum grau com tal afirmação, enquanto que o percentual correspondente para o grupo experimental cai para $11 \%$. Sabe-se que, em qualquer trabalho em grupo, existe uma grande tendência de um ou mais indivíduos monopolizarem as discussões (Warfield, 1976 apud Wright 1991). No entanto, o processo de AEM reduziu esta tendência no experimento, segundo a opinião dos participantes do grupo experimental.

Não foi caracterizada nas respostas a contribuição do uso da AEM quanto à questão do "acordo prático sobre a definição do formato do Mapa" (questão e), a concordância sobre "como o grupo distribui os objetivos entre as dimensões" (questão f) e a questão de se "O Mapa Estratégico refletiu a opinião do grupo sobre o exercício" (questão g). Embora o grupo experimental tenha sempre apresentado mais de $61 \%$ de concordância total ou parcial com estas afirmações, os grupos de controle foram sempre mais assertivos, com mais de $85 \%$ de concordância, predominando sempre a opção "concordo totalmente".

Considerando-se que a AEM reduziu a tendência à centralização da discussão em torno de um ou dois membros do grupo, algumas conclusões são possíveis:

a) O grupo de controle foi persuadido com mais convicção pelos seus líderes;

b) A AEM não conduz ao consenso e entendimento, o que contraria experimentos anteriores (e a literatura especializada sobre o tema);

c) A possibilidade de consenso dentro dos grupos experimentais foi prejudicada pela limitação de tempo disponível e pela limitação do software utilizado, que não permitiu a visualização do Mapa Estratégico acabado pelos grupos experimental, ao passo que os grupos de controle chegaram sempre a um desenho à mão do Mapa Estratégico.

A opção c parece mais plausível, o que nos leva à conclusão de que seria importante desenvolver uma versão aprimorada do software que permitisse automatizar a produção e manipulação dos modelos estruturais gerados. Desta forma, teríamos automaticamente a produção de um Mapa Estratégico inicial, passível de discussão, revisão e validação, imediatamente após ou durante a realização do trabalho em grupo. 


\subsection{Opinião dos participantes sobre a aplicação da AEM}

A terceira questão de apoio consistia em indagar a opinião dos grupos sobre a aplicação da AEM para a construção de mapas estratégicos. Devem ser destacadas duas respostas. Primeiramente, temos a questão $\mathbf{k}$ na qual 67,92\% dos respondentes do grupo experimental concordam (total ou parcialmente) que a AEM auxiliou o processo de construção de Mapas Estratégicos. Em segundo lugar, está a questão l, que apresenta a afirmação de que valeu a pena aplicar a ferramenta dentro do tempo proposto. O que torna esta questão merecedora de destaque é o fato de $73,58 \%$ dos participantes concordarem (parcial ou totalmente) com a pergunta. A boa avaliação da AEM pode ser evidenciada também pelos percentuais de discordância destas duas questões, já que os números são pequenos, se comparados com os comentários concordantes: na questão $\mathbf{k}$ os dois itens que representam os discordantes somam $13,21 \%$ enquanto que na questão $\mathbf{l}, 9,43 \%$ dos respondentes discordaram (total ou parcialmente) da afirmação.

A questão 6 para o grupo experimental consistia em perguntar, de forma direta, a opinião do grupo sobre o uso da AEM, que 44,23\% avaliaram como muito boa. Agrupando esta resposta com a segunda opinião da escala, a AEM recebe uma avaliação positiva de $78,85 \%$ dos respondentes, evidenciando que a ferramenta foi bem avaliada pelo grupo que trabalhou com ela. Neste momento, convém destacar algumas observações feitas pelos grupos experimentais em sala de aula, no momento de interação com os grupos de controle: mostrava-se mais prático e rápido resolver o exercício com o auxílio do software do que continuamente sujeitarse ao processo de iniciar e rejeitar múltiplas versões do mapa sobre o papel (perdendo o registro das análises anteriores) antes de atingir o formato desejado.

\subsection{Percepção da aprendizagem dos participantes}

A quarta e última indagação preparada para auxiliar esta pesquisa diz respeito à melhor evidência da percepção de aprendizagem dos integrantes do grupo com o uso da AEM. Apesar de positiva (o número de aprovações foi maior que o de discordâncias) a avaliação grupo de controle é mais convicta. Neste caso perguntou-se aos respondentes a respeito da percepção de aprendizagem da estratégia corporativa da empresa do caso em análise após a realização do exercício (questão h). Neste ponto, $80 \%$ dos respondentes do grupo de controle concordaram (total e parcialmente) que houve aumento da aprendizagem e do entendimento 
da estratégia após o exercício. No caso do grupo experimental, 64\% dos participantes responderam da mesma maneira. A avaliação da AEM a este respeito até foi positiva, mas não tanto quanto o grupo de controle. Para a pergunta feita exclusivamente ao grupo experimental (questão j), 54,72\% dos respondentes concordaram (parcial ou totalmente) com a afirmação. Tem-se aqui uma porcentagem também menor do que a apresentada pelo grupo de controle e até menor do que a apresentada pelo mesmo grupo experimental na questão $\mathbf{h}$.

Podem-se levantar alguns pontos a partir das informações apresentadas acima. A comparação com o grupo de controle nos mostra que a aplicação da AEM apresenta ganhos no processo de construção de um mapa estratégico, em especial porque AEM permite que o grupo que a usa trabalhe de forma mais estruturada do que o outro. Por outro lado, esta mesma comparação com o grupo de controle não forneceu evidências de que o uso da AEM pode trazer maiores benefícios em termos de reforço do entendimento da estratégia. É apresentada uma avaliação positiva dos participantes que usaram a AEM, mas com uma porcentagem inferior ao grupo de controle que resolveu o exercício por meio do papel.

\subsection{Considerações sobre a aplicabilidade da AEM}

O objetivo principal da pesquisa, apoiado por todos os itens comentados anteriormente, foi de investigar a aplicabilidade no uso do método AEM para auxiliar a elaboração de Mapas Estratégicos. A análise individual das respostas do questionário mostra que as opiniões dos dois grupos estudados são semelhantes, com uma pequena vantagem em termos de satisfação para o grupo de controle. A análise do grupo experimental, por sua vez, com base no uso da ferramenta AEM, foi positiva, com aceitação de que a ferramenta contribuiu para o sucesso da realização do exercício.

Em relação às respostas do questionário, observou-se em muitas ocasiões, no caso do grupo experimental, um número maior de respostas assinaladas em "concordo parcialmente" do que "concordo totalmente". Isso possivelmente resulta do formato de visualização permitido pelo software para mostrar o resultado final. Alguns participantes alegaram que seria preferível que o resultado fosse mostrado on-line. Esta crítica, na verdade, dirige-se ao resultado e não ao processo de discussão e utilização do método AEM - que, em si, foi avaliado positivamente. 
Além da avaliação dos questionários de ambos os grupos, realizou-se a análise dos Mapas Estratégicos produzidos pelos grupos. A questão de causa e efeito mostra-se mais evidente no grupo experimental, onde há um número maior de objetivos interligados, demonstrando que objetivos contribui para o que. No grupo de controle, foi mais freqüente encontrar objetivos apenas dispostos segundo as dimensões, sem mostrar como um dado objetivo contribuía para os demais objetivos e nem se ele era afetado por outro objetivo. O uso do AEM obrigou o grupo experimental a analisar todos os objetivos estratégicos e qual a ligação de cada um deles com os demais. Por sua vez, a análise do grupo de controle foi mais direcionada para a interação dos objetivos com o todo.

A ferramenta em si foi bem avaliada pelo grupo que a usou, além de apresentar resultados com Mapas Estratégicos mais detalhados. Mesmo que no acompanhamento dos questionários tenha mostrado desempenho de satisfação semelhante ao grupo de controle, os resultados da pesquisa mostram um caminho para o desenvolvimento de uma ferramenta de apoio para a concepção e acompanhamento da estratégia das empresas.

\subsection{Limitações e sugestões para novas pesquisas}

Algumas limitações encontradas dizem respeito à amostra obtida por conveniência e que, por isso, não pode ser considerada homogênea. Apesar de todos os respondentes fazerem parte, como alunos regulares, de programas de pós-graduação nos quais se exigem graduação completa e algum tempo de experiência profissional, uma análise mais profunda da amostra apontará diferentes níveis de experiência profissional, de experiência com a ferramenta e de níveis hierárquicos de atuação. Outro aspecto que contribui para o perfil não homogêneo da amostra é o fato de contarmos com a participação de uma turma in company formados por gerentes de uma indústria farmacêutica.

Por tratar-se de um experimento e por ter seu tempo de aplicação limitado, o grupo de controle não teve a possibilidade de observar em detalhe o processo de trabalho do grupo experimental e vice-versa, mas, em alguns momentos de interação, houve comentários por parte do grupo experimental no sentido de que é melhor trabalhar com o software do que ficar "escrevendo e apagando" diversas vezes no papel. Se fosse dada aos dois grupos a oportunidade de interagir e realizar comparações, um resultado conjunto poderia ser elaborado pelos dois tipos de grupos e seria possível extrair, a partir daí, uma nova discussão, 
com base na experiência que os respondentes teriam obtido dentro de suas respectivas possibilidades de experimentação.

As limitações de tempo e as decorrentes da forma pela qual o método foi escolhido para ser aplicado também devem ser citadas. Caso o tempo de aplicação do exercício fosse maior, seria possível trabalhar em um formato de workshop, no qual o resultado seria melhor trabalhado, para que os participantes analisassem o resultado e fizessem ajustes se fosse o caso. Esta fase é recomendada por Wright (1989, 1991, 1995), dado que, além de eventuais ajustes na estrutura, também é dada a oportunidade para que os participantes da discussão visualizem e reconheçam o resultado do grupo colocado no mapa. Presume-se, então, que, se os grupos experimentais tivessem a oportunidade de trabalhar com seus mapas em uma fase de retoque, os resultados seriam ainda mais condizentes com a opinião do grupo, que teria a oportunidade de trabalhar ainda mais com o mapa e, isto possivelmente, contribuiria para que a avaliação dos grupos experimentais em relação ao mapa e ao exercício fossem mais positiva nos questionários individuais.

O estado atual da AEM na forma de software ainda possui recursos a serem mais desenvolvidos em termos de relatórios e saídas (que atualmente precisam ser interpretadas). Esta limitação no software do método pode ter contribuído para uma menor avaliação da ferramenta no uso da construção de Mapas Estratégicos, já que o público pesquisado está acostumado a trabalhar com sistemas empresariais mais sofisticados e completos, contando com diversos relatórios/gráficos de apoio à decisão.

Diversas opções de novas pesquisas surgiram no decorrer da concepção e análise desta dissertação. Todas as sugestões devem possuir limitações e pontos críticos, mas podem ser desenvolvidas em um nível maior de profundidade em outra oportunidade.

Um dos temas está relacionado com a análise da aceitação (e boa avaliação) da AEM segundo o nível de experiência do respondente. Este corte de análise poderá contribuir para a verificação da questão de se quanto mais experiente for o profissional, mais facilmente este identifica que não será necessário o uso de ferramentas de apoio, uma vez que já está habituado a trabalhar sem auxílios. 
A sugestão de uma nova pesquisa se baseia na aplicação deste experimento em uma empresa que já emprega o BSC e Mapas Estratégicos. A eficácia da ferramenta poderia ser avaliada por meio da medição das diferenças entre o mapa anterior e aquele produzido pela AEM.

Outro aspecto está ligado a uma diferente categoria de experimento, na qual o grupo experimental fosse o próprio grupo de controle. Ou seja, no primeiro momento este grupo realizaria o exercício sem auxílio de software e, posteriormente, repetiria o exercício empregando a AEM como apoio. Assim, o mesmo grupo poderia estabelecer comparações entre os métodos.

Nas aplicações do experimento, a versão em software da ferramenta recebeu dos participantes da pesquisa diversas sugestões de melhorias. Algumas dessas podem contribuir substancialmente para sua melhoria, e uma nova versão desse software replicando este experimento pode trazer resultados até mais positivos na avaliação da ferramenta AEM. Algumas destas sugestões são baseadas no que foi ouvido dos alunos respondentes da pesquisa, com a redação e complementos do pesquisador.

Pelos resultados alcançados na pesquisa entende-se que existem evidências que apontam um caminho para o desenvolvimento de uma ferramenta de apoio para a concepção e acompanhamento da estratégia das empresas. A satisfação apontada em usar a AEM, principalmente se seu software passar por aprimoramentos, indica que existe uma opção interessante para o desenvolvimento do suporte ao gerenciamento de estratégias empresariais por meio da construção de Mapas Estratégicos.

\subsection{Considerações finais}

A aplicação da AEM mostrou-se útil para apoiar a elaboração de Mapas Estratégicos contribuindo para o alcance do consenso, por meio de um processo mais estruturado que viabiliza uma melhor participação individual na discussão em grupo. Os resultados mostraram que método AEM contribuiu também para a construção dos Mapas Estratégicos de forma mais completa explicitando as relações de causa e efeito entre os objetivos da empresa estudada. A ferramenta também auxiliou para que, mesmo analisando de forma mais completa todos os objetivos estratégicos do caso, fossem gerados Mapas Estratégicos mais rápidos do que os grupos que construíram seus mapas no papel. 
Esta contribuição da AEM encontrada na pesquisa poderá ser potencializada se o software que automatiza o método passar por alguns aprimoramentos, principalmente nos aspectos relacionados à apresentação gráfica dos resultados durante a discussão e construção do mapa. Outro aspecto para aproveitar todo o potencial do método é a condução da discussão, em um formato de um workshop, usando o tempo necessário para que os participantes verifiquem o resultado apresentado pelo software e providenciem eventuais ajustes do mapa.

Os resultados alcançados mostram que a continuidade desta linha de pesquisa pode trazer contribuições ao apoio no desenvolvimento e gerenciamento de estratégias e ao próprio desenvolvimento da AEM, em si, gerando aplicações a serem usadas para aumentar a competitividade de empresas brasileiras. 


\section{REFERÊNCIAS}

AHN, Heinz. Applying the Balanced Scorecard Concept: An Experience Report. Long Range Planning. n. 34, 2001.

ANSELMO, Estevão. Modelo de gestão não linear: a teoria do caos e complexidade aplicada à gestão de empresas de alto crescimento em ambientes dinâmicos e imprevisíveis. São Paulo, 2005. Tese (Doutorado em Administração) - Programa de Pós-Graduação em Administração, Faculdade de Economia, Administração e Contabilidade da USP.

BAKER, Michael J. Selecting a research methodology. The Marketing Review, v. 1, n. 3, p. 373-397, 2001.

BAKER, Michael J. Research methods. The Marketing Review, v. 3, n. 2, p. 167-193, 2002.

BATTELLE Institute. Portraits of Complexity: applications of Systems Methodologies to Societal Problems. n. 9, 1975.

BEBER, Sedinei; RIBEIRO, José Luiz; KLIEMANN, Francisco. Análise das causas do fracasso em implantações de BSC. Revista Produção Online. Florianópolis: UFSC, v.6, n. 2, 2006. Disponível em: www.producaoonline.ufsc.br. Acesso em 14/07/2008.

BOLAÑOS, Ricardo; FONTELA, Emilio; NENCLARES, Alfredo; PASTOR, Pablo. Using interpretive structural modelling in strategic decision-making groups. Management Decision. v. 43, n. 6, 2005.

CAMPBELL, Donald. T.; STANLEY, Julian C. Delineamentos experimentais e quaseexperimentais de pesquisa. São Paulo: EPU, 1979.

CAREW, Donald; PARISI-CAREW, Eunice. O gerente-minuto desenvolve equipes de alto desempenho. São Paulo: Record, 2007.

CASADO, Tânia. O Indivíduo e o Grupo: a chave do desenvolvimento. In: FLEURY, M. T. L. (Org.) As Pessoas na Organização. São Paulo: Gente, 2001.

CASTRO, Vicente; PROCHNIK, Victor; REZENDE, José Francisco; NOGUEIRA, Antônio. Uma Análise Empírica do Impacto do Balanced Scorecard sobre o Desempenho de Organizações Brasileiras. In: ENCONTRO DE ESTUDOS EM ESTRATÉGIA - 3Es, 4., 2009, Recife. Anais... Recife: ANPAD, 2009.

COOPER, Donald R. SCHINDLER, Pamela. Métodos de Pesquisa em Administração. Porto Alegre: Bookman, 2003.

COSTA, Ana Paula. Contabilidade Gerencial: um estudo sobre a contribuição do Balanced Scorecard. São Paulo, 2001. Dissertação (Mestrado em Controladoria e Contabilidade). Departamento de Contabilidade e Atuária, Faculdade de Economia, Administração e Contabilidade da Universidade de São Paulo. 
CUNHA, Maria Aparecida; MORGADO, Eduardo; REINHARD, Nicolau. Informática pública estadual: uma análise das preocupações estratégicas dos executivos. In: ENCONTRO ANUAL DA ANPAD, 20., 1996, Angra dos Reis. Anais... Angra dos Reis: ANPAD, 1996.

EDEN, C.; JONES, S.; SIMS, D. Thinking in organizations. Redwood Burn, 1979. apud RIEG, Denise L.; ARAUJO FILHO, Targino Mapas Cognitivos como ferramenta de estruturação e resolução de problemas: o caso da pró-reitoria de extensão da UFSCar. Gestão e Produção. v.10, n.2,p.145-162, ago. 2003.

FISCHMANN, Adalberto. Implementação de estratégias: identificação e análise de problemas. São Paulo, 1987. Tese de livre docência - Programa de Pós-Graduação em Administração, Faculdade de Economia, Administração e Contabilidade da Universidade de São Paulo.

GIL, Antonio Carlos. Como elaborar projetos de pesquisa. São Paulo: Atlas, 1987.

GORVETT, Rick; NINGWEI, Liu. Using Interpretive Structural Modeling to Identify and Quantify Interactive Risks. In: ASTIN COLLOQUIUM, 2007, Orlando. Anais... Orlando: Astin, 2007.

GRINBERG, Léon; SOR, Dario; BIANCHEDI, Elizabeth. Introdução às idéias de Bion: grupos, conhecimento, psicose, pensamento, transformações, prática psicanalítica. Rio de Janeiro: Imago, 1973. apud LUPOLI JUNIOR, José G. Impactos do comportamento de equipe na tomada de decisão estratégica: um experimento com grupos de trabalho. São Paulo, 2006. Tese (Doutorado em Administração) - Programa de Pós-Graduação em Administração, Faculdade de Economia, Administração e Contabilidade da Universidade de São Paulo.

HARDINGHAN, Alison. Trabalho em equipe. São Paulo: Nobel, 2002

HIKAGE, Oswaldo K.; SPINOLA, Mauro M.; LAURINDO, Fernando José B. Software de Balanced Scorecard: proposta de um roteiro para implantação. Produção. v. 16, n. 1, p. 140160, jan./abr. 2006.

HITT, Michael; IRELAND, R. Duane; HOSKINSSON, Robert. Administração Estratégica. São Paulo: Thomson Learning, 2008.

JHA, Kumar; DEVAYA, M. N. Modelling the risks faced by Indian construction companies assessing international projects. Construction Management and Economics. v. 26, 2008.

ILYAS, R.Mohammed; BANWET, D.K.; SHANKAR, Ravi. Interventional Roadmap for Digital Enablement Leading to Effective Value-chain Management in the Manufacturing Sector. Global Business Review. v. 207, n. 6, 2005.

ISM (Versão Windows) - Análise e Estruturação de Modelos (AEM). Versão 2.01. [S.I.]: James T. C. Wright, 2005.

KANAZAWA, Nobuaki; SASAHIRA, Toshiaki; KANEDA, Shigeo; HAGA, Hirohide.Automatic generation method of relation matrix for ISM. Frontiers in Artificial Intelligence and applications. JCKBSE, v.140, 2006. 
KAPLAN, Robert e NORTON, David. P. A estratégia em ação - Balanced Scorecard. Rio de Janeiro: Campus, 1997.

KAPLAN, Robert. Can bad things happen to good scorecards? Balanced Scorecard: insight, experience e ideas for strategy-focused organization report. Balanced Scorecard Report, v.1, n.1 e 2, p. 14-15, 1999.

KAPLAN, Robert e NORTON, David. P. Having Trouble With Your Strategy? Then map it. Harvard Business Review, v. 78, n. 5, p.167-176, sep./oct. 2000.

KAPLAN, Robert e NORTON, David. P. Mapas Estratégicos: convertendo ativos intangíveis em resultados tangíveis. Rio de Janeiro: Campus, 2004.

KERLINGER, Fred N. Metodologia da pesquisa em ciências sociais: um tratamento conceitual. São Paulo: EPU, 1980.

KRONMEYER FILHO, Oscar Rudy; KLIEMANN NETO, Francisco José; RIBEIRO, José Luiz Duarte. Gestão Estratégica e BSC: Gaps e Oportunidades de Melhoria. XXIV ENEGEP - Florianópolis, SC, Brasil, 03 a 05 de novembro de 2004.

LUPOLI JUNIOR, José G. Impactos do comportamento de equipe na tomada de decisão estratégica: um experimento com grupos de trabalho. São Paulo, 2006. Tese (Doutorado em Administração) - Programa de Pós-Graduação em Administração, Faculdade de Economia, Administração e Contabilidade da Universidade de São Paulo.

LEWIN, Kurt. Problemas de dinâmica de grupo. São Paulo: Cultrix, 1970. apud LUPOLI JUNIOR, José G. Impactos do comportamento de equipe na tomada de decisão estratégica: um experimento com grupos de trabalho. São Paulo, 2006. Tese (Doutorado em Administração) - Programa de Pós-Graduação em Administração, Faculdade de Economia, Administração e Contabilidade da Universidade de São Paulo.

MADIOLO, Adriana de Souza et al. Desenvolvimento e aplicação da metodologia baseada no Balanced Scorecard em uma empresa de logística. Anais do X SIMPEP Simpósio de Engenharia de Produção. Bauru: UNESP, 2003.

MARCONI, Marina; LAKATOS, Eva Maria. Fundamentos de Metodologia Científica. 5. ed. São Paulo: Atlas, 2003.

MARTINS, Roberto; MARQUITTI, Lígia. Desenvolvimento e Implementação de Balanced Scorecard numa unidade de uma Multinacional da Indústria Química: estudo de caso. In: XIII SIMPEP SIMPÓSIO DE ENGENHARIA DE PRODUÇÃO - SIMPEP, 13., 2006, Bauru. Anais... Bauru: UNESP, 2006.

MOORAJ, Stella; OYON, Daniel; HOSTETTLER, D. The balanced scorecard: a necessary good or an unnecessary evil? European Management Journal. v.17, n.5, oct., 1999.

NIVEN, Paul R. Balanced Scorecard passo-a-passo: elevando o desempenho e mantendo resultados. Rio de Janeiro: Qualitymark, 2005. 
NØRREKLIT, Hanne. The Balanced Scorecard: what is the score? A rhetorical analysis of the Balanced Scorecard. Accounting, Organizations and Society. n. 28. 2003.

OLIVEIRA, Maxwell. Balanced scorecard: uma análise da produção acadêmica brasileira na área de administração. Lavras, 2008. Dissertação (Mestrado em Administração). Departamento de Pós-Graduação da Universidade Federal de Lavras.

PAPALEXANDRIS, Alexandros; IOANNOU, George; PRASTACOS, Gregory; SODERQUIST, Klas Eric. An Integrated Methodology for putting the Balanced Scorecard into Action. European Management Journal. v.23, n. 2, 2005.

PIAPS. O Plano de Integração de Programas Sociais na Prevenção da Violência - PIAPS e o seu sistema de monitoramento e avaliação. São Paulo: FIA, 2002. Disponível em http://www.dominiopublico.gov.br/download/texto/pl000010.pdf Acesso em 17/09/2008.

PORTER, Michael. What is Strategy? Harvard Business Review. nov.dez,1996.

QUINN, James. Estratégias para Mudança. In: MINTZBERG Henry; QUINN, James. O processo da estratégia. Porto Alegre: Bookman, 3. ed. 2001.

RADUCZINER, Marcelo. Estudo de Benchmarking Gestão de Desempenho e Balanced Scorecard. Compass: Rio de Janeiro, 2006a.

RADUCZINER, Marcelo. Diferenciais, fatores de sucesso e tendências no uso do Balanced Scorecard. Apresentação realizada na FIAP. São Paulo, nov.,2006b.

RAMPERSAD, Hubert K. Total Performance Scorecard: Aligning Human Capital with Business Strategy and Ethics. Nanyang Business Review v. 4, n.1, 2005.

RAMPERSAD, Hubert K. Balanced scorecard pessoal. Rio de Janeiro: Qualitymark, 2006.

RAVI, V. SHANKAR, R. Analysis of interactions among the barriers of reverse logistics. Technological Forecasting and Social Change, v. 72, n. 8, 2005.

ROBBINS, Harvey. e FINLEY, Michael Por que as equipes não funcionam: o que não deu certo e como torná-las criativas e eficientes. Rio de Janeiro: Editora Campus, 1997.

SAGHEER, Silpa; YADAV, Surendra S.; DESHMUKH, S. G. An application of interpretative structural modeling of the compliance to food standards. International Journal of Productivity and Performance Management. v. 58, n. 2, 2009.

SATO, Carlos Eduardo Yamasaki; DERGINT, D. E. A.; HATAKEYAMA, Kazuo. Gerenciando Redes Colaborativas, Complexidade e Estratégias Tecnológicas em Integração de Sistemas. In: SEMINÁRIO LATINO-IBEROAMERICANO DE GESTIÓN TECNOLÓGICA - Altec, 11., 2005, Salvador. Anais... Salvador: Altec, 2005.

SCHOLEY, Cam. Strategy maps: a step-by-step guide to measuring, managing and communicating the plan. Journal of Business Strategy. v. 26, n. 3, 2005. 
TACHIZAWA, Takeshy; REZENDE, Wilson. Estratégia Empresarial: tendências e desafios. São Paulo: Makron Books, 2000. apud LUPOLI JUNIOR, José G. Impactos do comportamento de equipe na tomada de decisão estratégica: um experimento com grupos de trabalho. São Paulo, 2006. Tese (Doutorado) - Programa de Pós-Graduação em Administração, Faculdade de Economia, Administração e Contabilidade da USP.

THAKKAR, Jitesh; KANDA, Arun; DESHMUKH, S.G. Interpretive structural modeling (ISM) of IT-enablers for Indian manufacturing SMEs. Information Management \& Computer Security. v. 16, n. 2, 2008.

TÔRRES, José Júlio Martins. Teoria da complexidade: uma nova visão de mundo para a estratégia. In: ENCONTRO BRASILEIRO DE ESTUDOS DA COMPLEXIDADE, 2005, Curitiba. Anais... Curitiba: PUC/PR, 2005.

WARFIELD, John N. Societal systems, planning, policy and complexity. John Wyley and Sons. New York, 1976 apud WRIGHT, James Terence Coulter. Análise e estruturação de modelos (ISM) aplicado à selecção de projectos de pesquisa. In: SIMPÓSIO INTERNACIONAL DE COMUNICAÇÃO, SIGNIFICAÇÃO E CONHECIMENTO, 1989, Lisboa. Anais... Lisboa: Associação Portuguesa para o Desenvolvimento das Comunicações e Sociedade Portuguesa de Filosofia, 1989.

WARFIELD, John N. Science of Generic Design: Managing Complexity through Systems Design. Salinas: Intersystems Publications, 1990.

WRIGHT, James Terence Coulter. Análise e estruturação de modelos (ISM) aplicado à selecção de projectos de pesquisa. In: SIMPÓSIO INTERNACIONAL DE COMUNICAÇÃO, SIGNIFICAÇÃ̃ E CONHECIMENTO, 1989, Lisboa. Anais... Lisboa: Associação Portuguesa para o Desenvolvimento das Comunicações e Sociedade Portuguesa de Filosofia, 1989.

WRIGHT, James Terence Coulter. Contribuição à técnica de análise e estruturação de modelos (ISM) para o planejamento em grupo: uma abordagem de inferência lógica. São Paulo, 1991. Tese (Doutorado em Administração) Programa de Pós-Graduação em Administração, da Faculdade de Economia, Administração e Contabilidade da Universidade de São Paulo.

WRIGHT, James Terence Coulter. Análise e estruturação de modelos baseadas em inferência lógica: objetivos para o porto de Santos. RAUSP, São Paulo, v.30, n. 1, p. 90-96, jan./mar., 1995.

WRIGHT, James Terence Coulter. Planejamento e Gestão Estratégica na Indústria Farmacêutica. Revista Marketing Farmacêutico. n. 14. São Paulo, 2001.

WRIGHT, James Terence Coulter. SPERS, Renata Giovinazzo. O país no futuro: aspectos metodológicos e cenários. Estudos Avançados. São Paulo, v. 20, n. 56, jan./abr., 2006.

ZACARELLI, Sérgio. Estratégia e sucesso nas empresas. São Paulo: Saraiva, 2003. 


\section{APÊNDICE I - EXERCÍCIO DE APLICAÇÃO DO EXPERIMENTO}

\section{O Caso PROJ Engenharia S/A}

A PROJ é uma empresa especializada em prestação de serviços técnicos de gerenciamento de implantação de projetos. Dedica-se com exclusividade às atividades de gerenciamento, excluindo, portanto, os demais campos da engenharia, notadamente a construção, o projeto e a fabricação de equipamentos. Dentro de seu escopo de atividades, a PROJ está capacitada para oferecer os seguintes serviços:

- Gerenciamento global de programas, empreendimentos e obras;

- Desenvolvimento de planos gerenciais;

- Serviços de apoio ao gerenciamento;

- Gerenciamento da integração de pacotes tipo EPC (Engineering, Procurement, Construction) e Turn key; e

- Gestão de programas de concessão de serviços públicos.

Os maiores desafios estratégicos da empresa são: manter sua posição competitiva no mercado, consolidar estratégias de crescimento com diferenciação e reforçar a imagem de qualidade dos serviços prestados junto aos clientes e ao mercado.

Fundada na década de 70, com a finalidade de atuar como um corpo técnico de construtoras, a empresa possui em seu portfólio grandes empreendimentos brasileiros construídos nesse período, como a hidrelétrica Itaipu, a usina termonuclear Angra I, a implantação do Complexo de Carajás para a Vale, o projeto de saneamento Tietê I e II, e o Rodoanel Mário Covas, entre outros.

Em relação ao posicionamento de mercado, a PROJ vem se mantendo nos últimos anos entre as cinco melhores empresas no ranking de "Projetos \& Consultoria" publicado por uma conceituada revista do setor. Mais ainda, em 2006 foi eleita a "Gerenciadora do Ano", ou seja, a melhor empresa de gerenciamento de projetos do país. Em 2007, ocupou a quarta posição em faturamento entre as empresas de projetos e consultoria, sendo a única empresa cujo foco é exclusivamente gerenciamento de implantação de empreendimentos.

Sua estrutura organizacional compreende um presidente e quatro diretores técnicos aos quais se encontram ligados os vários gerentes de projetos. Observa-se no organograma a ocorrência de uma Diretoria Adjunta voltada exclusivamente para Gestão de Pessoas, o que demonstra que a PROJ considera seu capital humano como um fator de diferenciação em seu negócio.

A sede da PROJ é em São Paulo, mas possui diversas filiais situadas em importantes capitais brasileiras, que apóiam os escritórios dedicados aos projetos. Conta atualmente com cerca de 1.000 colaboradores, sendo aproximadamente a metade com nível superior - em sua maioria engenheiros (quase 90\%), além de arquitetos, economistas e administradores de empresa, distribuídos em diversas funções como fiscalização de obras, outros em inspeção de fornecimentos, planejamento e controle, entre outros.

Setores de atuação

Ao longo de sua história a carteira de clientes da PROJ migrou da iniciativa privada para os órgãos governamentais retornando posteriormente para o setor privado, situação que se 
mantém atualmente, com cerca de $40 \%$ clientes do setor público e $60 \%$ do setor privado. Em relação aos setores industriais e de infra-estrutura as participação acumulada dos valores dos contratos da PROJ por setor de atuação abrange pela ordem: mineração, saneamento, transporte/logística, energia, desenvolvimento urbano, meio ambiente, entre outros.

\section{A Estratégia}

A Diretoria da PROJ promove periodicamente reuniões de alinhamento estratégico com seus gerentes e coordenadores, a partir das quais são fornecidas e compartilhadas informações atualizadas da empresa quanto ao desempenho alcançado, às estratégias, e aos planos de desenvolvimento de negócios. As ações estratégicas são conduzidas principalmente pelos diretores, gerentes e coordenadores de projetos, que agregam os objetivos estratégicos da empresa aos objetivos operacionais dos projetos nos quais estão atuando.

A visão e a missão da empresa são continuamente divulgadas e praticadas por meio de um programa de gestão da qualidade que abrange não só as áreas diretivas e administrativas da empresa, mas também os contratos de prestação de serviços.

\section{Visão}

Posicionar-se entre os melhores do país em sua área de atuação, sendo reconhecido como um dos líderes do mercado de engenharia consultiva de implantações.

\section{Missão}

Prestar serviços de gerenciamento e de engenharia para empreendimentos além de promover iniciativas de negócios, com elevado padrão de qualidade a partir de abordagens diferenciadas.

\section{Diferenciação dos Serviços}

As ações estratégicas da empresa baseiam-se no marketing dos serviços de qualidade, com foco no Cliente, além de destacar seus Colaboradores como a chave do sucesso dessa estratégia. Seu conhecimento, foco no resultado e envolvimento são as bases para a diferenciação do serviço. A prestação de serviços técnicos de gerenciamento de empreendimentos diferenciados pela qualidade caracteriza-se a partir das seguintes ações:

- Capacitação intensiva de pessoal, com aporte de tecnologias sofisticadas;

- Desenvolvimento e soluções estruturadas para gestão do conhecimento;

- Implementação de soluções metodológicas avançadas alinhadas com os institutos internacionais (PMI);

- Melhoria contínua da qualidade dos serviços por meio de modernização tecnológica, uso intensivo de informática e aprimoramento dos processos;

- Foco no Cliente: reforço junto ao cliente da imagem de qualidade dos serviços prestados;

- Atendimento imediato às demandas com agregação de valor aos Clientes; e

- Implementação de soluções que possibilite ao Cliente atingir seus objetivos.

A PROJ, ao formular suas estratégias, leva em consideração não apenas as respectivas vantagens competitivas, mas também a sustentabilidade de cada segmento de atuação.

Faz parte da estratégia da empresa promover ações que aumentem sua competitividade nos setores de óleo e gás, transporte, indústria e gestão de utilidades e concessões. Por outro lado prevê-se maior atratividade nos setores de saneamento, desenvolvimento, e gestão de utilidades e concessões. 


\section{Objetivos Estratégicos}

Com a descrição da empresa e de uma visão sobre sua estratégia, apresenta-se a seguir sua lista de objetivos estratégicos.

\section{Objetivos Estratégicos da PROJ Engenharia S/A}

1. Alinhar metodologia de gerenciamento às metodologias preconizadas pelos institutos internacionais

2. Ampliar rede de relacionamento no setor de gerenciamento de empreendimentos

3. Aumentar a participação de mercado em volume e valor

4. Buscar maior retorno sobre o investimento

5. Buscar novas oportunidades em Clientes existentes

6. Buscar novas oportunidades com foco em novos Clientes

7. Cumprir com qualidade o escopo dos contratos atuais

8. Disseminar Cultura e Valores

9. Garantir a satisfação dos Clientes nos contratos existentes

10. Identificar "pessoal chave" e sucessores, capacitando-os para ocuparem cargos gerenciais

11. Implementar procedimentos de melhorias contínuas nos processos de prestação de serviços

12. Promover ações de comunicação institucional

13. Promover a gestão de pessoas com foco em capacitação de colaboradores

14. Promover a gestão de pessoas com foco em satisfação de colaboradores

15. Promover a gestão do conhecimento

Quadro 1: Lista de objetivos estratégicos da Proj.

\section{Exercício: Necessidade de aprimorar a implementação da estratégia}

Como acontece em muitas organizações, a implementação da estratégia é a etapa mais difícil do processo de Planejamento Estratégico no âmbito da PROJ. Isto pode ser explicado, em parte, pelo fato de que os colaboradores alocados nos projetos estejam mais envolvidos nas ações focadas no cumprimento do escopo contratual e menos nas ações de caráter estratégico.

Para promover a implementação das estratégias de modo mais abrangente dentro da organização, a PROJ vem incentivando a aplicação do Mapa Estratégico e do BSC Balanced Scorecard. Para auxiliar o início desta implementação, seu grupo deve construir um Mapa Estratégico a partir da lista de objetivos estratégicos e das demais informações fornecidas neste caso.

Bom trabalho! Dúvidas: dcarvalho@usp.br 


\section{APÊNDICE II - QUESTIONÁRIOS}

\section{Questionário (grupo de controle)}

\section{Número do seu grupo:}

Caro(a) aluno(a),

Por favor, responda às questões abaixo a respeito de seu perfil e suas impressões sobre este exercício. Estes dados serão manipulados apenas por mim com o único objetivo de analisá-los para a minha pesquisa. Somente informações consolidadas serão divulgadas. Obrigado!!

\section{Informações pessoais}

Idade:

$$
\text { Sexo ( ) Masculino ( ) Feminino }
$$

Empresa (opcional):

Setor da empresa:

Cargo:

Formação (graduação):

1. Qual o seu principal objetivo em fazer este MBA?

( ) Obter o título de Especialista

( ) Aprender novas técnicas e teorias

( ) Outros:

2. Qual o seu interesse na disciplina de Estratégia Competitiva?

( ) Cumprir o programa obrigatório do curso e ser aprovado na disciplina

( ) Explorar mais este assunto e utilizar seus conceitos profissionalmente

( ) Outros:

3. Avalie seu conhecimento e interesse sobre BSC e Mapas Estratégicos

( ) Teve contato pela $1^{\mathrm{a}}$ vez neste curso ou palestra

( ) Conhece o tema por meio de leituras ou contatos informais

( ) Já fez cursos/treinamentos sobre o tema

( ) Trabalha com a ferramenta e tem capacitação teórica e prática

4. A organização onde você trabalha utiliza Mapa Estratégico ou BSC?
( ) Utiliza ambos
( ) Não utiliza nenhum dos dois
( ) Somente o Mapa
( ) Somente o BSC
( ) Não sei

5. Já participou da construção de um Mapa Estratégico ou de um BSC antes?
( ) Sim, de ambos
( ) Sim, mas somente do Mapa

( ) Não, nenhum dos dois

( ) Sim, mas somente do BSC 
Dê sua opinião sobre o andamento e o resultado deste exercício

(Marque um "x" na opção que julgar mais adequada para cada uma das sentenças)

\begin{tabular}{|c|c|c|c|c|c|}
\hline & $\begin{array}{l}\text { Discordo } \\
\text { totalmente } \\
\text { (1) }\end{array}$ & $\begin{array}{l}\text { Discordo } \\
\text { parcialmente } \\
\text { (2) ou mais } \\
\text { discordo que } \\
\text { concordo }\end{array}$ & $\begin{array}{l}\text { Nem } \\
\text { concordo } \\
\text { nem } \\
\text { discordo } \\
(3) \\
\end{array}$ & $\begin{array}{l}\text { Concordo } \\
\text { parcialmente } \\
\text { (4) ou mais } \\
\text { concordo que } \\
\text { discordo }\end{array}$ & $\begin{array}{l}\text { Concordo } \\
\text { totalmente } \\
\text { (5) }\end{array}$ \\
\hline $\begin{array}{l}\text { a. Tive dificuldade em resgatar os } \\
\text { conceitos de estratégia para utilizar } \\
\text { neste exercício }\end{array}$ & & & & & \\
\hline $\begin{array}{l}\text { b. A interação e troca de idéias do } \\
\text { grupo contribuiu para a conclusão do } \\
\text { exercício }\end{array}$ & & & & & \\
\hline $\begin{array}{l}\text { c. Consegui contribuir com o que } \\
\text { considerei relevante/necessário à } \\
\text { discussão }\end{array}$ & & & & & \\
\hline $\begin{array}{l}\text { d. Poucos membros (ou um único } \\
\text { membro) monopolizaram a discussão }\end{array}$ & & & & & \\
\hline $\begin{array}{l}\text { e. O grupo entrou em um acordo } \\
\text { prático sobre a definição do formato } \\
\text { do Mapa }\end{array}$ & & & & & \\
\hline $\begin{array}{l}\text { f. Concordo como o grupo distribuiu } \\
\text { os objetivos entre as dimensões do } \\
\text { mapa }\end{array}$ & & & & & \\
\hline $\begin{array}{l}\text { g. O Mapa Estratégico refletiu a } \\
\text { opinião do grupo sobre o exercício }\end{array}$ & & & & & \\
\hline $\begin{array}{l}\text { h. Após a discussão e a construção } \\
\text { do Mapa, minha percepção sobre o } \\
\text { entendimento da estratégia descrita } \\
\text { do caso, aumentou }\end{array}$ & & & & & \\
\hline $\begin{array}{l}\text { i. Fiquei satisfeito(a) com o resultado } \\
\text { do exercício }\end{array}$ & & & & & \\
\hline
\end{tabular}

6. Vocês utilizaram alguma ferramenta ou método para a construção do Mapa Estratégico? Se sim, por favor, diga qual foi e na sua visão qual o procedimento utilizado. 


\section{QUESTIONÁRIO (grupo experimental)}

Número do seu grupo:

Caro(a) aluno(a),

Por favor, responda às questões abaixo a respeito de seu perfil e suas impressões sobre este exercício. Estes dados serão manipulados apenas por mim com o único objetivo de analisá-los para a minha pesquisa. Somente informações consolidadas serão divulgadas. Obrigado!!

\section{Informações pessoais}

Idade: Sexo ( ) Masculino ( ) Feminino

Empresa (opcional):

Setor da empresa:

Cargo:

Formação (graduação):

1. Qual o seu principal objetivo em fazer este MBA?

( ) Obter o título de Especialista

( ) Aprender novas técnicas e teorias

( ) Outros:

2. Qual o seu interesse na disciplina de Estratégia Competitiva?

( ) Cumprir o programa obrigatório do curso e ser aprovado na disciplina

( ) Explorar mais este assunto e utilizar seus conceitos profissionalmente

( ) Outros:

3. Avalie seu conhecimento e interesse sobre BSC e Mapas Estratégicos

( ) Teve contato pela $1^{a}$ vez neste curso ou palestra

( ) Conhece o tema por meio de leituras ou contatos informais

( ) Já fez cursos/treinamentos sobre o tema

( ) Trabalha com a ferramenta e tem capacitação teórica e prática

4. A organização onde você trabalha utiliza Mapa Estratégico ou BSC?
( ) Utiliza ambos
( ) Não utiliza nenhum dos dois
( ) Somente o Mapa
( ) Somente o BSC
( ) Não sei

5. Já participou da construção de um Mapa Estratégico ou de um BSC antes?

( ) Sim, de ambos ( ) Não, nenhum dos dois

( ) Sim, mas somente do Mapa

( ) Sim, mas somente do BSC 
Dê sua opinião sobre o andamento e o resultado deste exercício

(Marque um "x" na opção que julgar mais adequada para cada uma das sentenças)

\begin{tabular}{|c|c|c|c|c|c|}
\hline & $\begin{array}{l}\text { Discordo } \\
\text { totalmente } \\
\text { (1) }\end{array}$ & $\begin{array}{l}\text { Discordo } \\
\text { parcialmente } \\
\text { (2) ou mais } \\
\text { discordo que } \\
\text { concordo }\end{array}$ & $\begin{array}{l}\text { Nem } \\
\text { concordo } \\
\text { nem } \\
\text { discordo } \\
\text { (3) }\end{array}$ & $\begin{array}{l}\text { Concordo } \\
\text { parcialmente } \\
\text { (4) ou mais } \\
\text { concordo que } \\
\text { discordo }\end{array}$ & $\begin{array}{l}\text { Concordo } \\
\text { totalmente } \\
\quad(5)\end{array}$ \\
\hline $\begin{array}{l}\text { a. Tive dificuldade em resgatar os } \\
\text { conceitos de estratégia para utilizar } \\
\text { neste exercício }\end{array}$ & & & & & \\
\hline $\begin{array}{l}\text { b. A interação e troca de idéias do } \\
\text { grupo contribuiu para a conclusão } \\
\text { do exercício }\end{array}$ & & & & & \\
\hline $\begin{array}{l}\text { c. Consegui contribuir com o que } \\
\text { considerei relevante/necessário à } \\
\text { discussão }\end{array}$ & & & & & \\
\hline $\begin{array}{l}\text { d. Poucos membros (ou um único } \\
\text { membro) monopolizaram a } \\
\text { discussão }\end{array}$ & & & & & \\
\hline $\begin{array}{l}\text { e. O grupo entrou em um acordo } \\
\text { prático sobre a definiçãa do } \\
\text { formato do Mapa }\end{array}$ & & & & & \\
\hline $\begin{array}{l}\text { f. Concordo como o grupo } \\
\text { distribuiu os objetivos entre as } \\
\text { dimensões }\end{array}$ & & & & & \\
\hline $\begin{array}{l}\text { g. O Mapa Estratégico refletiu a } \\
\text { opinião do grupo sobre o exercício }\end{array}$ & & & & & \\
\hline $\begin{array}{l}\text { h. Após a discussão e a construção } \\
\text { do Mapa, minha percepção sobre o } \\
\text { entendimento da estratégia descrita } \\
\text { do caso, aumentou }\end{array}$ & & & & & \\
\hline $\begin{array}{l}\text { i. Fiquei satisfeito(a) com o } \\
\text { resultado do exercício }\end{array}$ & & & & & \\
\hline $\begin{array}{l}\text { j. A utilização da ferramenta AEM } \\
\text { auxiliou-me a compreender melhor } \\
\text { a estratégia descrita no caso }\end{array}$ & & & & & \\
\hline $\begin{array}{l}\text { k. A ferramenta de estruturação de } \\
\text { objetivos (AEM) auxiliou o } \\
\text { processo de construção dos Mapas }\end{array}$ & & & & & \\
\hline $\begin{array}{l}\text { 1. Valeu a pena utilizar a } \\
\text { ferramenta dentro do tempo } \\
\text { proposto ao exercício }\end{array}$ & & & & & \\
\hline
\end{tabular}


6. Qual sua opinião sobre a utilização da AEM neste exercício?

( ) Muito boa, auxiliou a fazer o exercício com mais qualidade do que faríamos sem a ferramenta

) Média, ajudou a fazer o exercício sem grandes vantagens em relação aos outros grupos

) Razoável, tentou orientar a condução do trabalho sem grande sucesso

) Ruim, explique:

7. Você conhece outra forma/método de construir Mapas Estratégicos? Se Sim, qual?

8. Se respondeu "sim" para a questão anterior, que avaliação você faz da AEM em comparação a este modelo?

Agradeço sua colaboração!! 
APÊNDICE III - FOLHA DE RESPOSTA

(somente para o grupo de controle)

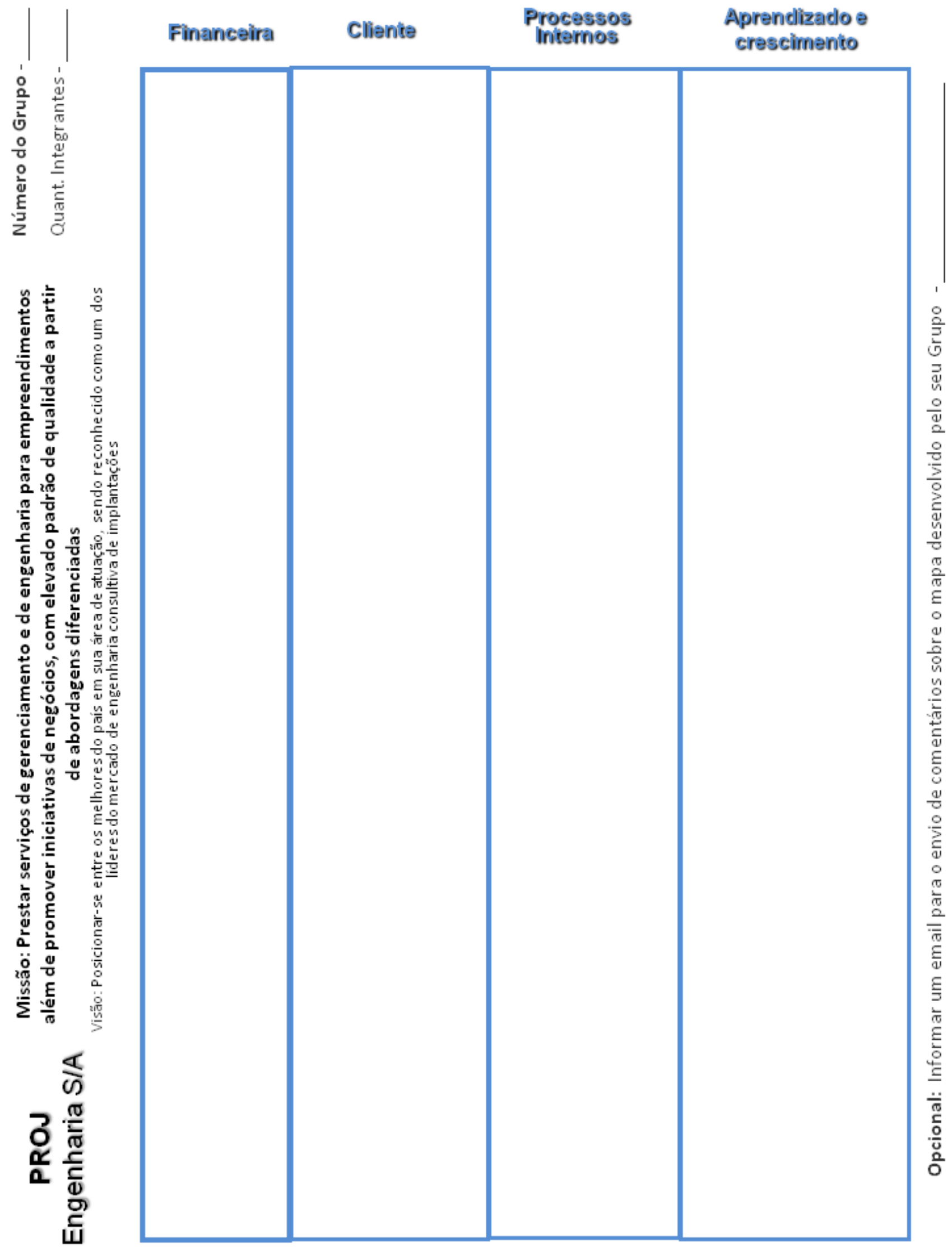


APÊNDICE IV - MAPAS PRODUZIDOS PELOS GRUPOS 


\section{Grupos de controle}

Lista de grupos

- FIA: MBA Executivo Internacional, Turma 36 - Grupo 1

- FIA: MBA Executivo Internacional, Turma 36 - Grupo 2

- FIA: MBA Executivo Internacional, Turma 36 - Grupo 4

- FIA: MBA Executivo Internacional, Turma 35 - Grupo 3

- FIA: MBA Executivo Internacional, Turma 35 - Grupo 4

- FIA: MBA Executivo Internacional, Turma 35 - Grupo 5

- FIA: International MBA - Grupo 1

- FIA: International MBA - Grupo 2

- FIA: Especialização em Gestão Estratégica - Grupo 3

- Mackenzie - Grupo 2

- UNIP - Grupo 2 


\section{FIA - MBA Executivo Internacional T36 - grupo 1}






\section{FIA - MBA Executivo Internacional T36 - grupo 2}

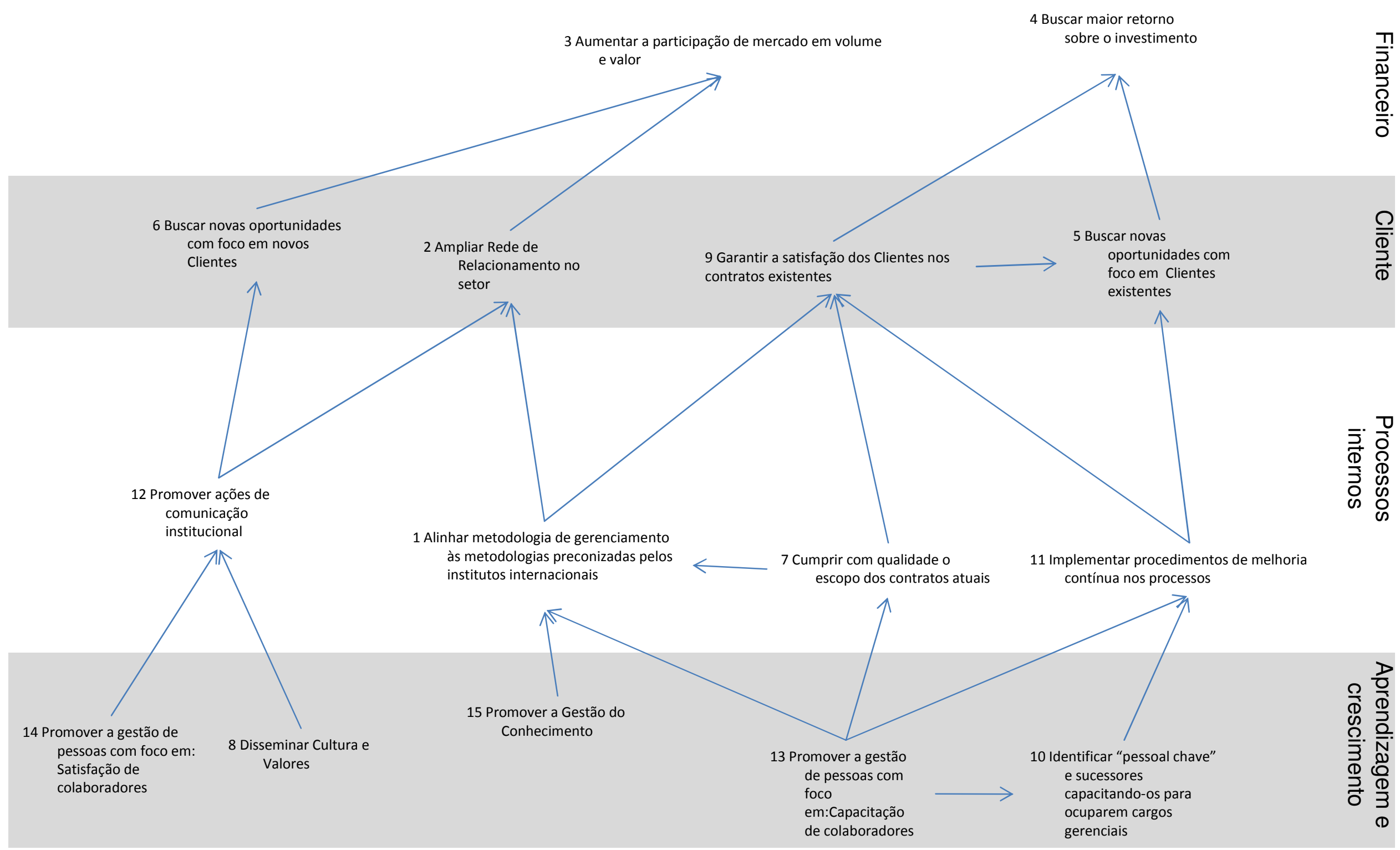


FIA - MBA Executivo Internacional T36 - grupo 4

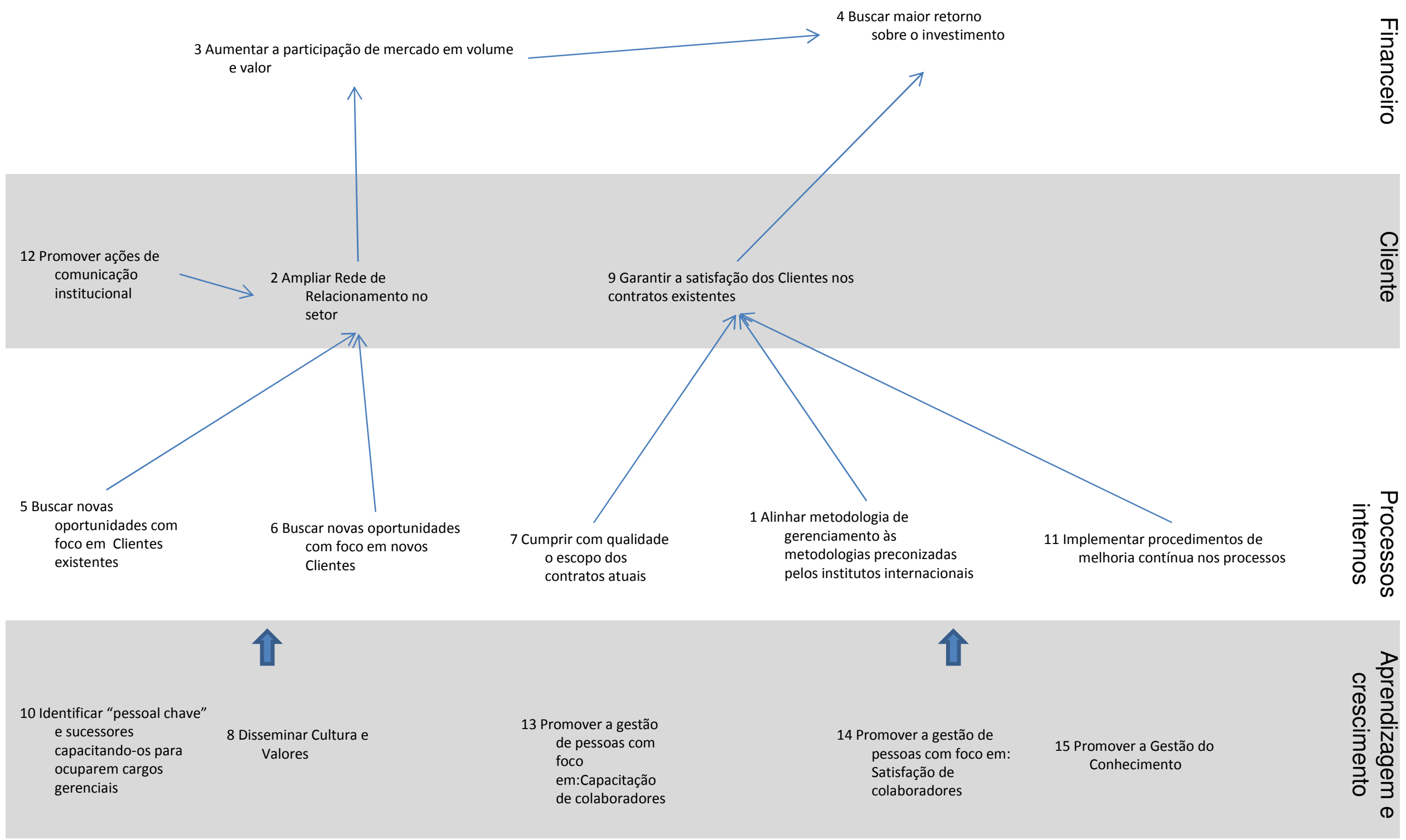


FIA MBA Executivo Internacional T35 -

\section{grupo3 \\ Estratégia de \\ Crescimento}

3 Aumentar a participação de mercado em volume

e valor

\section{Estratégia de \\ Produtividade}

4 Buscar maior retorno

sobre o investimento

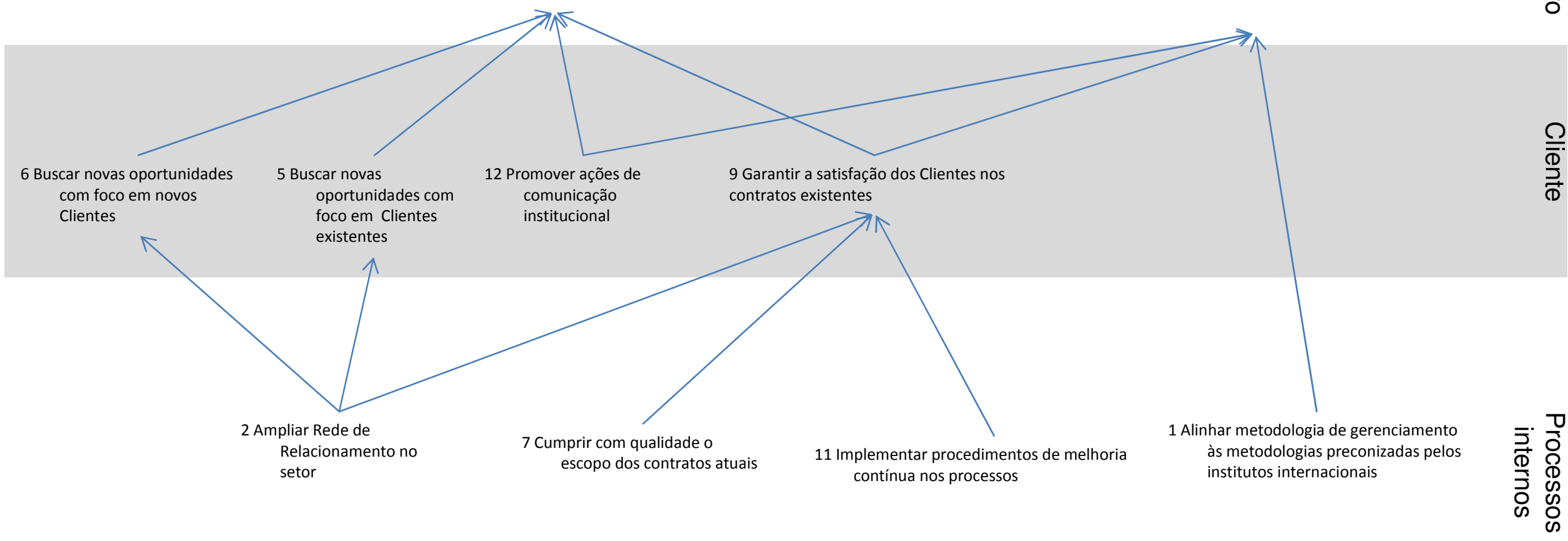

13 Promover a gestão de pessoas com foco

em:Capacitação de colaboradores
15 Promover a Gestão do Conhecimento
8 Disseminar Cultura e Valores
10 Identificar "pessoal chave" e sucessores

capacitando-os para

ocuparem cargos

gerenciais
14 Promover a gestão de pessoas com foco em Satisfação de colaboradores 
FIA MBA Executivo Internacional T35 - grupo 4
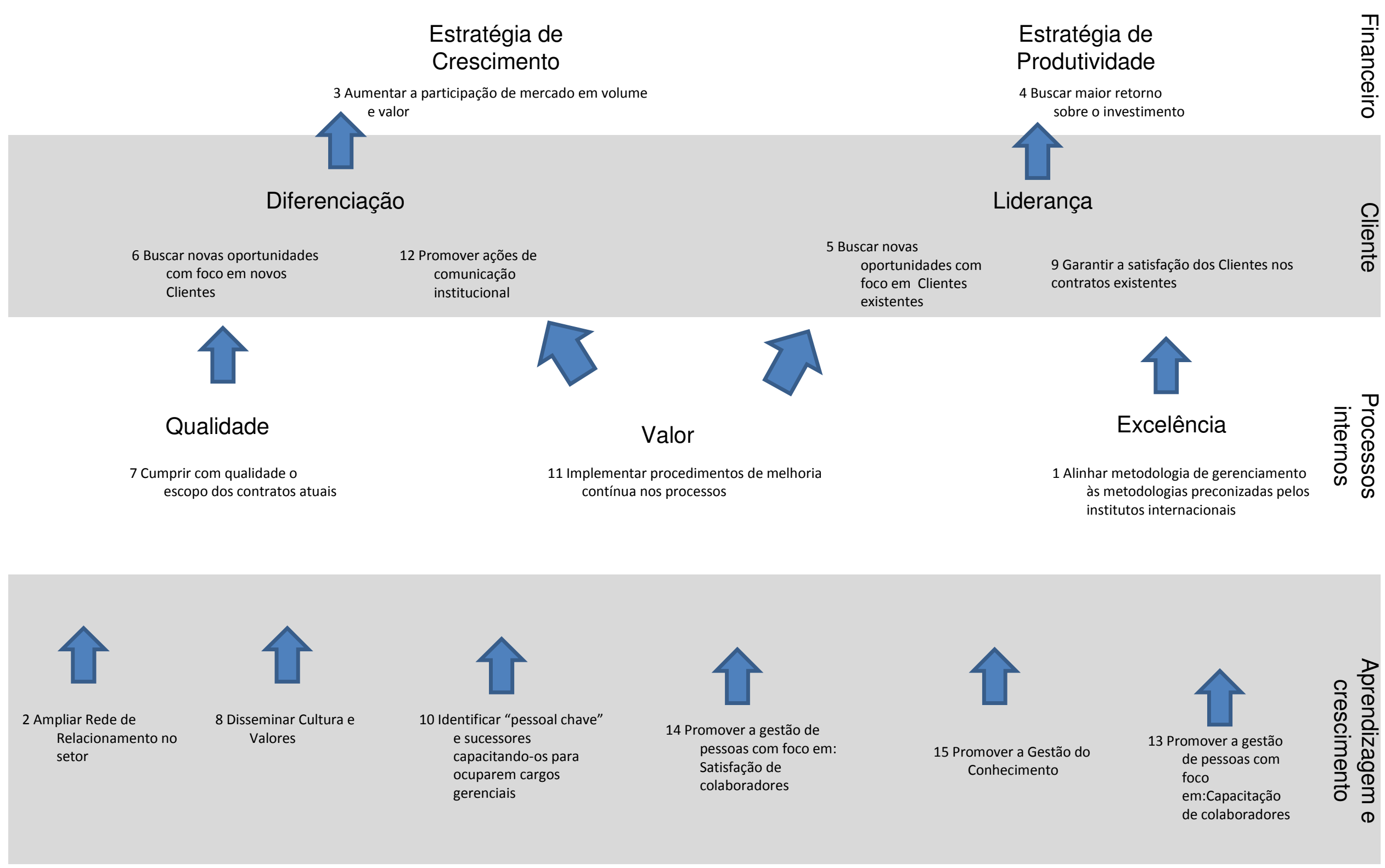
FIA MBA Executivo Internacional T35 - grupo5

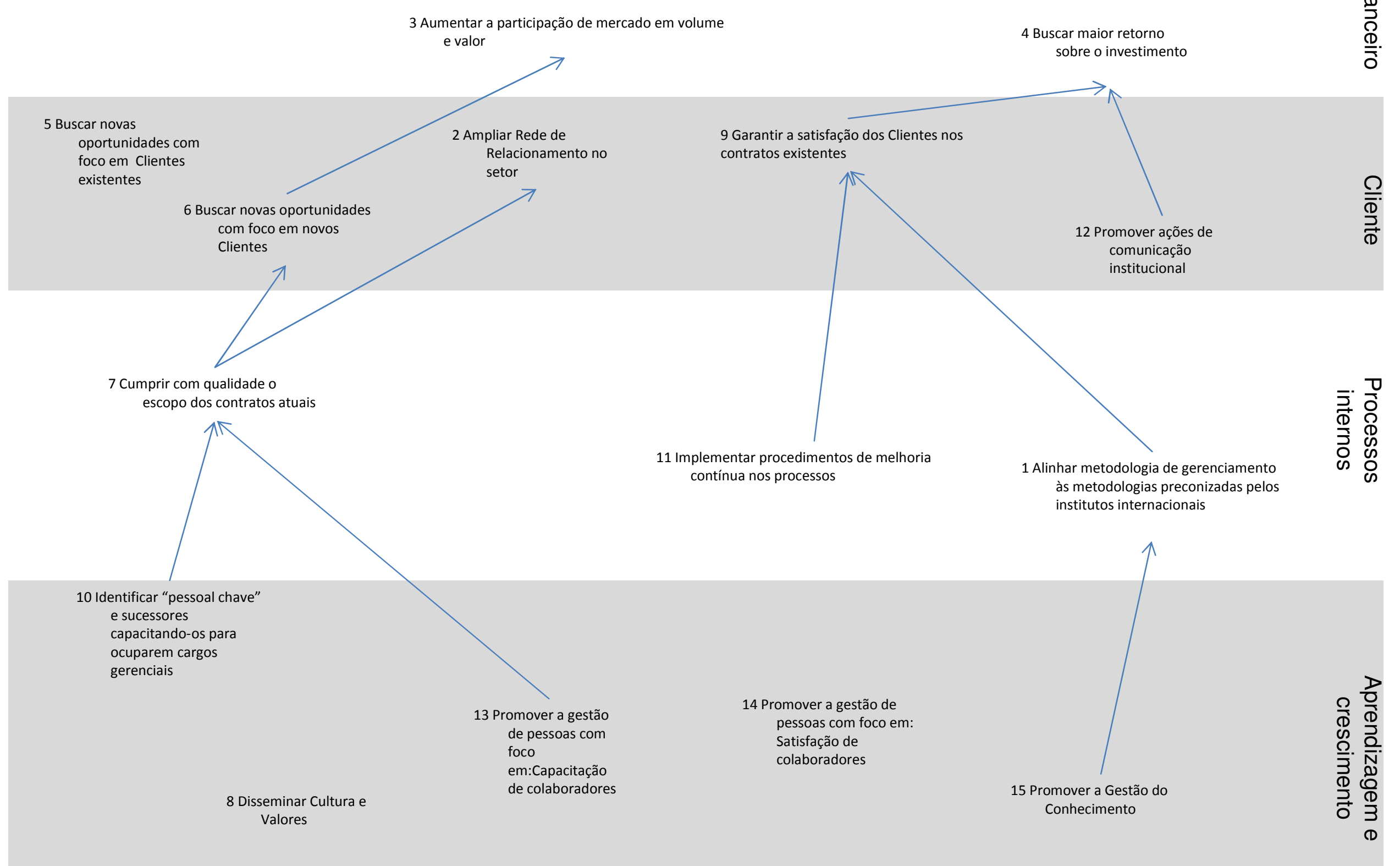




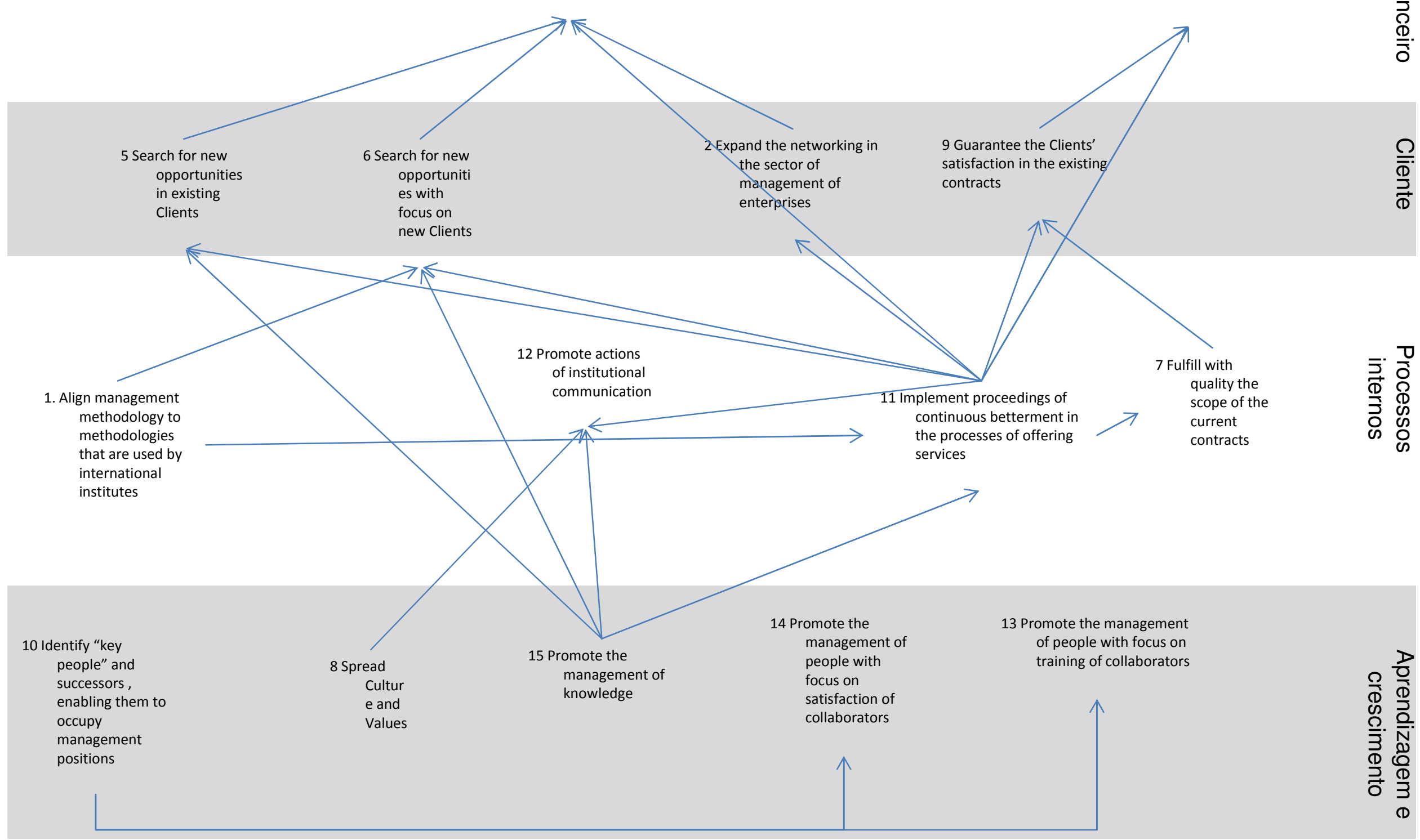


FIA - International MBA - grupo 2

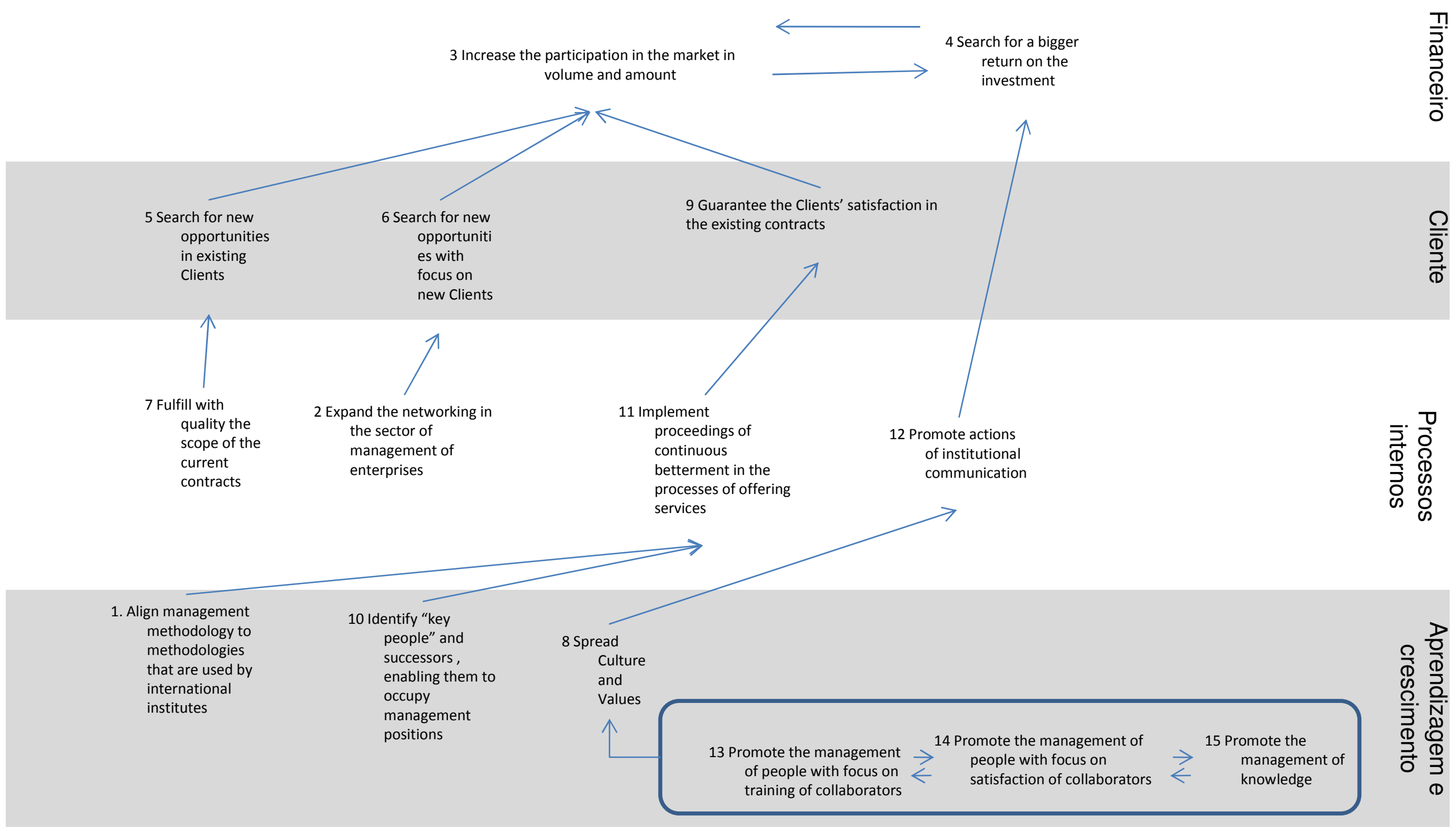


FIA Especialização - grupo 3

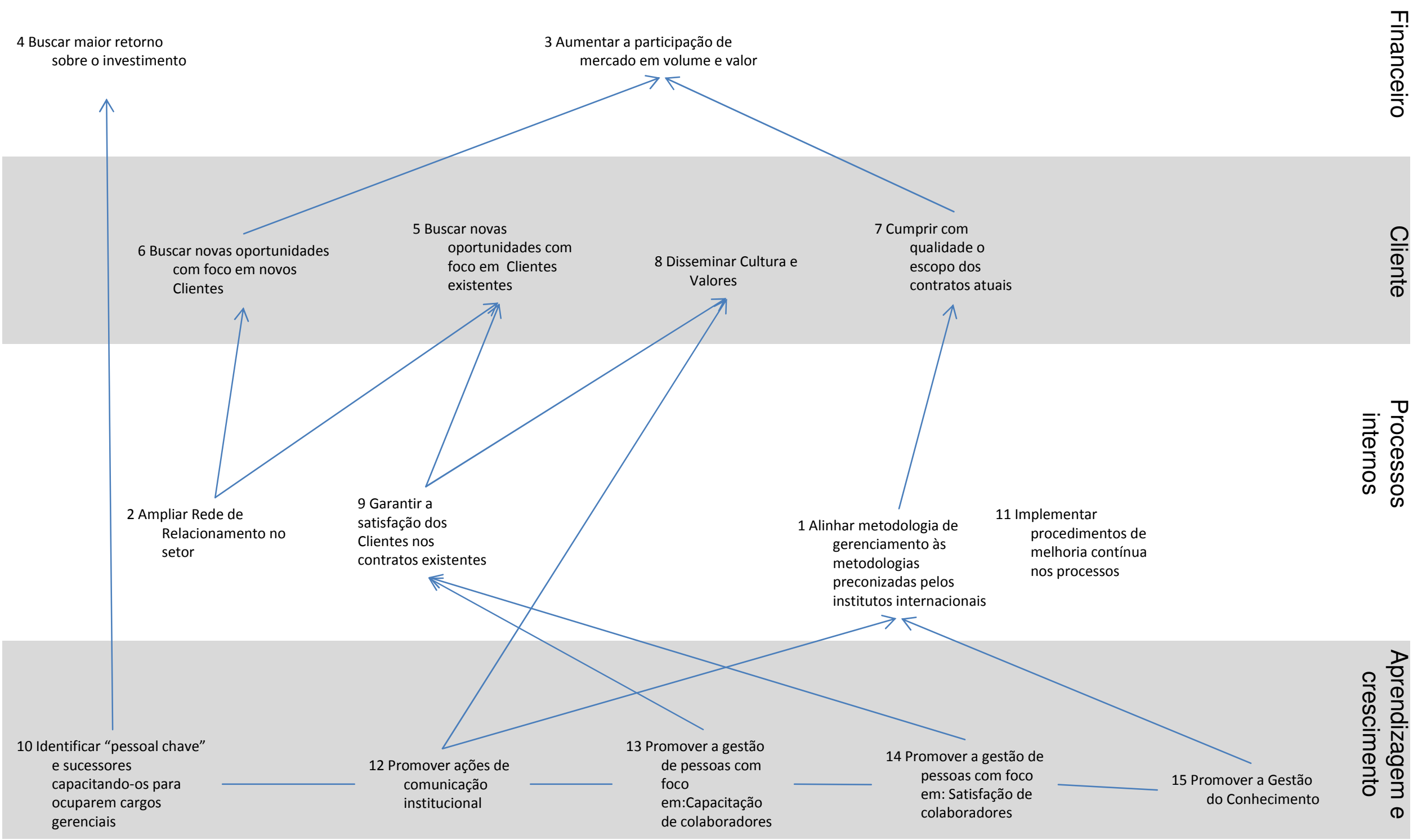




\section{Mackenzie - grupo 2}

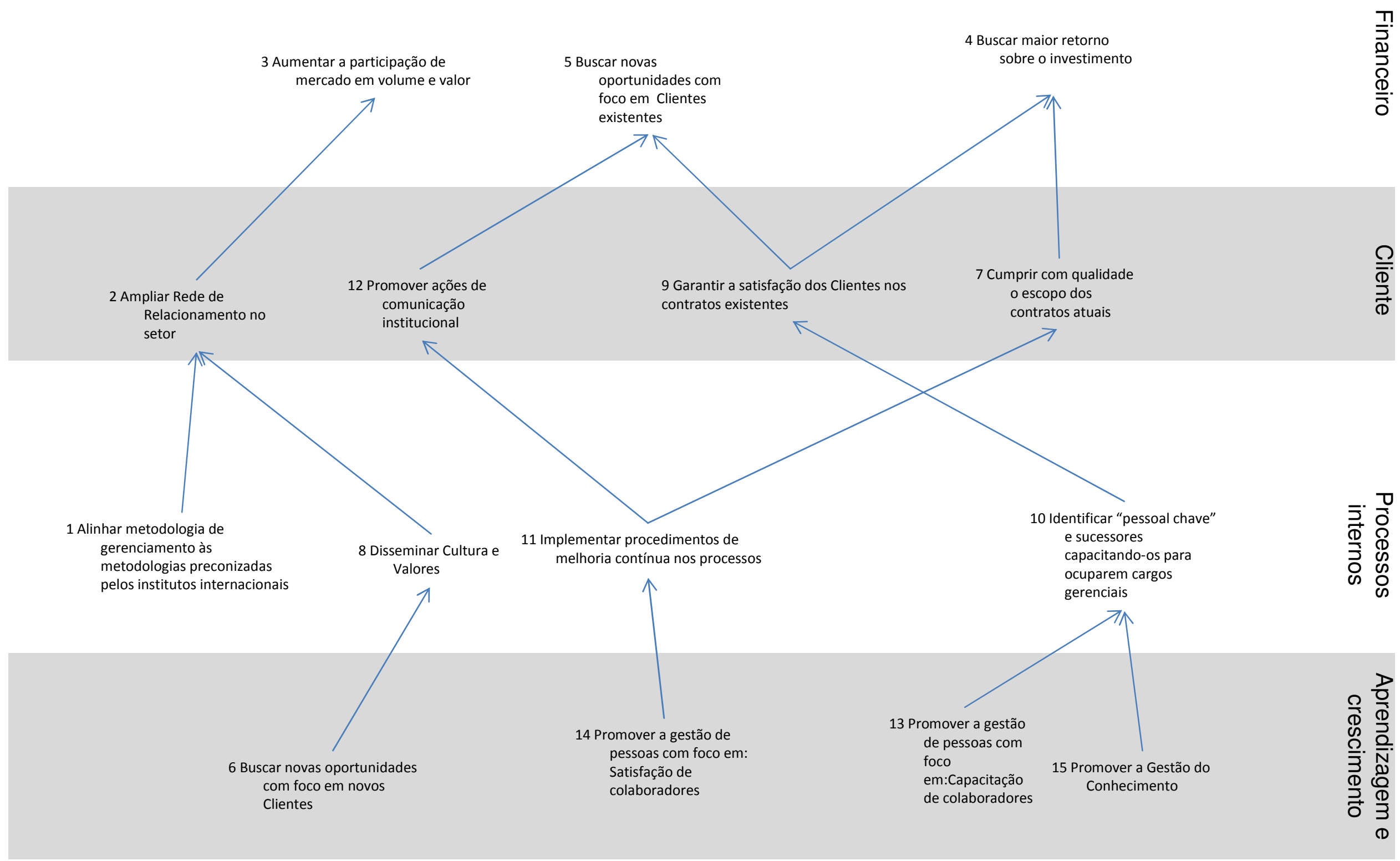




\section{Unip - grupo 2}

4 Buscar maior retorno

sobre o investimento

3 Aumentar a participação de

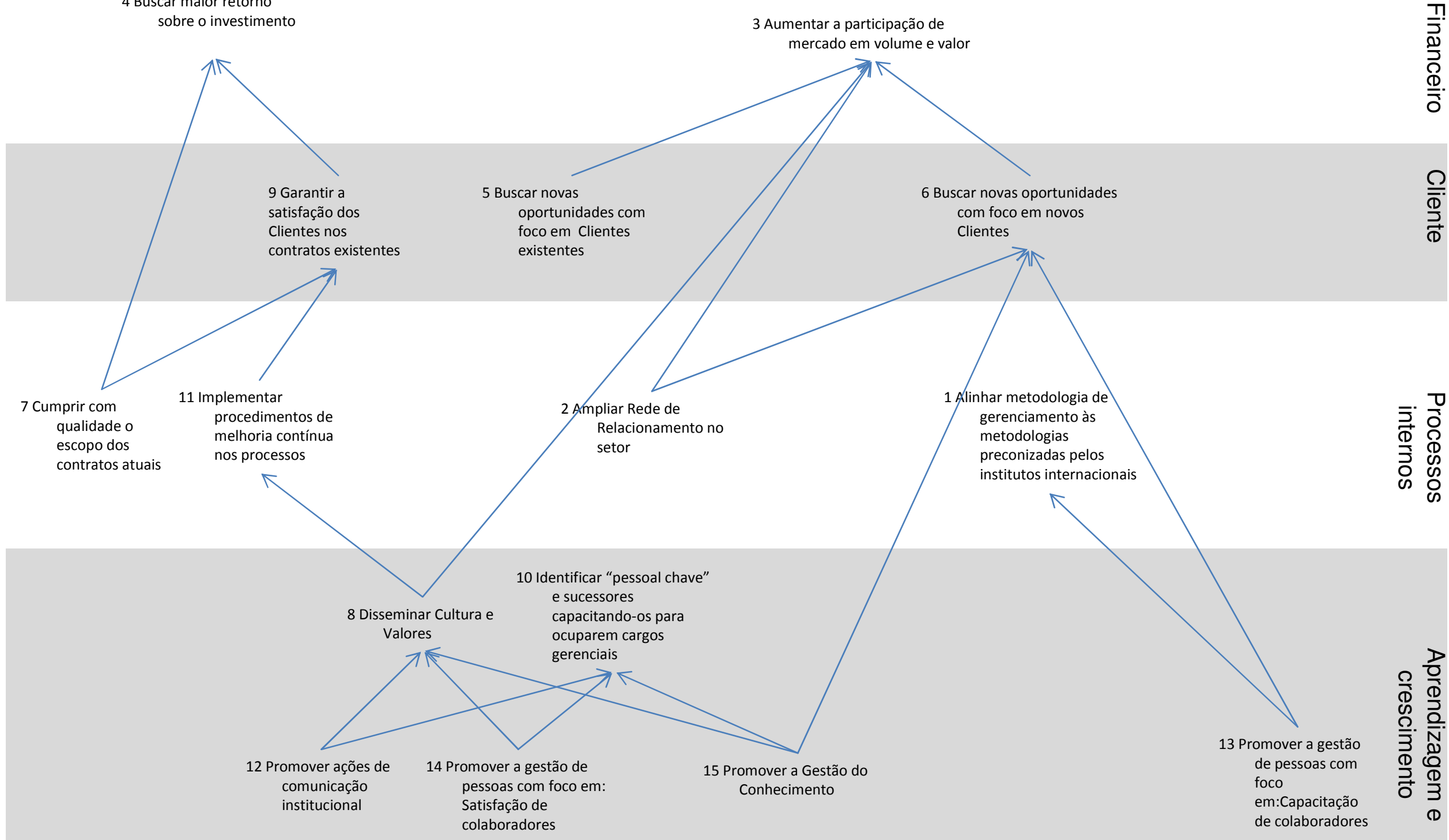




\section{Grupos experimentais}

Lista de grupos

- FIA: MBA Executivo Internacional, Turma 36 - Grupo 3

- FIA: MBA Executivo Internacional, Turma 36 - Grupo 5

- FIA: MBA Executivo Internacional, Turma 35 - Grupo 1

- FIA: MBA Executivo Internacional, Turma 35 - Grupo 2

- FIA: International MBA - Grupo 3

- FIA: International MBA - Grupo 4

- FIA: Especialização em Gestão Estratégica - Grupo 1

- FIA: Especialização em Gestão Estratégica - Grupo 2

- Mackenzie - Grupo 2

- UNIP - Grupo 2 


\section{AEM FIA - MBA Executivo Internacional T36 - grupo 3}

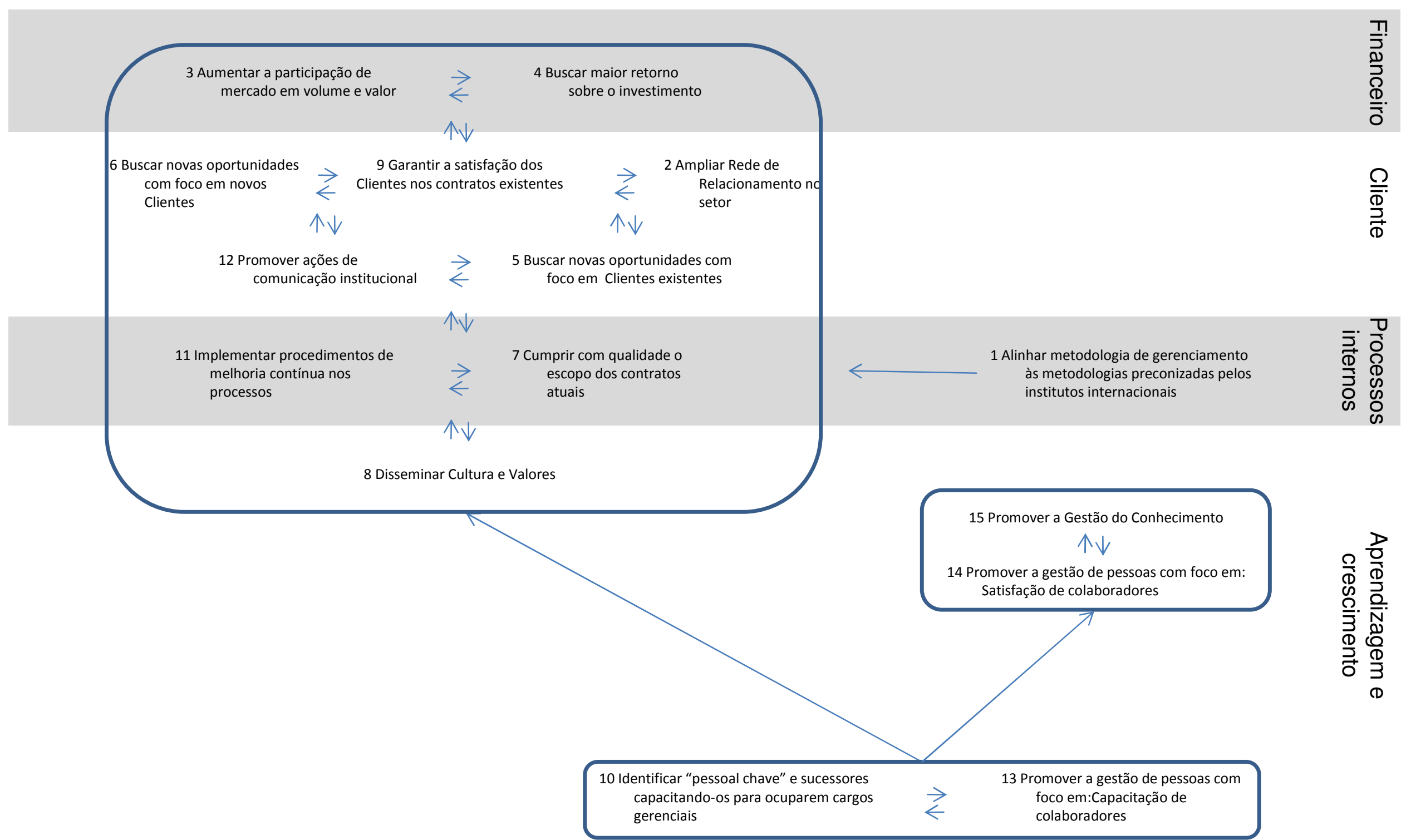




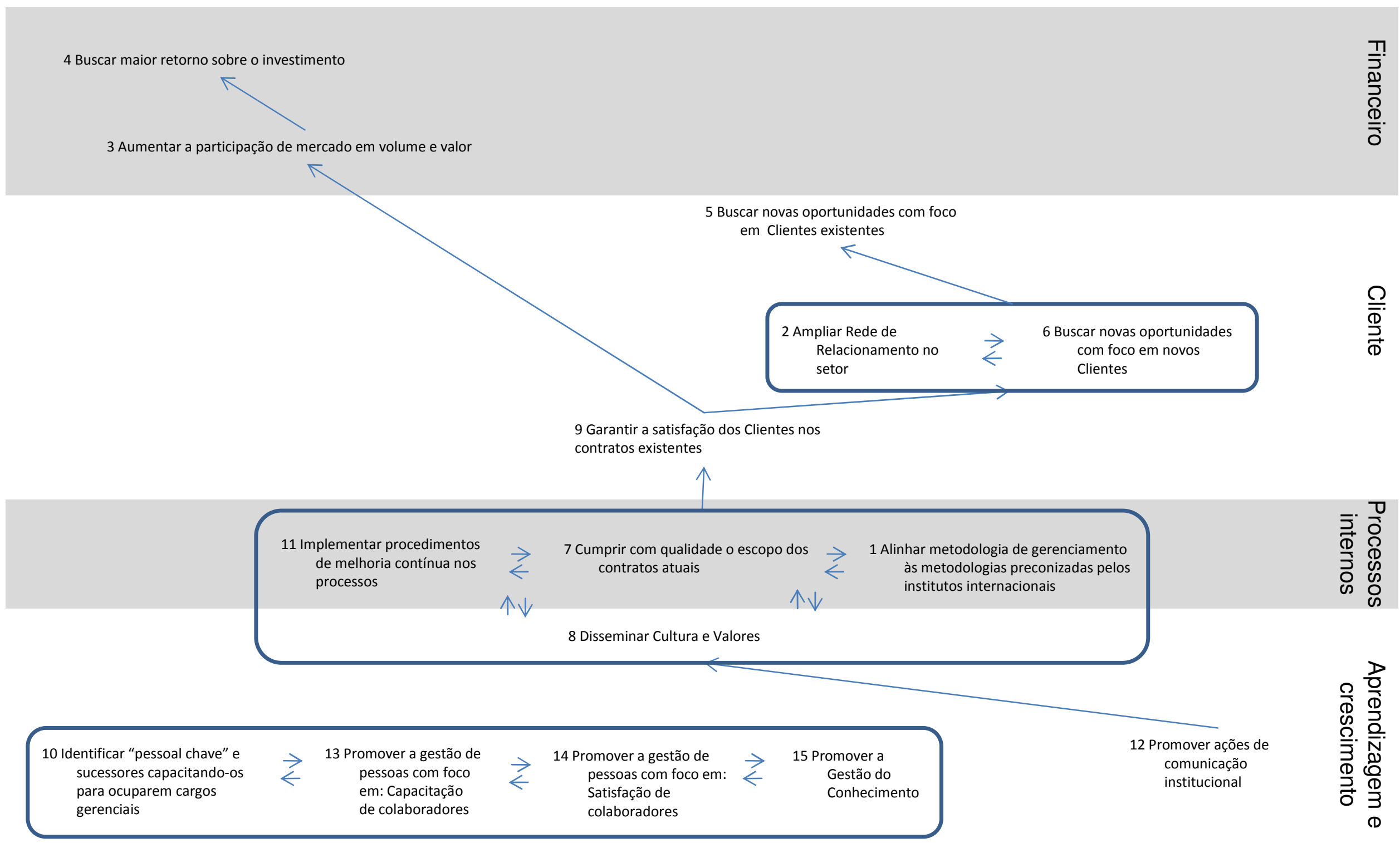




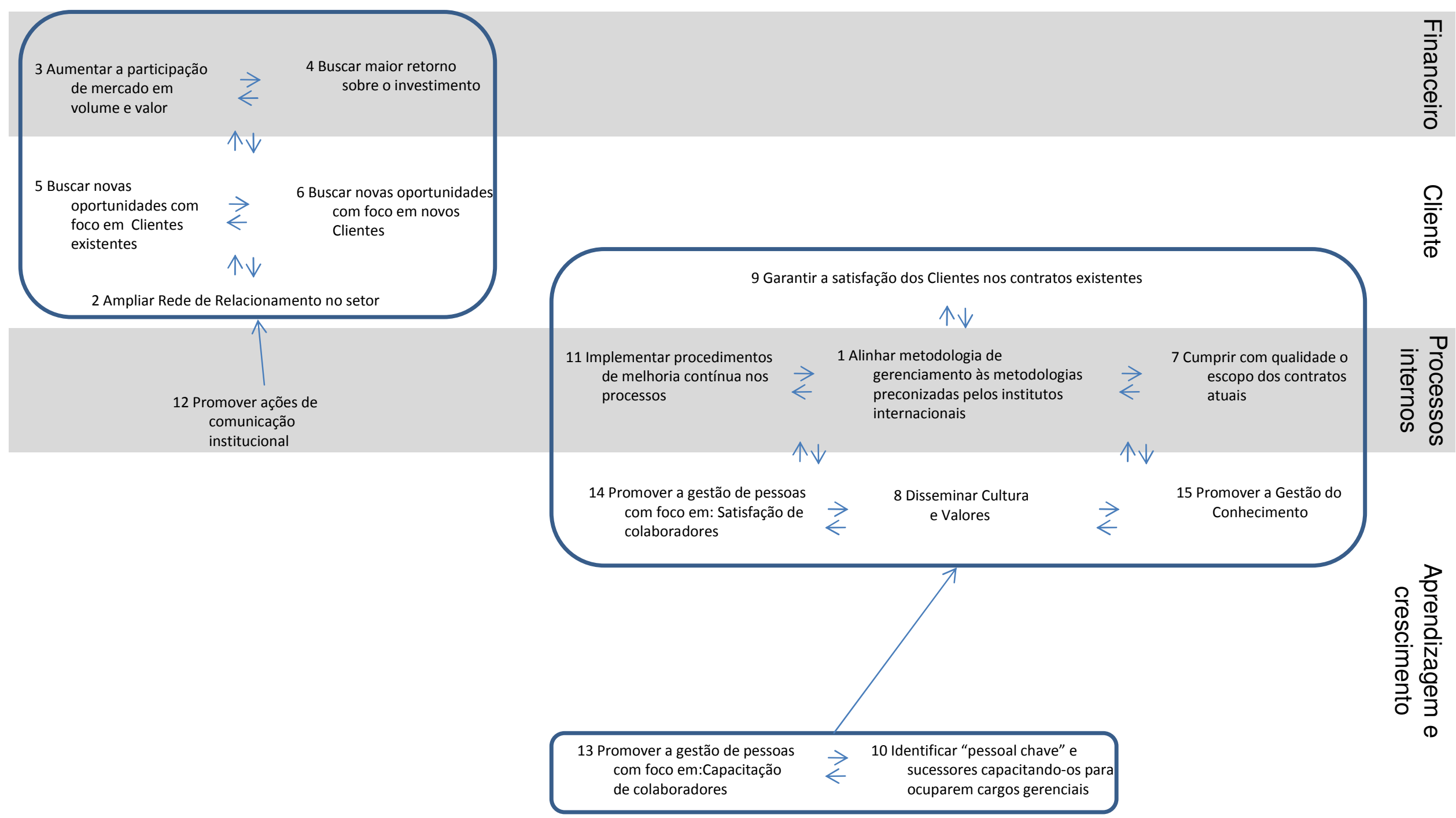




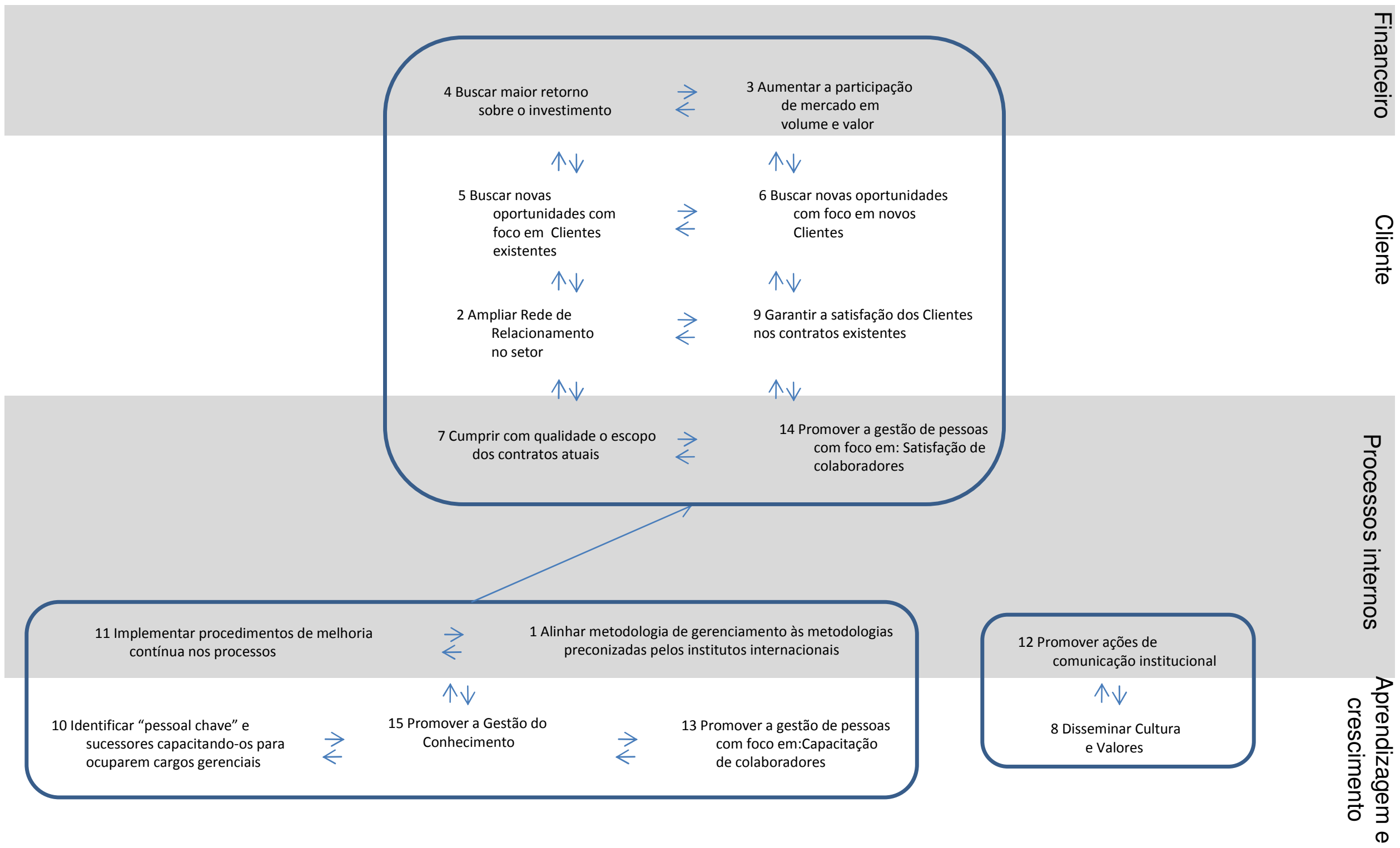




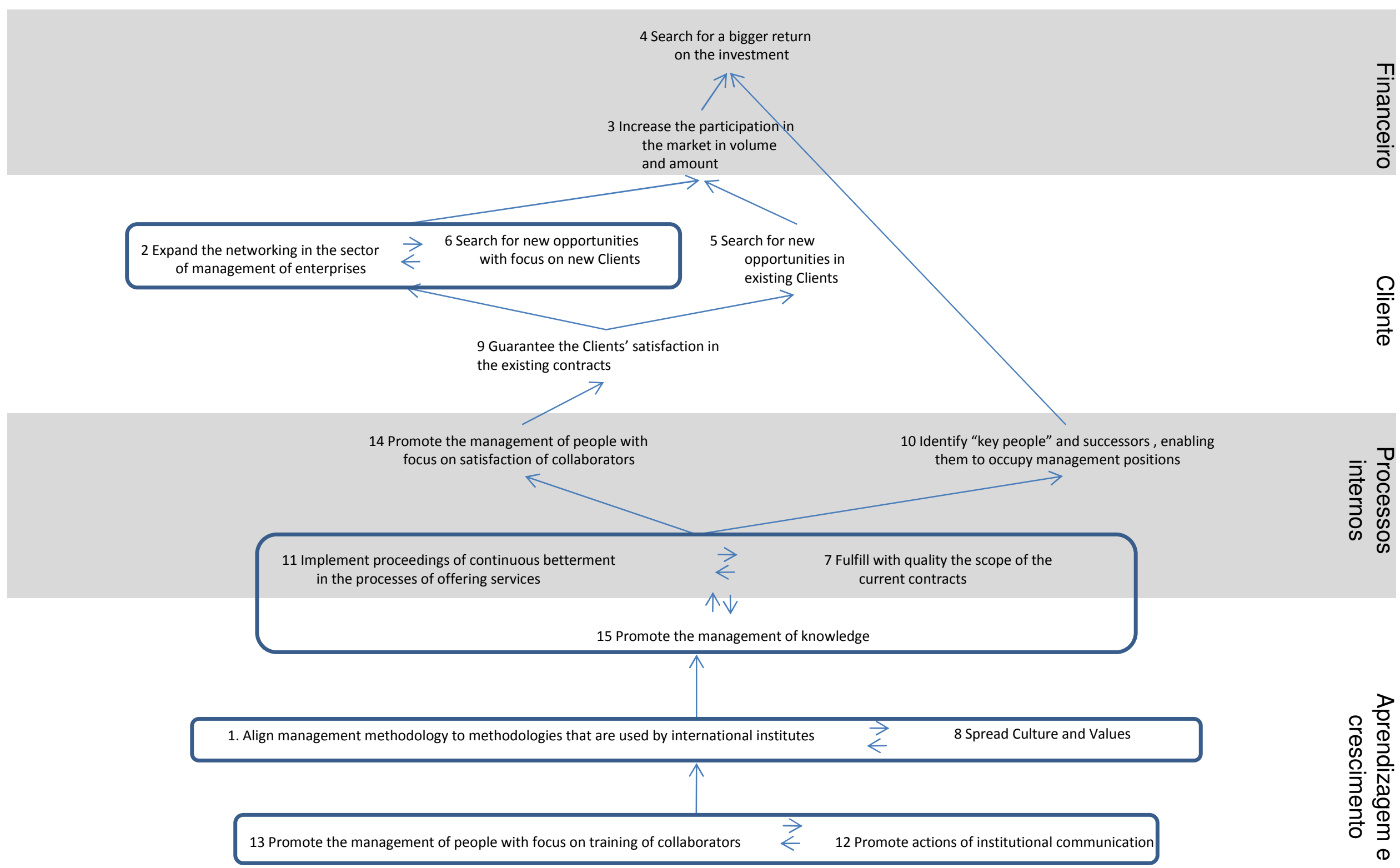




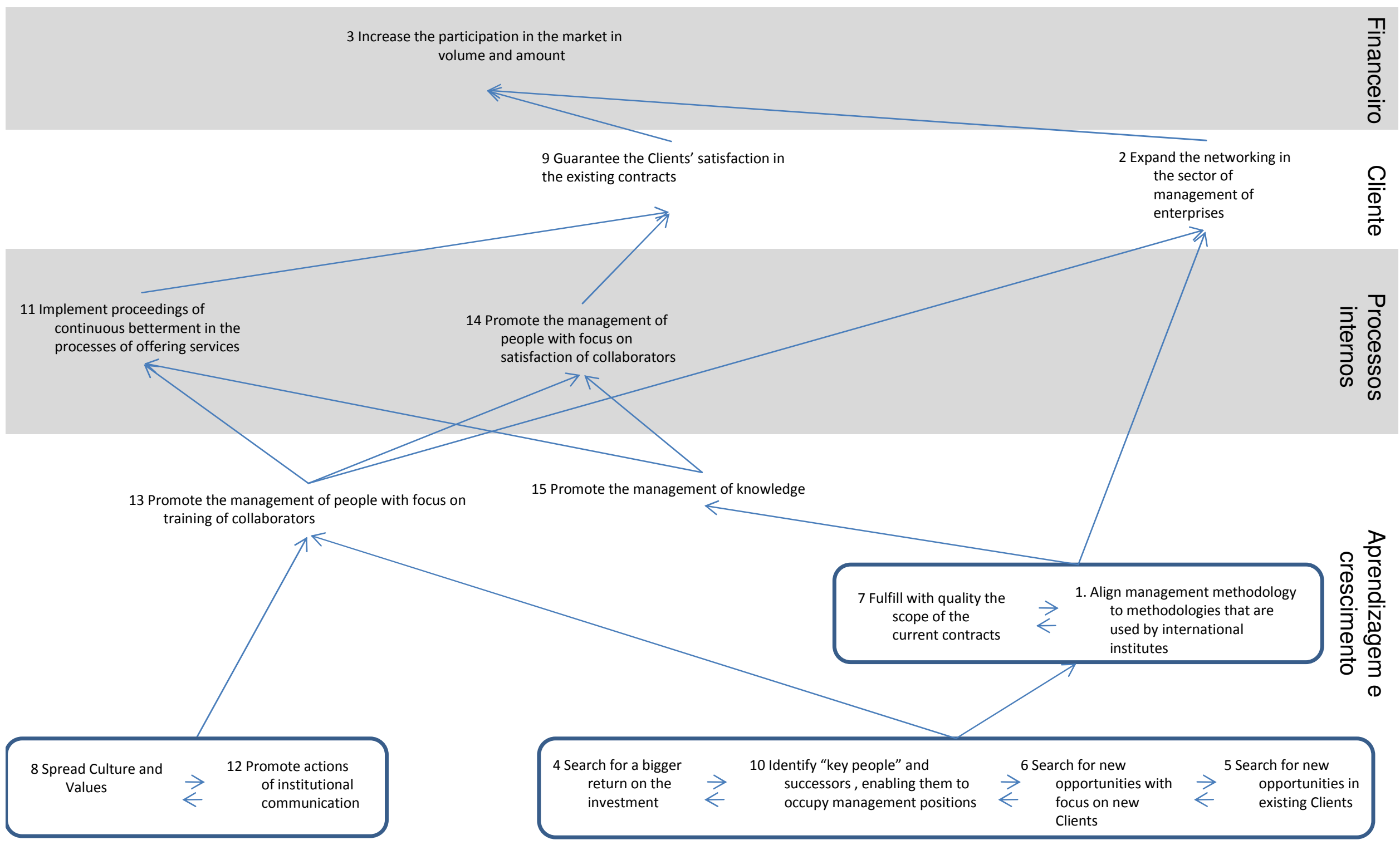




\section{AEM}

FIA Especialização-grupo 1

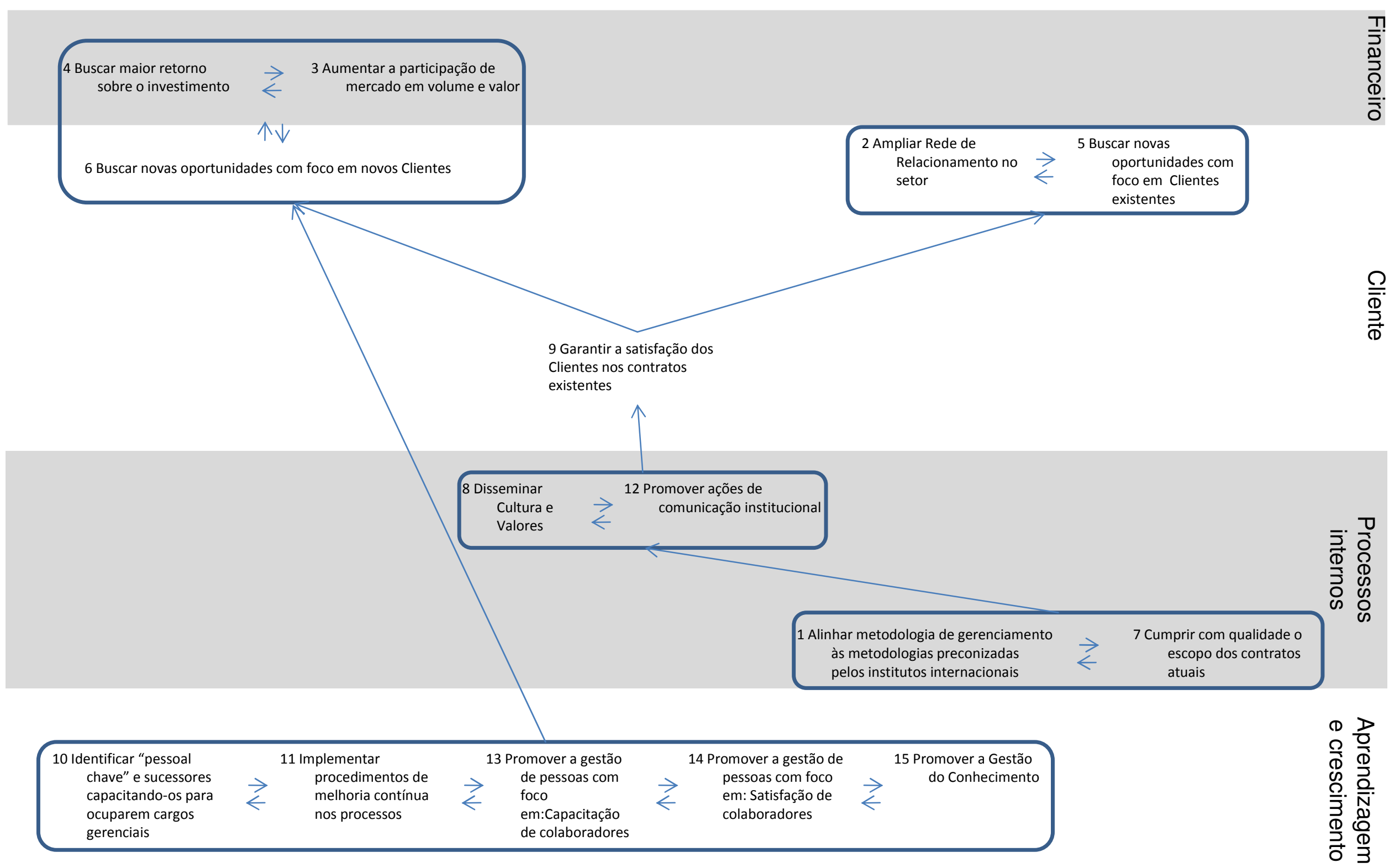




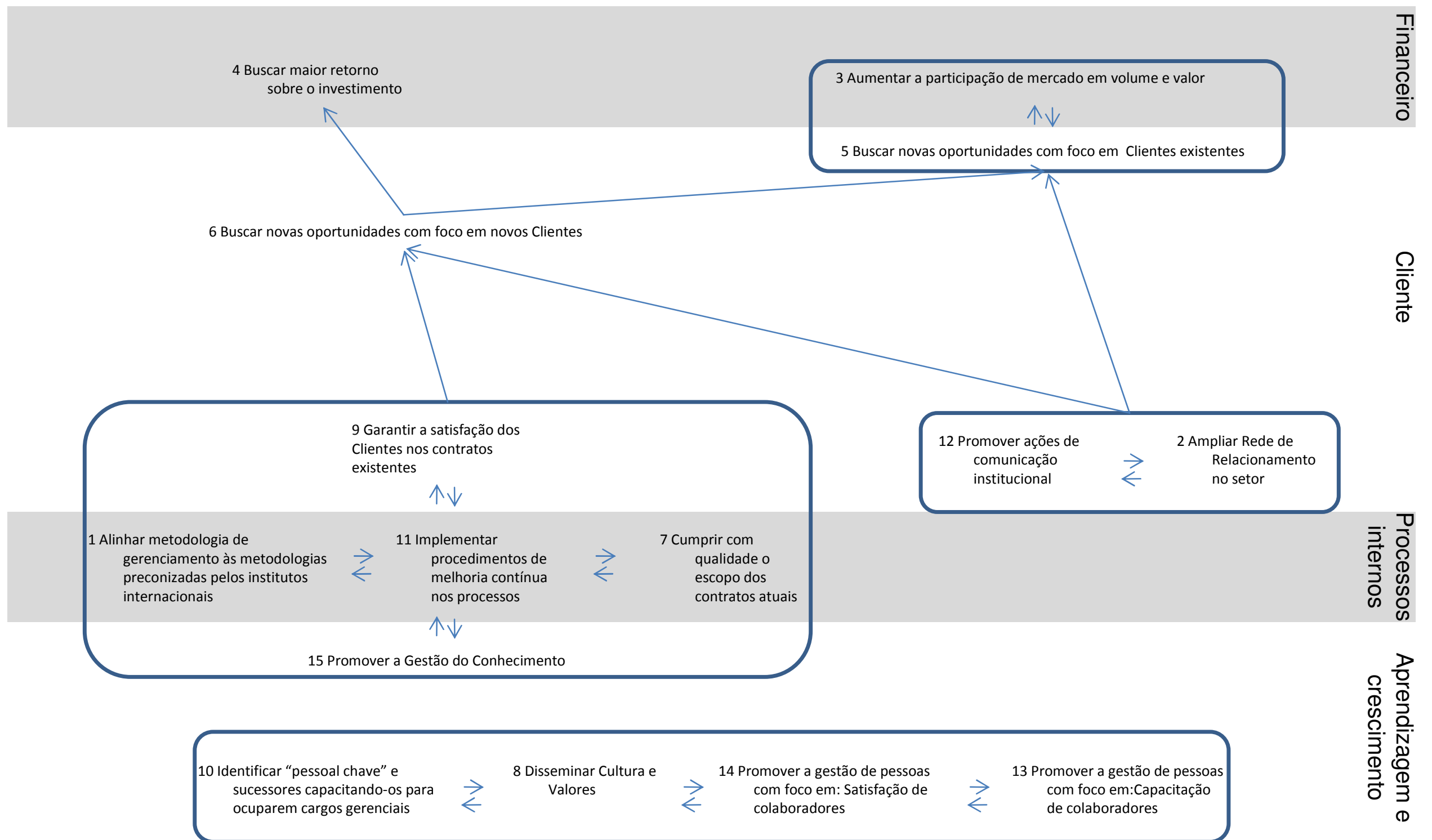


AEM

Mackenzie grupo 1

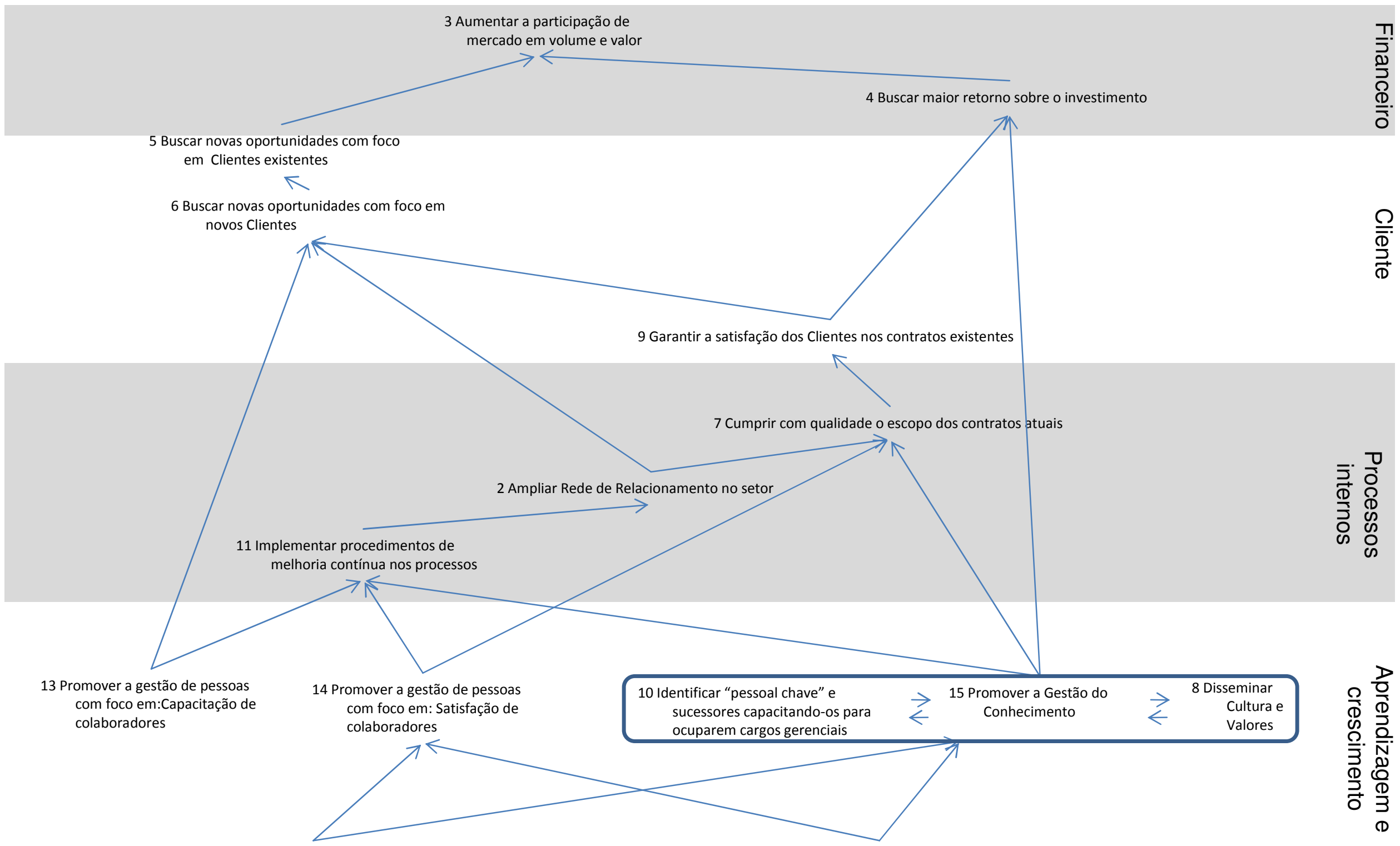


AEM Unip - grupo 1

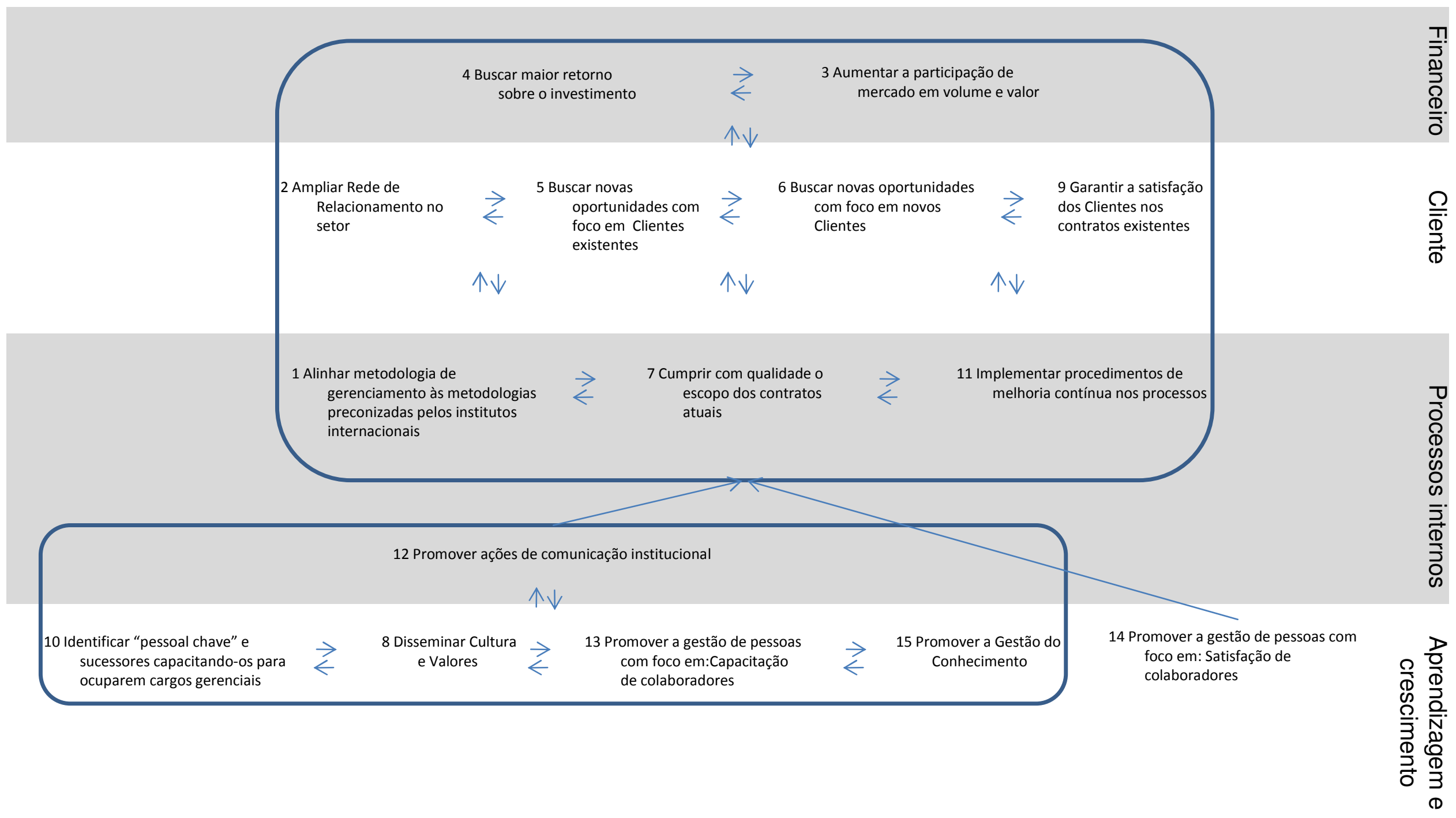

